\title{
Improving wellbore cement performance through the application of nano-materials for oil and gas integrity
}

\author{
Benjamin J. Kleiner
}

Follow this and additional works at: https://researchrepository.wvu.edu/etd

\section{Recommended Citation}

Kleiner, Benjamin J., "Improving wellbore cement performance through the application of nano-materials for oil and gas integrity" (2015). Graduate Theses, Dissertations, and Problem Reports. 5990.

https://researchrepository.wvu.edu/etd/5990

This Thesis is protected by copyright and/or related rights. It has been brought to you by the The Research Repository @ WVU with permission from the rights-holder(s). You are free to use this Thesis in any way that is permitted by the copyright and related rights legislation that applies to your use. For other uses you must obtain permission from the rights-holder(s) directly, unless additional rights are indicated by a Creative Commons license in the record and/ or on the work itself. This Thesis has been accepted for inclusion in WVU Graduate Theses, Dissertations, and Problem Reports collection by an authorized administrator of The Research Repository @ WVU. For more information, please contact researchrepository@mail.wvu.edu. 


\title{
IMPROVING WELLBORE CEMENT PERFORMANCE \\ THROUGH THE APPLICATION OF NANO-MATERIALS \\ FOR OIL AND GAS INTEGRITY
}

\author{
Benjamin J. Kleiner
}

A Thesis submitted to the Benjamin Statler College in Mineral Resources

at West Virginia University
in partial fulfillment of the requirements for the degree of
Master of Science in
Petroleum and Natural Gas Engineering

\author{
Ilkin Bilgesu, Ph.D., Chair \\ Kashy Aminian, Ph.D. \\ Samuel Ameri, M.S.
}

Department of Petroleum and Natural Gas Engineering

Morgantown, West Virginia 2015

Keywords: Cement, nano particles, wellbore, integrity, oil, gas, petroleum. Copyright 2015

Benjamin J. Kleiner 


\title{
ABSTRACT \\ IMPROVING WELLBORE CEMENT PERFORMANCE
}

\section{THROUGH THE APPLICATION OF NANO-MATERIALS}

\author{
FOR OIL AND GAS INTEGRITY
}

Benjamin J. Kleiner

It is the ultimate goal that the application of nano-materials in wellbore cement enhance not only the integrity of the cement, but also the public view of the petroleum industry. Wellbore integrity should be a paramount concern of all petroleum companies due to the potential severity of the consequences if integrity is not maintained.

Ecosystems, animal and plant life, and even human life are at great risk if wellbore integrity fails. It is this fact that the motivation for this thesis is based upon. Nano silica is the nano-particle under investigation for this thesis. Furthermore, wellbore integrity will be improved upon by the addition of an elastomer particle. A new blend specifically designed for use in wellbore cement will be formulated. The mixture of nano silica and an elastomer particle will be used in combination to increase the cements resilience to failure. This thesis is an experimental investigation rather that purely hypothetical.

There have been proven results of the incorporation of nano silica into cement and concrete with the construction industry as the intended use. Furthermore, crumb rubber has also been tested and provided beneficial results once more for use in the construction industry. However, the incorporation of both these particles, in the concentrations chosen in class $\mathrm{G}$ cement for wellbore integrity has not been proposed.

There will be a series of tests performed by Halliburton with our oversight to properly test and analyze all key properties to determine if the proposed blend will be beneficial as a wellbore integrity means. The tests will include quantitative and API tests as well as non-API and qualitative tests. The ultimate defining parameter to draw conclusions from is the compressive strength test. However, an increase in strength along with a decrease in migration pathway formation potential is the primary goal of the proposed blend.

This research found that with the incorporation of $2 \%$ nano silica and $2 \%$ crumb rubber into class $\mathrm{G}$ cement, all critical properties were enhanced. These properties include an increase in compressive strength of 3.5\% after 48 hours, $0 \%$ free fluid where the base case had $.52 \%$, a $35 \%$ decrease in thickening time (to $100 \mathrm{BC}$ ), a decrease in fluid loss by $50 \%$, and a decrease in transition time (to 500 psi) of $15 \%$. The combination of $2 \%$ nano silica and $2 \%$ crumb rubber has thus been confirmed to provide beneficial qualities to class $\mathrm{G}$ cement for wellbore integrity. 


\section{ACKNOWLEDGMENTS}

I would like to express my deepest gratitude to those who have made it possible for me to complete this thesis and be where I am today. First and foremost l'd like to thank my

thesis advisor Dr. Bilgesu for accepting me to study under him and construct this thesis.

I would also like to thank Len Fry from Halliburton for assisting us with this study. Additionally, I would like to thank Kingsat Technology Co. and CRM for providing me with the nano silica sample and the crumb rubber particles. Last but not least, I would like to thank my family and friends for the support and molding me into the person I am today. 


\section{TABLE OF CONTENTS}

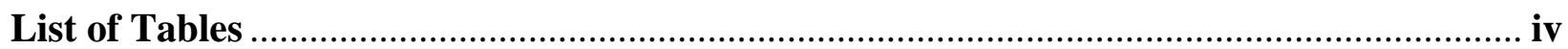

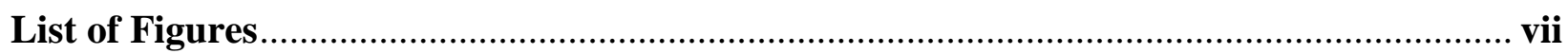

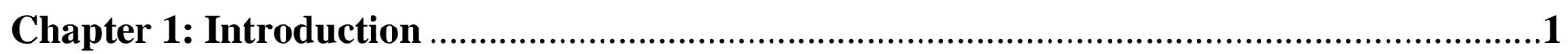

\section{Chapter 2: Literature Review}

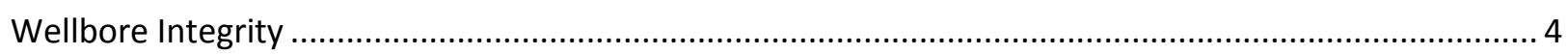

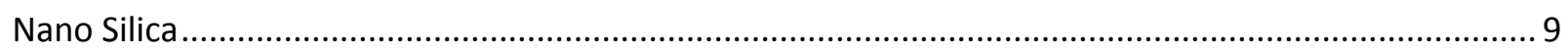

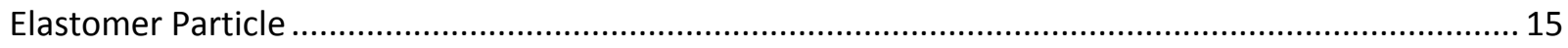

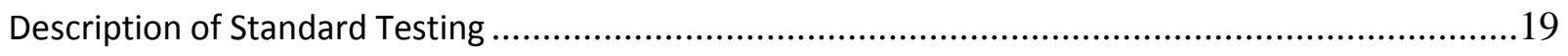

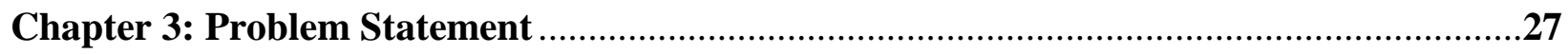

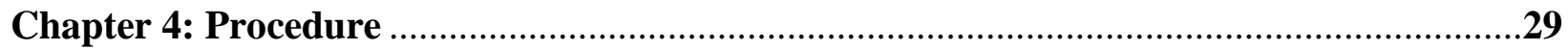

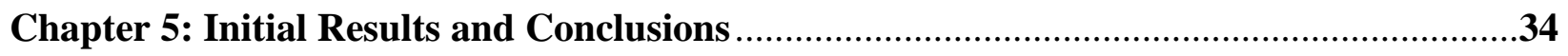

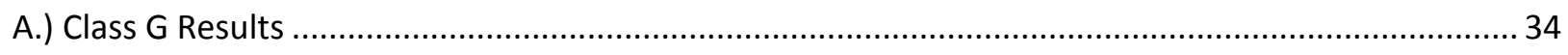

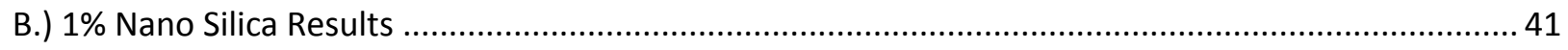

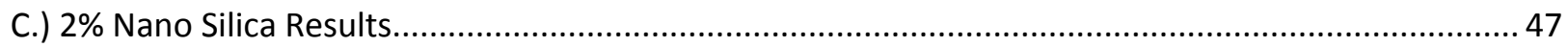

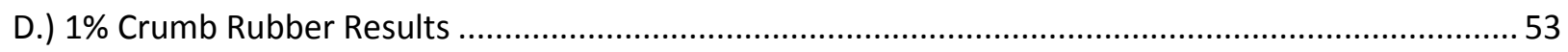

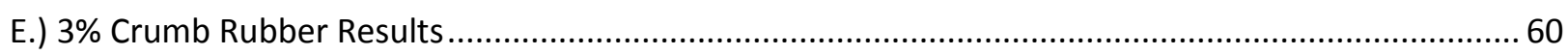

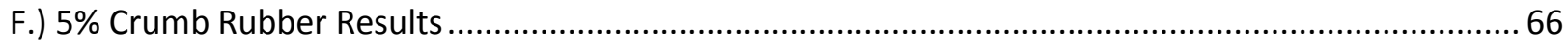

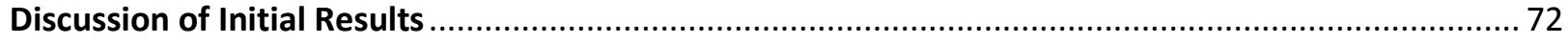

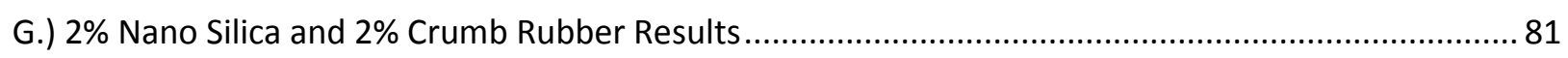

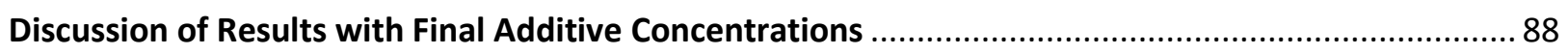

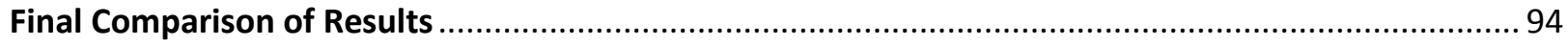

Chapter 6: Summary of Conclusions …………………….....................................................

Chapter 7: Feasibility Analysis........................................................................................98 
Chapter 8: Recommendations

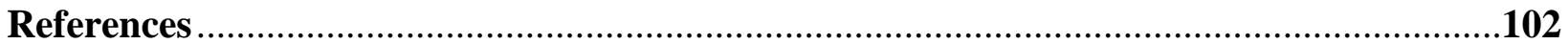




\section{LIST OF FIGURES}

Page

Figure 1: Nano silica cement hydration chemical equation, (Singh, 2013).....

11

Figure 2: Comparison between traditional concrete, silica fume concrete and nano particle concrete (Singh, 2013).....

Figure 3: Scanning Electron Microscope (SEM) image comparing standard cement to that of nano silica cement (Singh, 2013).

Figure 4: Diagram of various nanomaterials and their associated effects (Iqba and Mahajan, 2012)..

Figure 5: Nano silica percent concentration By Weight of Content (BWOC) used in the test samples.....

Figure 6: Crumb rubber concentration BWOC used in the test samples

Figure 7: Consistometer photo (Fann, 2015)

Figure 8: Fluid loss instrument photo (Fann, 2015).

Figure 9: Compressive strength instrument photo (allbiz, 2015).....

Figure 10: Ultrasonic Cement Analyzer (UCA) photo (Direct Industry, 2014).

Figure 11: Static gel strength instrument photo (Universal, 2013)......

Figure 12: Rheometer photo (Laval Lab, 2015)...

Figure 13: Nano Silica photo (Sinosi Group, 2015)......

Figure 14: Crumb rubber photo (CRM) 
Figure 15: Class $\mathrm{G}$ compressive strength graph

Figure 16: Class G Time, Temperature and Transition graph

Figure 17: 1\% Nano Silica compressive strength graph 45

Figure 18: 1\% Nano Silica Time, Temperature and Transition graph 46

Figure 19: 2\% Nano Silica compressive strength graph 51

Figure 20: 2\% Nano Silica Time, Temperature and Transition graph 52

Figure 21: 1\% Crumb Rubber compressive strength graph. 57

Figure 22: 1\% Crumb Rubber Time, Temperature and Transition graph .58

Figure 23: 3\% Crumb Rubber compressive strength graph. 63

Figure 24: 3\% Crumb Rubber Time, Temperature and Transition graph 64

Figure 25: 5\% Crumb Rubber compressive strength graph. 69

Figure 26: 5\% Crumb Rubber Time, Temperature and Transition graph .70

Figure 27: Rheological models diagram (drillingformulas.com, 2010) .73

Figure 28: Thickening Time for all initial test samples .75

Figure 29: Measured volume of fluid loss in milliliters for all initial test samples .75

Figure 30: Compressive strength for all initial test samples 76

Figure 31: Transition time graph for all initial tests samples .77

Figure 32: Graph of PV vs. YP for the base case of class G cement sample. .78

Figure 33: Graph of PV vs. YP for the $2 \%$ nano silica BWOC sample .78 
Figure 34: Graph of PV vs. YP for the 3\% rubber crumb BWOC sample

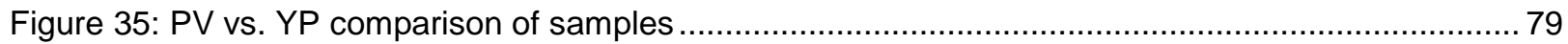

Figure 36: 2\% Nano Silica and 2\% Crumb Rubber compressive strength graph ................................ 85

Figure 37: 2\% Nano Silica and 2\% Crumb Rubber Time, Temperature and Transition graph.

Figure 38: Thickening Time for class G cement vs. $2 \%$ nano silica and $2 \%$ crumb rubber

Figure 39: Measured volume of fluid loss in milliliters (mls) for class G cement vs. $2 \%$ nano silica and $2 \%$ crumb rubber.....

Figure 40: Transition time of class $\mathrm{G}$ cement vs. $2 \%$ nano silica and $2 \%$ crumb rubber

Figure 41: Compressive strength graph for class $\mathrm{G}$ cement vs. $2 \%$ nano silica and $2 \%$ crumb rubber

Figure 42: Graph of PV vs. YP for $2 \%$ nano silica and $2 \%$ crumb rubber. .93 


\section{LIST OF TABLES}

Table 1: Nano silica percent concentration By Weight Of Content (BWOC) used in the test samples

Table 2: Crumb rubber concentration BWOC used in the test samples

Table 3: Test conditions of Class G cement

Table 4: Properties of Class G cement used in analysis

Table 5: Mixability test for class G cement

Table 6: Thickening Time test for class G cement.

Table 7: API Rheology tests for class G cement

Table 8: API Fluid loss test for Class G cement

Table 9: Free Fluid test for class G cement

Table 10: Compressive strength for class $G$ cement

Table 11: Test conditions of $1 \%$ Nano Silica

Table 12: Properties of $1 \%$ nano silica cement used in analysis

Table 13: Mixability test for $1 \%$ nano silica cement

Table 14: Thickening Time test for $1 \%$ nano silica cement

Table 15: API Rheology tests for $1 \%$ nano silica......

Table 16: API Fluid loss test for $1 \%$ nano silica cement.

Table 17: Free Fluid test for $1 \%$ nano silica.

Table 18: Compressive strength for $1 \%$ nano silica

Table 19: Test conditions of $2 \%$ Nano Silica

Table 20: Properties of $2 \%$ nano silica cement used in analysis 
Table 21: Mixability test for $2 \%$ nano silica cement .

Table 22: Thickening Time test for $2 \%$ nano silica cement

Table 23: API Rheology tests for $2 \%$ nano silica

Table 24: API Fluid loss test for $2 \%$ nano silica cement.

Table 25: Free Fluid test for $2 \%$ nano silica .50

Table 26: Compressive strength for $2 \%$ nano silica 50

Table 27: Test conditions of $1 \%$ crumb rubber .53

Table 28: Properties of $1 \%$ crumb rubber cement used in analysis 53

Table 29: Mixability test for $1 \%$ crumb rubber cement .54

Table 30: Thickening Time test for $1 \%$ crumb rubber cement...... .54

Table 31: API Rheology tests for $1 \%$ crumb rubber .55

Table 32: API Fluid loss test for $1 \%$ crumb rubber cement .55

Table 33: Free Fluid test for $1 \%$ crumb rubber 56

Table 34: Compressive strength for $1 \%$ crumb rubber .56

Table 35: Test conditions of $3 \%$ crumb rubber 59

Table 36: Properties of $3 \%$ crumb rubber cement used in analysis 59

Table 37: Mixability test for $3 \%$ crumb rubber cement 60

Table 38: Thickening Time test for $3 \%$ crumb rubber cement. 60

Table 39: API Rheology tests for $3 \%$ crumb rubber 61

Table 40: API Fluid loss test for $3 \%$ crumb rubber cement 61

Table 41: Free Fluid test for $3 \%$ crumb rubber 62

Table 42: Compressive strength for $3 \%$ crumb rubber 62

Table 43: Test conditions of $5 \%$ crumb rubber 65 
Table 44: Properties of 5\% crumb rubber cement used in analysis

Table 45: Mixability test for $5 \%$ crumb rubber cement

Table 46: Thickening Time test for $5 \%$ crumb rubber cement.

Table 47: API Rheology tests for $5 \%$ crumb rubber

Table 48: API Fluid loss test for $5 \%$ crumb rubber cement

Table 49: Free Fluid test for $5 \%$ crumb rubber 68

Table 50: Compressive strength for $5 \%$ crumb rubber

Table 51: Test conditions of $2 \%$ nano silica and $2 \%$ crumb rubber 80

Table 52: Properties of $2 \%$ nano silica and $2 \%$ crumb rubber cement used in analysis 81

Table 53: Mixability test for $2 \%$ nano silica and $2 \%$ crumb rubber cement 82

Table 54: Thickening Time test for $2 \%$ nano silica and $2 \%$ crumb rubber cement 82

Table 55: API Rheology tests for $2 \%$ nano silica and $2 \%$ crumb rubber. .83

Table 56: API Fluid loss test for $2 \%$ nano silica cement and $2 \%$ crumb rubber.. 83

Table 57: Free Fluid test for $2 \%$ nano silica and $2 \%$ crumb rubber. .84

Table 58: Compressive strength for $2 \%$ nano silica and $2 \%$ crumb rubber..... 84

Table 59: Mixability comparison for all samples 94

Table 60: Thickening time comparison for all samples. .95

Table 61: Rheologies comparison for all samples . 95

Table 62: Fluid loss comparison for all samples 95

Table 63: Free fluid comparison for all samples 96

Table 64: Compressive strength comparison for all samples .96 


\section{CHAPTER 1: INTRODUCTION}

This thesis will be experimental in that it will be more based on hands on testing and real world applicability and less based on theoretical models and hypothesis. A new cement mixture for use in petroleum industry will be designed. This mixture will be composed of varying combinations of two particles, in class $\mathrm{G}$ cement, for use in oil and gas wellbores; a combination never tested before. The two particles will be a nano particle, nano silica, and an elastomer particle, crumb rubber. The basic purpose of the nano silica is to increase the compressive strength of the cement. This is accomplished because of the nano silica's increased surface area, and ability to fill more gaps and holes within the cement. As for the elastomer particle, its basic purpose is to increase the elastic resilience of cement, an obvious property that all cement lacks. The elastomer particle chosen is that of crumb rubber, a finely ground powder of natural rubber. The benefit of increased elasticity in wellbore cement is its resilience to seismic events, changing pressures, casing expansion, any sudden jolt to the cement that typical cement would be unable to withstand. The expectation is that the nano silica be able to properly coat and fully integrate the elastomer particle into the cement. With the full integration, the two can compensate the others deficiency. Where nano silica lacks in elastic response, elastomer particles will compensate for, and where elastomer particles lack in compressive strength, nano silica will compensate for. Varying amounts of each particle must be tested through a variety of strength tests to determine the optimal percentage that increases the discussed properties. With this percentage, the proposed cement blend with be more resilient to any type of failure anytime throughout 
the life of a well. We hope to achieve a minimum of approximately $1-5 \%$ increase in strength and a decrease in transmissibility in regards to the formation of migration pathways during cement setting.

The abundant research and patents that have been performed on nano silica demonstrates its merit. The vast majority of the background research performed was with the intended consumer being the construction industry. Crumb rubber is similar in the same regards in that the majority of background research has the intended consumer being the construction industry. There have been a few studies of the incorporation of both particles in a concrete blend with varying results. The results are not always positive due to the previously mentioned integration problems and interaction to the aggregate in concrete. If the background research has proven one thing, it is that wellbore integrity is a top concern and requires the best cement possible to provide the optimal means of upholding integrity.

The tests performed are mixability, thickening time, rheologies, fluid loss, free fluid, and compressive strength. From these tests, we can determine if the proposed blend will be possible to create and if it will provide beneficial characteristics to wellbore integrity. The two particles will be tested individually to determine the optimal percentages of each particle. The optimal percentages will be determined by analyzing the results from each particle and determining which concentration provided the most advantages. From this, the test containing the optimal concentration of each particle can be performed and analyzed against a base case of just class $\mathrm{G}$ cement. This will provide with the means to draw a conclusion as to whether the proposed blend can help improve wellbore integrity. The integrity of a wellbore is a paramount concern to the 
drilling company and to the public as a whole and this is the motivation behind this research. 


\section{Wellbore Integrity}

Non-productive time is most prominently caused by wellbore instability and failure. This failure can be a result of misunderstanding the wellbore conditions, improper drilling practices, unavailability or improper interpretation of geomechanical properties. Therefore, it is obvious that to achieve maximum, long-term production, it is desirable to minimize uncertainties associated with wellbore integrity. It has been established that near-wellbore stresses can be modified through the variation of wellbore integrity approaches while staying within the pore pressure and fracture pressure gradient window (Savari and Kumar, 2012).

The primary goal of wellbore integrity management is to ensure the technical integrity of wells throughout their life through the implementation of standard guidelines in order to allow them to operate continuously to achieve the targeted production rates. Wellbore Integrity Management Systems (WIMS) are a standard guideline implemented by most operating companies for safe drilling at different phases (Savari and Kumar, 2012).

A majority of wellbore integrity research projects focus on the appropriate arrangement and implementation of wellbore fluids in a particular phase of a wells life. The majority of background research found focuses upon how the different types of cement currently implemented by operating company's effect wellbore integrity. Based upon these observations, desirable qualities can be chosen in order to adequately propose a wellbore cement that can augment current wellbore integrity practices. As defined by NETL, "Wellbore cement integrity is paramount to safe, successful oil and natural gas drilling. An unstable cement can compromise wellbore control, and research 
indicates that poor cement integrity is a primary factor contributing to loss of zonal isolation in oil and gas reserves." Additionally, NETL says "Although cementing designs and placement practices are well established in many operational environments, the extreme subsurface conditions found in deep water oil and unconventional natural gas reservoirs pose new challenges to achieving reliable cement jobs." (Kutchko, 2014)

Qualities such as Young's modulus, Poison's ratio, compressive strength and tensile strength parameters play an important role in the ability of cement to withstand the stresses down hole (DeBruijn, et. al., 2009). In order to take full advantage of the performance of the cement system, best practices must be employed in order effectively distribute the cement all around the casing and annulus. Furthermore, density, thickening time, and water absorbed are also key attributes that directly affect the performance of the cement system in regards to wellbore integrity.

In order to accurately assess the risks associated with wellbore placement and operation, we must improve our general understanding of cement stability under extreme field conditions. The primary placement concerns with regards to wellbore cement include fluid loss, contamination, and dynamic settling. Primary wellbore cement concerns post placement and throughout the life of the well include cement expansion and shrinkage, free water development, temperature and pressure stability, hydration, gas and fluid migration, and cement-formation interactions. By identifying key elements for cement design, we can help create new and updated standards as well as best practices to ensure safe operations (Kutchko, 2014).

There are a multitude of forces and conditions that can compromise the wellbore integrity through cement failure. Some of the forces seen are temperature changes that 
directly affect casing expansion. Casing expansion applies forces directly onto the casing-cement interface. Additionally, soft formations themselves may apply forces onto the formation-cement interface. This occurs through the shifting of individual beds as is the case for slow tectonic activity over time, or large scale, sudden shifting such as seismic activity. Changes in pressure may also exert pressure variations onto the casing and subsequently onto the cement. Pressure changes can occur over time when a reservoir becomes depleted or when an injection well is introduced, or more suddenly as is the case for a kick. These pressure alterations directly affect the casing and cement, but also may have an influence on temperature. This is due to the pressure temperature relationship given by Gay-Lussac's Law (ChemTeam). This then leads to the problems that changes in temperature can inflict as previously mentioned.

Wellbores in general are high heat exchangers, which leads to the importance of temperature measurements. There are a lot of unknowns still today that revolve are the temperature cycles as a slurry travels to the bottom of a well, and back up the annulus and cools. However, cement curing is an exothermic reaction, thus adding to the cumulative heat in the system. Therefore, post-placement pressure and temperature cycles can also cause failure, just because the cement "looks good" during placement does not mean optimal wellbore cement integrity for the life of the well. The postplacement pressure and temperature cycles can cause mechanical failures, potential flow paths, and/or loss of zonal isolation (Kutchko, 2014).

These challenges have already brought about many solution attempts for areas such as south Texas where they routinely see extreme pressures and temperatures (DeBruijn, et. al., 2009). A key solution is the application of High Density Elastic Cement 
(HDEC). This cement has been mechanically modified so that the set cement can be more elastic and resilient. This cement has been implemented in 40 test wells by the year 2009. The HDEC has the primary purpose of solving HTHP problems in these wells. However, HTHP also brings forth the requirement for heavyweight drilling mud and increased fracturing pressure required for stimulation, which can also intensify the forces applied to the cement (Wray, 2009). HDEC is a key component to the importance of this research. Therefore the requirement for a more resilient cement becomes clear. This research can build upon the success and goals of HDEC with hopes to further advance the capabilities and properties of the cement. Through the addition of nano silica, the density can increase even higher. Furthermore, with the addition of a readily available, inexpensive elastic particle, the cement can become even more applicable throughout more areas than just Texas.

NETL says, "Industry understands the challenges of obtaining reliable cement jobs in deep oil and natural gas production wellbores" which is very important to the applicability of this research. The availability and ease to which this cement mixture can be created is a key component to industry acceptance. Some foamed cement and high tech additives are a bit too much for the industry as a whole to fully accept, especially when the benefits are not conclusive. The cement design proposed in this research is based upon designs that are known to work. Silica is a common element in cement and Crumb Rubber has also been incorporated into cement in the construction industry. With the incorporation of nano silica in combination with Crumb Rubber, advances in wellbore integrity can be made within the "comfort zone" of the industry. It is not a radical new idea that is too expensive, too difficult, or too unrealistic to be applied in real 
world situations. Those parameters are what a new wellbore cement design must follow in order to reach industry acceptance. 


\section{Nano Silica}

The majority or research performed involving nano silica, or even nano materials in general, pertain to the use in concrete. Simply speaking, concrete includes aggregates such as gravel in the slurry and is very different from pure cement that is used for wellbores. Most research also focuses on class A cement, which again has its primary purpose in the construction industry. Nevertheless, the research shows the mechanical advantages to the incorporation of nano silica rather than normal sized silica. The portions of nano silica derived from previous research give us a good base line to start our experiments at.

Before the additives can be examined, the cement itself must be analyzed. This allows us to see what components our additives will be mixed with in order to predict if any reactions may occur. Typical physical requirements for API cements must be analyzed in order to create a suitable mixture. Such requirements include each cement class with its associated water requirements, maximum free fluid content, minimum compressive strength, minimum thickening time, and curing pressure (ASTM, 2015). Further requirements and values can also be referenced from American Society for Testing and Materials (ASTM) standards to ensure accuracy in our results. Such values include typical compressive strengths for a specific temperature and pressure after a given amount of time. We can also find typical concentrations and compositions of various additives for class $\mathrm{G}$ or $\mathrm{H}$ cement (ASTM, 2015).

There are two specifications for cement classes: American Society for Testing and Materials (ASTM) and American Petroleum Institute (API). ASTM provides for eight classes of cement: Types I, IA, II, IIA, III, IIIA, IV, and V. API also provides specifications 
for eight classes: Class A through $\mathrm{H}$. The class $\mathrm{G}$ cement (the cement used in this study) has a slightly higher compressive strength and is used for wellbore cementing (Society of Petroleum Engineers, 2014.)

In recent years, many researchers have proven that the incorporation of small amounts of nano silica has increased the strength of cement for early-age tests, and 28day tests (Zhang, et. al., 2012). This study used a 20-30 nano meter silica dioxide powder. The nano silica had to be hydrophilic in order to ensure water absorption and integration into the cement. The nano silica used is $99.8 \%$ pure and has a specific surface area of $160-200 \mathrm{~m}^{2} / \mathrm{g}$. The surface area is the key to the advantages that nano particles provide. A larger surface area allows for more contact with the rest of the cement and in addition, more contact with the elastomer particle. Other particles present in the powder are: $\mathrm{Al}_{2} \mathrm{O}_{3}, \mathrm{C}, \mathrm{TiO}_{2}$, and $\mathrm{Fe}_{2} \mathrm{O}_{3}$; however, these particles are in extremely small percentages: $<=.05 \%,<=0.2 \%,<=.04 \%$, and $<=.01 \%$, respectively. Furthermore, it has a pH value of approximately 4-7 and a specific gravity of 2 .

Physically, nano silica studies show that it acts as a reactive filler, which reduces bleeding and increases packing density of solid materials by occupying space between cement and slag particles. (Zhang, et. al., 2012) From a chemical point of view, nano silica is a highly reactive pozzolanic material. This means that it has the capability to form compounds containing cementitious properties. It reacts with cements natural calcium hydroxide, which is formed by the addition of water to the calcium oxide containing cement $\left(\mathrm{CaO}+\mathrm{H} 2 \mathrm{O} \rightarrow \mathrm{Ca}(\mathrm{OH})_{2}\right)$. Therefore, with the addition of water, the $63 \%$ calcium oxide in class $\mathrm{G}$ cement starts to form calcium hydroxide. This then leads to the pozzolanic reaction between calcium hydroxide and nano silica thus adding to the 
strength. The nano silica actually adds additional C-S-H molecules, the main constituent for strength and density in the hardened cementitious system. Figure 1 shows a nano silica based nucleation reaction including the pozzolanic reaction.

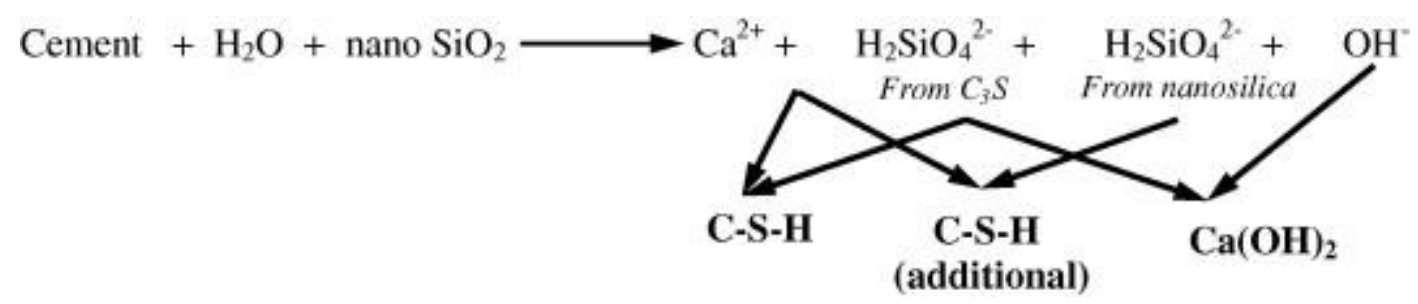

Figure 1: Nano silica cement hydration chemical equation (Singh, 2013)

It can thus be expected that the nano silica will reduce the porosity and permeability in the cement. The nano silica particles have a filler effect by filling the voids between the cement grains (Singh, 2013). Therefore, a slight increase in density and improved bonding is also produced. This increased bonding can increase the strength by creating a more tightly linked cement.

The increased density is also a benefit to micro annuli and migration pathway prevention. Most research is performed for construction style cement and concrete. However, the
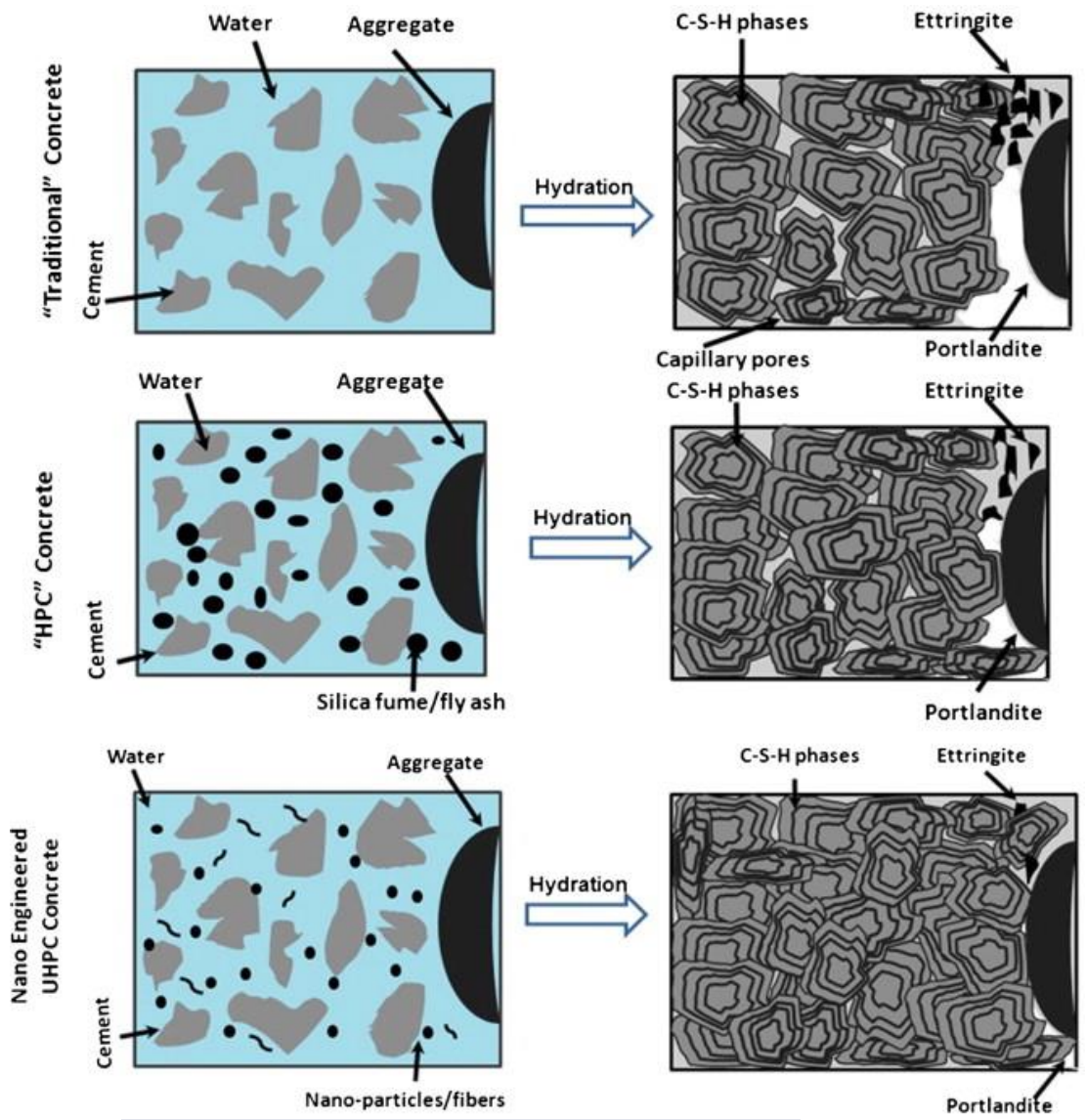

(Figure 2: Comparison between traditional concrete, silica fume concrete and nano particle concrete (Singh, 2013)) 
basic mechanical properties that nano silica provides are the same if not better without the addition of an aggregate. Figure 2 shows a visual representation of the effect of nano silica in the formation of cement.

The additive must have enough compressive strength in order to withstand the compressive loads at the cement-casing interface, as well as the Mohr-Coulomb forces (brittle materials response to shear stress) within the cement sheath itself. Furthermore, the cement system must be capable of withstanding compressive forces from its own overburden pressure during the solidification phase. Figure 3 is an example of a scanning electron microscope image of the differences between regular cement (left), and nano silica cement (right).
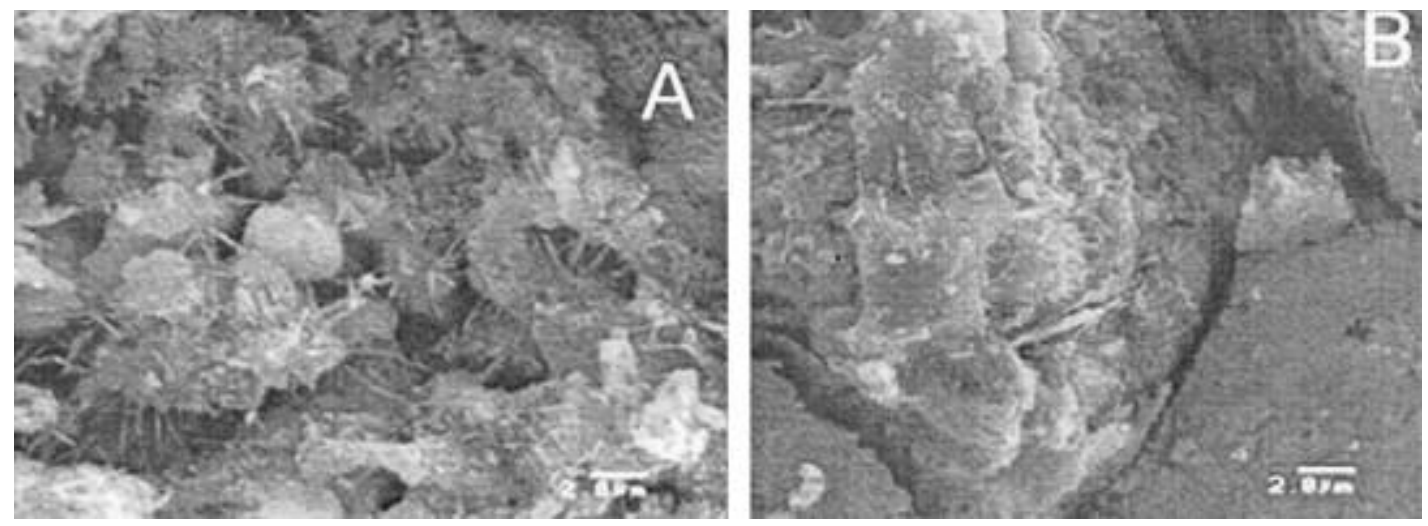

Figure 3: Scanning Electron Microscope (SEM) image comparing standard cement to that of nano silica cement (Singh, 2013)

Nano silica is a readily available product that can be purchased in large quantities throughout the world for reasonable price. This is very important to the applicability of the additive for use in real world situations. Expensive additives can be prohibitively expensive to utilize at a commercial level. In addition to the above listed benefits, research into nano silica concrete has also found that it provides a reduction in 
Ca-leaching and an accelerated hydration rate (Singh, 2013). This accelerated hydration rate is very important in that it prevents gas migration pathways from ever forming. In a typical cementing scenario, gas migration pathways can form in the cement slurry before the slurry hardens. However, if the hydration process is slightly accelerated, migration pathways are prevented from ever forming (Zhang, et. al., 2012). In total, the addition of nano silica optimistically anticipates a more refined pore structure, strength enhancement, increased durability, a reduction in Ca-leaching, an accelerated hydration rate and improved bonding. Previous research indicates, although intended for construction grade concrete, that an optimal percentage for nano silica is around 3\% (Hussain and Krishna, 2014).

There are a large number of patents incorporating the usage of nano silica into concrete and cement, which is precisely why a unique, multiple particle blend was chosen for this research. Furthermore, there are many types of nano particles that have been studied and patented as well, however nano silica is by far the most feasible. The combination of nano silica and crumb rubber was chosen because of nano silica's proven results and the complimenting benefits of crumb rubber to provide a totally new unique cement blend. The summary of the effects of the nano particles are shown in Figure 4 together alongside other types of nano particles. 


\begin{tabular}{|l|l|}
\hline Nanomaterial & \multicolumn{1}{|c|}{ Effect on Property } \\
\hline Nano-silica & $\begin{array}{l}\text { Reduced } \mathrm{CO}_{2} \text {-emissions, reduction in } \\
\text { porosity/permeability, increased } \\
\text { durability, crack resistance, high } \\
\text { strength }\end{array}$ \\
\hline Carbon nanotube & $\begin{array}{l}\text { Improved compressive strength, tensile } \\
\text { bending strength, flexural strength, } \\
\text { durability, piezoelectric response, blast } \\
\text { resistance, sensing ability }\end{array}$ \\
\hline $\begin{array}{l}\text { Polymer/clay } \\
\text { nanocomposites }\end{array}$ & $\begin{array}{l}\text { Increased tensile strength, reduced } \\
\text { oxygen permeability, enhanced heat } \\
\text { resistance }\end{array}$ \\
\hline $\begin{array}{l}\text { Nano-calcium } \\
\text { carbonate }\end{array}$ & $\begin{array}{l}\text { Improved hardness, compressive } \\
\text { strength, shortening of C,S hydration } \\
\text { period }\end{array}$ \\
\hline Nano-titania & $\begin{array}{l}\text { Effective self-cleaning, degradation of } \\
\text { NOx, corrosion resistance, flame } \\
\text { resistance, abrasion resistance }\end{array}$ \\
\hline Nano-alumina & $\begin{array}{l}\text { Increased elastic modulus, } \\
\text { compressive strength, thermal shock } \\
\text { resistance, ability to withstand rapid } \\
\text { temperature change }\end{array}$ \\
\hline Nano-zinc oxide & $\begin{array}{l}\text { Increased compressive strength, aging } \\
\text { resistance }\end{array}$ \\
\hline $\begin{array}{l}\text { Increased bonding strength, modulus } \\
\text { of elasticity, reduced moisture } \\
\text { absorption }\end{array}$ \\
\hline Nano-celluse
\end{tabular}

Figure 4: Diagram of various nanomaterials and their associated effects (Iqba and Mahajan, 2012) 


\section{Elastomer Particle}

The need for an elastic resilience comes when one accounts for all of the various causes of wellbore failure. This includes the effects of variable temperatures and pressures such as a kick, soft formations, and seismic activity has on a wellbore and the associated wellbore cement. These are the most direct causes of wellbore failure through a lack of elastic resilience, however there are causes that are more indirect as well. Such indirect causes are the expanding and contracting of the casing, tectonic activity, formation fluid variation, heavy rains weakening the top section of the well, stimulation perforations causing unwanted cement fractures, and aquifer changes which can apply irregular forces directly or indirectly to the wellbore cement. Logging or workovers can also apply sudden jolts to the wellbore that cause irregular forces to the wellbore cement. It may seem that some of these causes are never heard of, however in the Marcellus shale alone, from 1958 to 2013, approximately $6.3 \%$ of all wells drilled have had a barrier failure or well integrity failure (Davies, et al., 2015). These failures could be just the result of a poor cement job, or an external stimulus, as mentioned above.

"The planned location of gas wells in a seismically active region that regularly experiences major ground shaking will almost certainly result in the degradation of wellbore sealant materials" (DELAWARE Riverkeeper, 2011). Research shows that even in Appalachian Basin alone, seismic activity is a real threat. Furthermore, companies in Pennsylvania are not required to monitor wellbore integrity after seismic activity. During a seismic event, faulting may occur causing large shear stresses on a wellbore with the top of the well moving in the opposite direction than the bottom of the 
well. This is even more threatening to wellbores in California and other areas with high seismic activity. This stress can shear casings apart and crack cement sheaths in the worst case scenarios (DELAWARE Riverkeeper, 2011).

Soft formations cause a similar problem with a different approach. Soft formations may have individual beds that, over the life of the well, shift and apply steadily increasing amounts of stress on the wellbore. Salt formations are known for their fluidity and ability to slowly move over time. Additionally, salt domes are sometimes viewed as desirable location for well placement. The stresses seen in these locations are applied from the outside formations, inward. This means that the stresses are applied directly to the cement sheath. Over time, these cumulative effects of the forces may cause cement integrity failure even in good cement jobs due to the cements inability for elastic resistance.

When a confined tubular, as with wellbore casing, is heated, expansion occurs. This expansion can be very problematic to the cement-casing bond. Furthermore, the expansion will also apply forces onto the cement due to both horizontal and vertical expansion. However, higher tensile strength cements will be more capable of resisting radial cracking. One would expect that with an increased density cement from the addition of nano silica, an increase in brittleness would also occur. However, the elastomer particle will reverse that effect and actually provide an elastic resilience to the cement. It is on this basis that this research hopes to achieve a balancing and complementary effect of each additive to benefit the other. Most research again is based upon the addition of crumb rubber in concrete, and not cement. Furthermore, the 
crumb rubber used is often chipped rubber, a very large aggregate. The crumb rubber chosen in this research an almost powder like additive and is 420 microns and smaller.

Typical cement has a poisons ratio of about 0.1 to 0.2 , however, rubber has a poisons ratio of about 0.48 to 0.5 (Engineering Toolbox). With proper integration of the crumb rubber, this study aims to increase the poisons ratio of the cement slightly.

Poisons ratio is similar to the compression force test in that it uses uniaxial compressive force to deform the cement sample. Therefore, if the cement fails under a relatively low compressive force, one concludes that the sample was unable to deform and resist the stress. Relatively speaking, if the sample was unable to deform then that proves that its poisons ratio is lower. Therefore, it becomes clear that poisons ratio, and more simply, elasticity, is directly proportional to compressive strength (Elert, 2015). From this, we can conclude that if we achieve full integration and bonding of the crumb rubber we will also see an increase in compressive strength relative to the control test. If the concentration of the crumb rubber becomes too high, we will see a failure of bonding thus causing a degradation of compressive strength.

Research shows that with the addition of crumb rubber provides an improvement of non-structure crack resistance, shock wave absorption, resistance to acid, and lower heat conductivity (Kaloush, et. al., 2005). Previous research also shows that the crumb rubber samples did not shatter, indicating an increased ability to absorb the forces placed on the sample (Kaloush, et. al., 2005). Furthermore, crumb rubber concrete also reduced the weight and density in comparison to conventional concrete (Topcu, 1995). Crumb rubber alone has been seen to reduce the strength of cement, however, with the incorporation of higher amounts of nano silica in comparison to crumb rubber, this study 
expects to maintain the increased strength. The main cause of the decreased strength is the lack of bonding to the cement structure and the increase volume of air in the cement. The increase in air volume occurs when crumb rubber is not integrated into the cement. This results in isolated, independent rubber particles unconnected to any of the surrounding cement creating a small void space surrounding each particle. However, the very high surface area of the nano silica will allow for the full coating of crumb rubber. Additionally, the nano silica will be used in percentages by weight very close to that of crumb rubber. Furthermore, other variations will also be tested to see if that is not necessary due to nano silica high surface area. With the addition of nano silica, a full coating of the crumb rubber can occur thus allowing proper integration into the cement structure. Additionally, the nano silica will be able to fill any air pockets and eliminate the strength reduction caused by air entrapment. With the bonding problem eliminated, the crumb rubber will not decrease the cement strength therefore allowing the full effect of nano silica to transpire. Research indicates, although with an intended use of construction concrete, that an optimal percentage of crumb rubber in conjunction with nano silica is about $5 \%$. Crumb rubber has a melting point of $350^{\circ} \mathrm{F}$, which indicates that there will be no problems handling downhole temperatures. 


\section{Description of Standard Testing}

\section{A. THICKENING TIME TEST:}

The thickening test is based on API Recommended Practice 10B-2. This purpose of this test is to determine the duration that the cement slurry remains in a fluid state and is capable of being pumped under simulated downhole temperature and/or pressure conditions. The test is performed with a Consistometer. This highpressure/high temperature (HPHT) device is usually rated at pressures up to 6,000 psi and temperatures up to $400^{\circ} \mathrm{F}$.

Before the slurry test was performed, the cement slurry is mixed in a cup in accordance to API Recommended Practice 10A, and placed in the consistometer for testing. This involved placing the class $\mathrm{G}$ cement in a blender, adding the appropriate concentrations of nano silica, crumb rubber and water, and mixing until the slurry becomes workable. The temperature and pressure conditions were modified to match the conditions that the slurry would encounter downhole. The test is performed until the consistency of the slurry reaches a state considered to be unpumpable in the wellbore. The time that it takes the slurry to reach this state is called the thickening time, or pumpable time. For this test, the slurry was considered to be set after attaining a consistency of 100 Bearden Consistency (BC) units under a dynamic state using the HPHT consistometer (Salam, et. al., 2013). The viscosity can then be plotted over time for the given temperature and pressure conditions. A Consistometer is shown in Figure 7. 


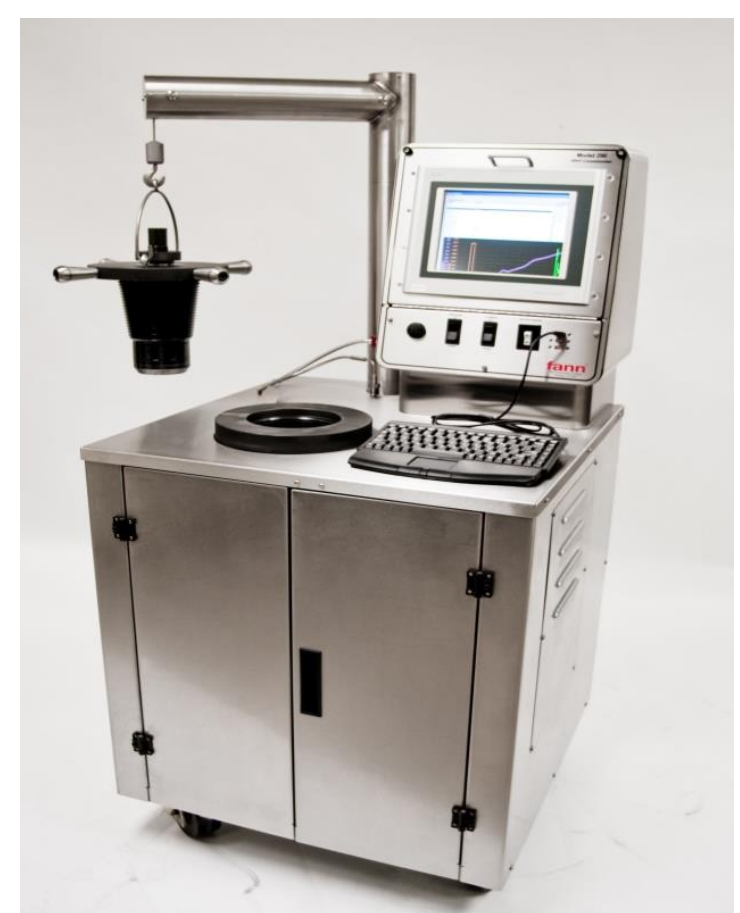

Figure 7: Consistometer (Fann, 2015)

\section{B. FREE FLUID TEST:}

The free fluid test is based on the API Recommended Practice 10B-2. It represents the volume of fluid, expressed as a percent, which separates from a cement slurry when left static. This test is important because insufficient fluid loss control can result in the cement slurry dehydrating and bridging off the annulus, preventing the slurry from being pumped to its final destination (Fann, 2015). This test can be performed without the use of an instrument. However the next test requires the use of a fluid loss instrument. In this test the conditioned slurry is placed in the fluid loss instrument and tested under pressure to determine fluid loss. The test is performed by applying pressure on the slurry. This pushes out fluid from the slurry into a collection cylinder where it can be measured. This fluid loss instrument is shown in Figure 8. 


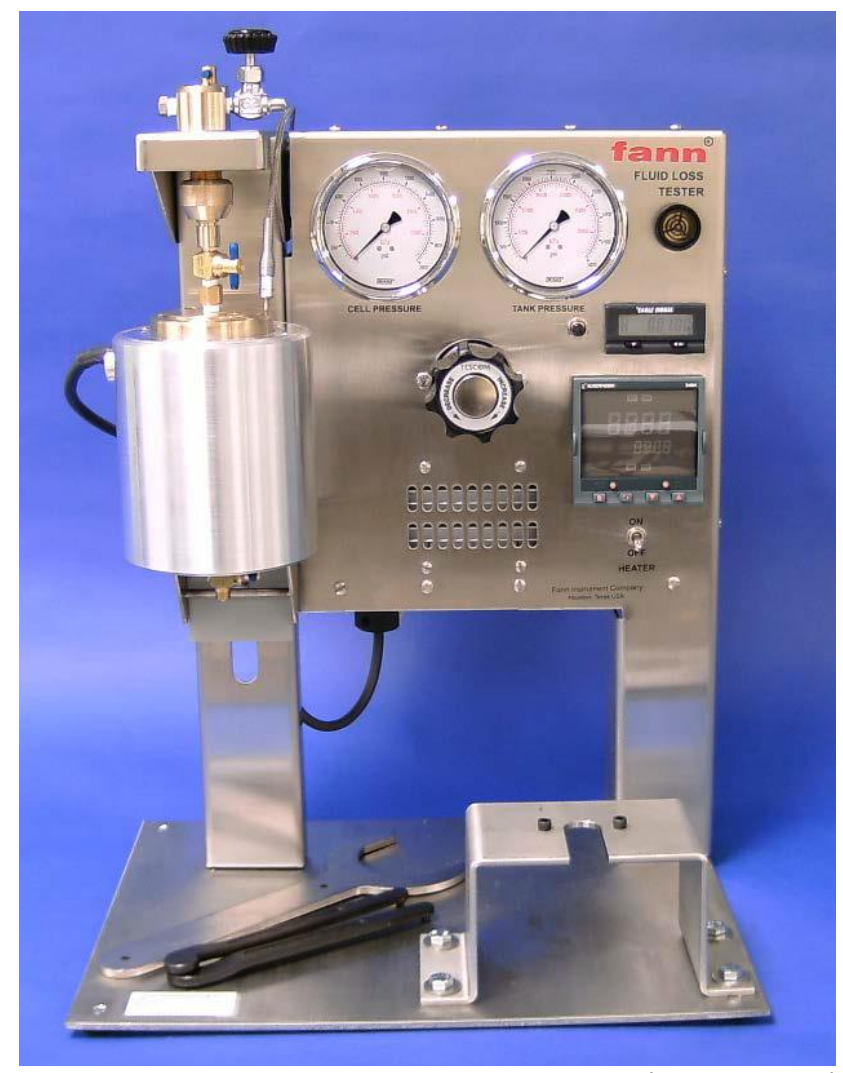

Figure 8: Fluid loss instrument photo (Fann, 2015)

\section{COMPRESSIVE STRENGTH TEST:}

The compressive strength test is an important test that follows the procedure based on API Recommended Practice 10B-2. In first step, the cement samples are cured for a period of time. Once the cement samples are solidified and cured for the chosen period of time, they are placed in an instrument and compressive stress is applied. This is done by applying force vertically up or down on the sample with it supported from the opposite side. The instrument uses a hydraulically activated piston to apply the force. The amount of maximum amount of force applied before failure is recorded. Failure occurs when the cement sample cracks and the force applied starts to decrease. The reported compressive strength itself is the measured force when failure 
is observed divided by the cross-sectional area of the cement sample. This test is performed for both confined and unconfined cement samples. The difference between confined and unconfined is the lateral support for confined samples. A laterally supported cement sample does not allow the cement to expand horizontally when being compressed vertically. This support creates an indirect resistance to failure from vertical stresses and mimics the down hole conditions of cement where outward expansion due to the surrounding formation is restricted. The overburden stress is applied onto the wellbore cement while it is laterally supported. Figure 9 shows one type of instrument used to test unconfined compressive strength (UCS):

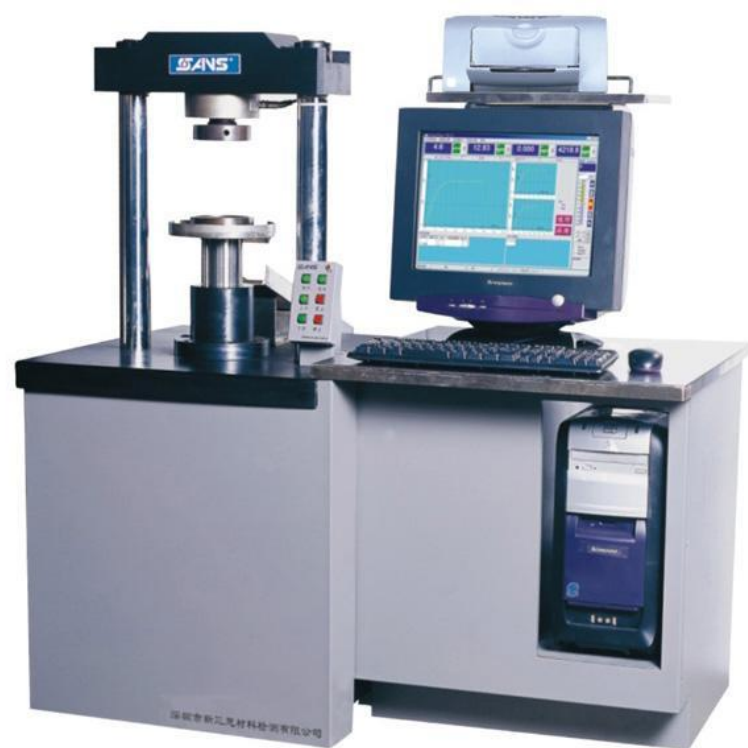

Figure 9: Compressive strength instrument (Allbiz, 2015) 


\section{TRANSITION TIME TEST:}

The transition time experiment measures the time it takes for the slurry to go from $100 \mathrm{lbs} . / 100 \mathrm{ft}^{2}$ to $500 \mathrm{lbs} . / 100 \mathrm{ft}^{2}$ of compressive strength. Transition time experiment is based on API Recommended Practice 10B-2. The test is important because at $500 \mathrm{lbs} . / 100 \mathrm{ft}^{2}$ the cement is considered capable of holding its own hydrostatic weight. Furthermore, the quicker $500 \mathrm{lbs} . / 100 \mathrm{ft}^{2}$ compressive strength is reached, the sooner it develops impermeability to gas, lowering the probability of the formation of gas migration pathways. This is a measure of the evolution of relative permeability of a cement slurry during hydration and reveals if the slurry can control gas (Bonett and Pafitis, 1996).

There are two main types of equipment available for the analysis of transition time. One is the Ultrasonic Cement Analyzer (UCA) which can measure continuous compressive strength while the slurry sets. The second type of equipment is the static gel strength (SGS) analyzer that can measure the time for the slurry to go from 100 lbs. $/ 100 \mathrm{ft}^{2}$ to $500 \mathrm{lbs} . / 100 \mathrm{ft}^{2}$ compressive strength. The SGS analyzer can be used to determine compressive strength as well, however the UCA cannot determine static gel strength. "The UCA applies an ultrasonic pulse to cement slurry and measures the change in velocity as the ultrasonic signal travels through the slurry as it cures. These ultrasonic velocity measurements are correlated to the cement's compressive strength" (Direct Industry, 2014). This method allows for a nondestructive means of measuring compressive strength. Figures 10 and 11 show UCA and SGS, respectively: 


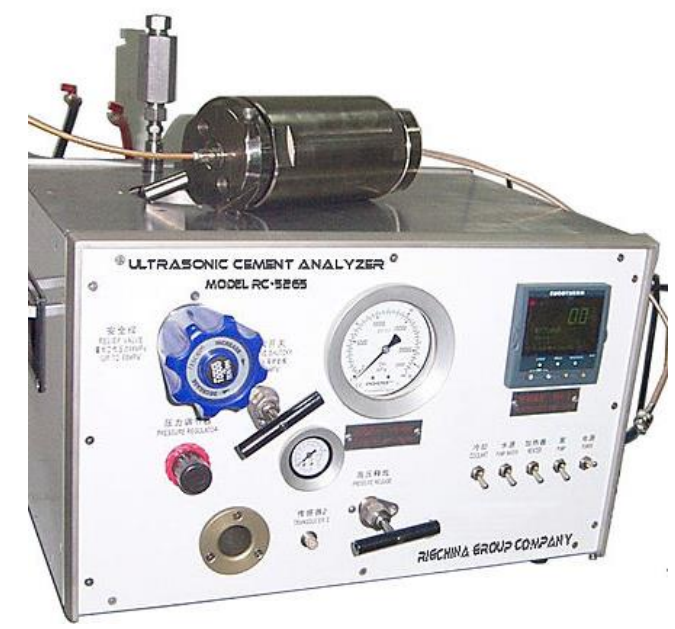

Figure 10: Ultrasonic Cement Analyzer (UCA) (Direct Industry, 2014)

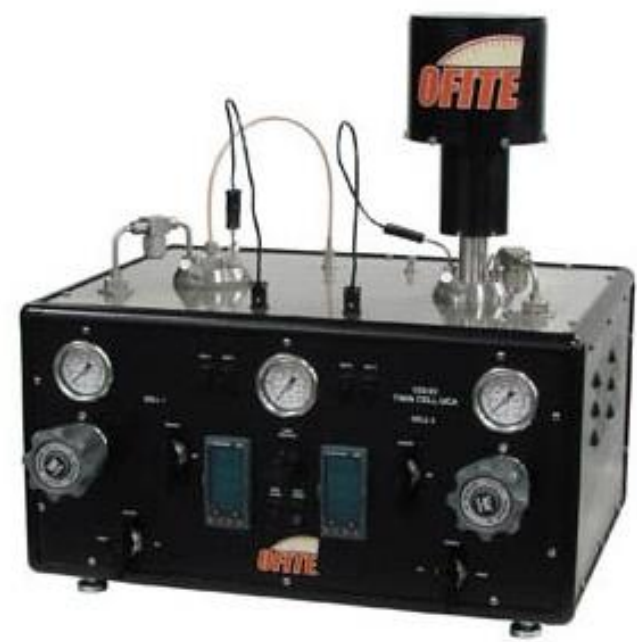

Figure 11: Static gel strength instrument (Universal, 2013) 


\section{E. RHEOLOGY TESTS:}

The Rheology of a cement slurry deals with the flow of said slurry with regards to its workability. This is an important property for the cement slurry in order to maintain uniform distribution down hole. This is a study of the slurry's ability to flow, and it is measured while flowing. The cement slurry is tested in a Rheometer ranging from 3 to 300 rpm rotational speeds. This procedure follows API Recommended Practice 10B-2. The Rheological properties under consideration include plastic viscosity, $\mu$, yield stress, $\tau_{\mathrm{o}}$, and shear stress, $T$. These properties are defined by the Bingham model for nonNewtonian fluid flow for cement mixtures and it is given by the equation: $\tau=\tau_{\mathrm{o}}+\mu \gamma$, where $y$ the shear rate (Ferraris, 1999). Figure 12 is an example of a Rheometer:

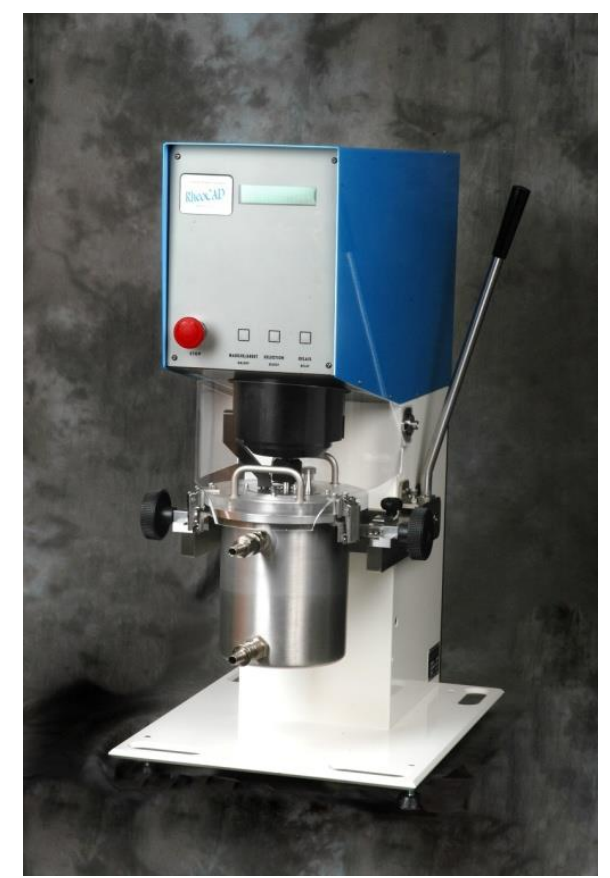

Figure 12: Rheometer (Laval Lab, 2015) 


\section{F. MIXING TEST:}

Mixability is a non API test and it is used to determine the ease at which the additives of the slurries can be thoroughly and completely mixed together. The results are based on a scale from zero to five, with zero being unmixable and five have optimal mixability.

\section{G. CRUSH TEST:}

The crush test is similar to the compressive strength test and it uses the same type of force. However, where the compressive strength can be nondestructive and/or cease at the point of failure, the crush test continues past the point of failure to record the compressive strength as the sample is crushed. This test is only performed to verify the results from the UCS test. It is based on the API Recommended Practice 10B-2

along the same guidelines as the compressive strength test with similar results. The experiment is very similar to that of the UCS. 


\section{CHAPTER 2: PROBLEM STATEMENT}

When $6.3 \%$ of all wells drilled in the Application basin from 1958 to 2013 fail, the need for a solution is very real. Additionally, the majority of producing companies do not monitor their wells regularly for cement integrity. Only when they see a flow rate or pressure related problem on their end, do they investigate (Davies, et al., 2015). However, a well may have been slowly leaking for many years before the leak became large enough to effect pressure or flow rate gages and alert someone.

Public opinion is very important to the petroleum industry for both commercial and public reasons. No investor or land owner will consult with a petroleum company if they think that a well will leak. While each oil spill is very important to that company, the idea that the industry is doing nothing to change it still remains. Therefore, the need for a wellbore cement to prevent and resist the formation micro fractures throughout the entire life span of the well is very desirable for public relations as well.

It appears that the majority of wellbore cement studies are performed to either decrease weight, and/or increase compressive strength. However, elasticity is also an important attribute that needs attention as well. Cement is generally perceived to be relatively brittle and weak in elastic response. Although in oil producing regions like California, a need to resist seismic activity is obvious. California sees earthquakes almost every day, and has countless wells throughout the state. Furthermore, California is not the only place in the world that sees earthquakes. Seismic activity does more than apply compressive forces onto the cement; it may shake, the wellbore, or parts of the wellbore. The cement's standard compressive forces require an elastic resilience in 
order to withstand these irregular forces. It is therefore essential for the cement to have an increased elastic response in order to adequately handle these conditions.

Crumb rubber can be tested in itself and has been proven to be elastic in nature. Natural rubber is known to be very elastic. Without nano silica creating the connectivity required, the crumb rubber disconnects from the cement and creates more problems than it solves. The crumb rubber when detached from the surrounding cement creates holes and air pockets where the particles are located throughout the cement resulting in discontinuities throughout. These discontinuities decrease the cement strength and provide no elastic resilience. With proper integration into the cement blend, it becomes part of the final cured cement. Only with nano silica can it be adequately coated enough to allow for full contact and connectivity to the rest of the cement. When connectivity is achieved, the properties of the crumb rubber will influence the rest of the sample. Essentially, if increased compressive strength can be achieved with the addition of crumb rubber, then this proves that the crumb rubber has been fully integrated. This research hopes to find the optimal concentrations to allow for increased compressive strength, while still fully integrating the crumb rubber. No such tests have been performed for class $\mathrm{G}$ cement for the purpose of wellbore integrity. Due to the number of wellbore integrity failures accounted for by a breach of barrier, the need for this research becomes very clear. 


\section{CHAPTER 3: PROCEDURE}

The thesis is based on experimental work on cement samples. It is the goal of this work to prove that an increase in the desirable mechanical properties is possible through the proposal blend. Therefore, in order to adequately prove this, various tests are performed on cured cement samples that have been formed containing nano silica and crumb rubber. These results are compared with a base test to prove or disprove the effects of the additives.

The formulation of percent composition of each particle in the cement sample was determined. The basis for this was from background research indicating an optimal concentration in the area of $3 \%$ nano silica and $5 \%$ crumb rubber. From this base line, a series of tests were conducted at the lower concentrations, from $1 \%$ to the high concentrations of $5 \%$. However, the slurry becomes unmixable and the properties become undesirable when higher concentrations are tested, and therefore deemed unnecessary and not performed. Furthermore, higher concentrations will become too costly to perform. Tables 5 and 6 shows the percentages used in this study.

\begin{tabular}{|r|r|}
\hline Nano-silica \%BWOC & Asphilitate particle \%BWOC \\
\hline 0 & 0 \\
\hline $1 \%$ & $1 \%$ \\
\hline $2 \%$ & $3 \%$ \\
\hline $3 \%$ & $5 \%$ \\
\hline
\end{tabular}

Table 1: Nano silica percent Table 2: Crumb rubber concentration concentration By Weight Of BWOC used in the test samples. Content (BWOC) used in the test samples.

A control test was done with no additives and class $\mathrm{G}$ cement to obtain a baseline to compare results with. After concentrations were selected, the total weight of 
each sample was calculated. The calculations were based on a sample size having a specific weight, including a safety factor to ensure an adequate amount. The weight of the sample, multiplied by the percent concentration yielded the weight of the particle required for that test.

Selection of additives begins with the decision of what type and characteristics of the additives desired. As for nano silica, a particle size within the range of 10-100 nano meters was desired. Furthermore, the nano silica particles were also required to be hydrophilic. This is because they had to be incorporated into a cement slurry containing water. For proper integration into the cement slurry, the nano silica particles had to be compatible with water. If the nano silica was incompatible with water, hydrophobic, we would see a repelling effect from the particles. This repelling effect would prevent the nano silica from being mixed into the cement slurry and either leave just cement and the nano silica left behind, or a decreased cement strength due to a lack of bonding. Figure 13 shows the nano silica used in this study. The desired nano silica particles were obtained from a vendor in China.

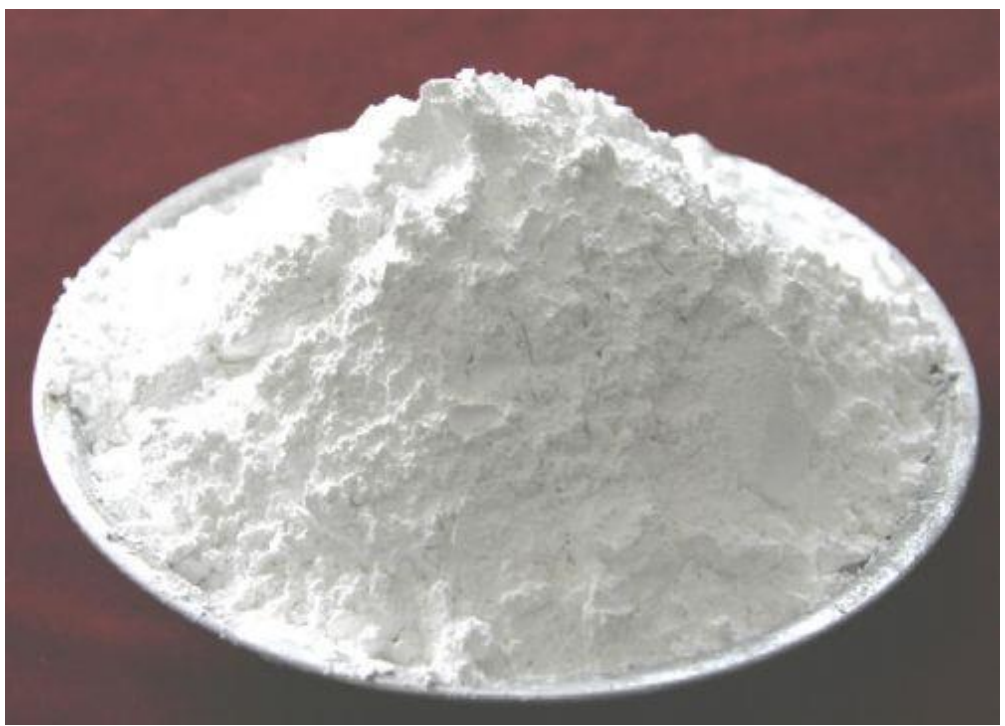

Figure 13: Nano Silica (Sinosi Group, 2015) 
Many different types of elastomer particles are available, however, the most feasible, readily available particle is that of crumb rubber. Crumb rubber provides optimal elastic properties and has a history of involvement in concrete. This will be further discussed in the feasibility section. Crumb rubber is readily available just about anywhere in the world and in a wide variety of sizes and quantities. It is also relatively cheap in terms of a large-scale cement additive. The crumb rubber that was acquired for this research was that of minus 40 mesh, or about 420 microns. This is a feasible size for the industry to acquire and use easily. Larger sizes start to act as an aggregate essentially turning the cement into concrete. In the case of smaller sizes, the price would drastically increase as well as the hazards associated with handling. The sample of class $\mathrm{G}$ cement used in this research was provided by Halliburton. Figure 14 shows the crumb rubber used in this study.

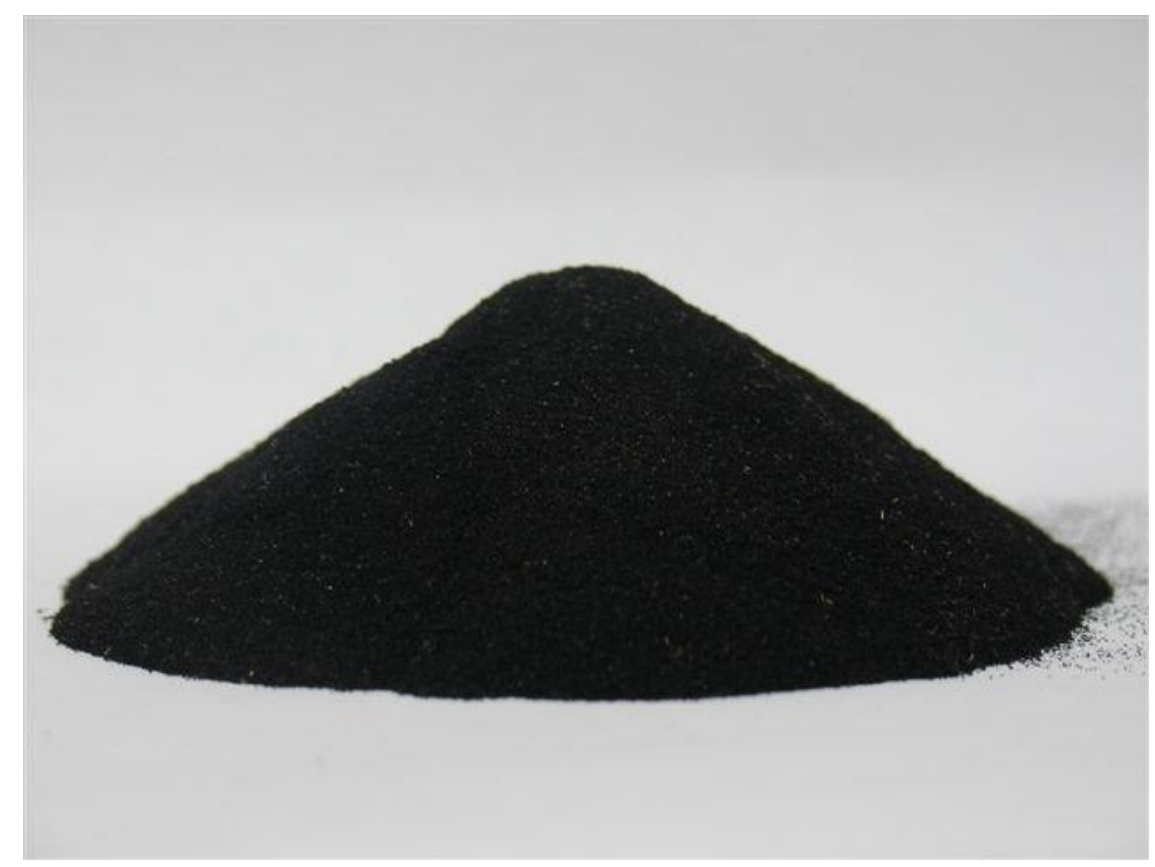

Figure 14: Crumb Rubber (CRM) 
During the experimentation phase of the research, the following API tests are conducted at each concentration previously determined: thickening time (BC time) up to $100 \mathrm{BC}$, free fluid, fluid loss, unconfined compressive strength (UCS), transition time $\left(100 \# / 100 \mathrm{ft}^{2}\right.$ to $\left.500 \mathrm{ft}^{2}\right)$, capable of holding own hydrostatic, rheologies 3 to $300 \mathrm{rpm}$, mixability (non api), using the slurry conditioned at a temperature of 180 degrees $F$ and 3000 pounds per square inch to mimic downhole conditions. The samples were prepared and tested at the Halliburton cement laboratory equipped with proper equipment. This study focused on an increase in compressive strength of cement while incorporating crumb rubber, thus to prove that the crumb rubber is fully integrated.

When the experimentation phase was complete, the analysis of results were graphed and tabulated in order to accurately study trends and patterns. This will also allow one to compare and contrast the properties and characteristics of each concentration. Each individual test was tabulated against all other sampled for that specific test to allow for clear interpretation of individual results. Furthermore, each test was analyzed against background research and industry expectancies to ensure its accuracy. From these correlations, the optimal sample is determined. With known concentrations, the test was replicated and the mechanical properties of the combined nano silica and crumb rubber were determined.

Once the results are accurately represented, analyzed and interpreted, conclusions are drawn. These conclusions started on the explanations of concentrations that did not meet the goals of this research. Then conclusions were made about the concentrations that showed an increase in desirable mechanical properties. Lastly, the optimal concentration can be examined. 
With the conclusions in place, this report presents; recommendations for further study, and a feasibility analysis of the applicability of this research. This study has proven the benefits of nano technology for use in wellbore cement. Furthermore, nano silica and crumb rubber have proven to be feasible in the concentrations determined. 


\section{CHAPTER 4: INITIAL RESULTS AND CONCLUSIONS}

A.) Class G Cement:

In this section, results are presented for experiments conducted with class $\mathrm{G}$ cement without additives. These experiments provide a baseline to compare the results from this section with cement samples containing nano silica and crumb rubber. Table 3 provides the testing conditions that the trial was performed under. The class $\mathrm{G}$ cement trial with no additives was tested at $3000 \mathrm{psi}$ and a bottom hole control temperature (BHCT) and bottom hole circulating temperature (BHST) $180^{\circ} \mathrm{F}$.

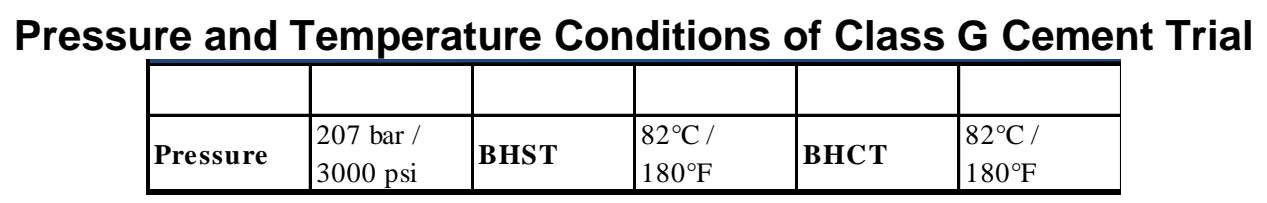

Table 3: Test conditions of Class G cement 
Table 4 shows that the trial containing class $\mathrm{G}$ cement with no additives has a slurry density of $15.8 \mathrm{lb} / \mathrm{gal}$. The slurry yield is $1.15 \mathrm{ft}^{3} /$ sack with a water requirement of $5.09 \mathrm{gal} / \mathrm{sack}$. The total fluid for the mix required is $5.09 \mathrm{gal} / \mathrm{sack}$. If the only fluid added to the mix is water, then the total fluid required will equal the water requirement.

\section{Composition and Property Analysis of Class G Cement Trial}

\begin{tabular}{|r|l|c|l|l|l|}
\hline \multicolumn{1}{|l|}{ Conc } & $\underline{\text { UOM }}$ & \multicolumn{1}{|c|}{ Cement/Additive } & \multicolumn{3}{|c|}{ Cement Properties } \\
\hline 100 & $\%$ BWOC & Evansville Lehigh Premium G & $\begin{array}{l}\text { Slurry } \\
\text { Density }\end{array}$ & 15.8 & lbm/gal \\
\hline 5.09 & $\mathrm{gal} / \mathrm{sack}$ & Fresh Water & Slurry Yield & 1.1541 & $\mathrm{ft} 3 / \mathrm{sack}$ \\
\hline \multicolumn{2}{|l|}{} & $\begin{array}{l}\text { Water } \\
\text { Requirement }\end{array}$ & 5.091 & $\mathrm{gal} / \mathrm{sack}$ \\
\hline & $\begin{array}{l}\text { Total Mix } \\
\text { Fluid }\end{array}$ & 5.09 & $\mathrm{gal} / \mathrm{sack}$ \\
\hline & & & & \\
\hline & & & & \\
\hline & $\begin{array}{l}\text { Water } \\
\text { Source }\end{array}$ & Fresh Water & \\
\hline & $\begin{array}{l}\text { Water } \\
\text { Chloride }\end{array}$ & & \\
\hline
\end{tabular}

Table 4: Properties of Class G cement used in analysis 
Measurements - Class G Cement

Table 5 shows that the class $\mathrm{G}$ trial with no additives attained a mixability of 5 while being mixed under an average rpm of 12,000 . Furthermore, the blend addition time at 4,000 rpm was 15 seconds. This shows that the sample was capable of being easily mixed.

\section{Mixability Test for Class G Cement with No Additives}

\begin{tabular}{|c|c|c|}
\hline \multicolumn{3}{|c|}{ Mixability (0 - 5) - 0 is not mixable } \\
\hline $\begin{array}{l}\text { Mixability } \\
\text { rating }(0-5)\end{array}$ & $\begin{array}{l}\text { Avg rpm mixing under } \\
\text { load }(\mathbf{1 2 , 0 0 0 )}\end{array}$ & $\begin{array}{l}\text { Blend addition time } \\
\text { (sec) @ 4,000 RPM }\end{array}$ \\
\hline 5 & 12000 & 15 \\
\hline
\end{tabular}

Table 5: Mixability test for class G cement

Table 6 shows a thickening time of 1 hour and 45 minutes to $100 \mathrm{Bc} .100 \mathrm{Bc}$ is the primary result for this test. Furthermore, the time required to reach 30 and $40 \mathrm{Bc}$ was 1 hour and 33 minutes, $50 \mathrm{Bc}$ was 1 hour 35 minutes and $70 \mathrm{Bc}$ was 1 hour 39 minutes.

Thickening Time Test for Class G Cement with No Additives

\begin{tabular}{|c|c|c|c|c|c|c|c|c|}
\hline \multicolumn{9}{|c|}{ Thickening Time } \\
\hline Temp $\left({ }^{\circ} \mathbf{F}\right)$ & \begin{tabular}{|l|} 
Pressure \\
$(\mathrm{psi})$
\end{tabular} & \begin{tabular}{|l|} 
Reached in \\
(min)
\end{tabular} & Start BC & \begin{tabular}{|l|l}
$30 \mathrm{Bc}$ \\
(hh:mm)
\end{tabular} & \begin{tabular}{|l}
$40 \mathrm{Bc}$ \\
(hh:mm)
\end{tabular} & \begin{tabular}{|l|l}
$50 \mathrm{Bc}$ \\
(hh:mm)
\end{tabular} & \begin{tabular}{|l|l}
70 Bc \\
$(\mathrm{hh}: \mathrm{mm})$
\end{tabular} & $\begin{array}{l}100 \text { Bc } \\
\text { (hh:mm) }\end{array}$ \\
\hline 180 & 3000 & 30 & 9 & $1: 33$ & $1: 33$ & $1: 35$ & $1: 39$ & $1: 45$ \\
\hline
\end{tabular}

Table 6: Thickening Time test for class G cement 
Table 7 shows the rheology's tests which provided a PV/YP of $41.95 / 18.86$ at $80^{\circ} \mathrm{F}$ and $94.45 / 57.47$ at $180^{\circ} \mathrm{F}$. This test shows the viscosities of the cement slurry while being mixed under various rpm. The viscosity and rpm then provides the shear stress and shear rate which can be graphically represented.

\section{API Rheology under $80^{\circ} \mathrm{F}$ and $180^{\circ} \mathrm{F}$ for Class G Cement with No Additives}

\begin{tabular}{|c|c|c|c|c|c|c|c|c|c|c|}
\hline \multicolumn{11}{|c|}{ API Rheology } \\
\hline $\operatorname{Temp}\left({ }^{\circ} \mathbf{F}\right)$ & RPM & 300 & 200 & 100 & 60 & 30 & 6 & 3 & $\begin{array}{l}\text { Cond Time } \\
(\mathrm{min})\end{array}$ & $\mathrm{PV} / \mathrm{YP}$ \\
\hline 80 & Viscosity & 58 & 46 & 35 & 29 & 24 & 18 & 13 & $\mathbf{0}$ & $41.95 / 18.86$ \\
\hline $\operatorname{Temp}\left({ }^{\circ} \mathbf{F}\right)$ & RPM & 300 & 200 & 100 & 60 & 30 & 6 & 3 & $\begin{array}{l}\text { Cond Time } \\
(\min )\end{array}$ & $\mathbf{P V} / \mathbf{Y P}$ \\
\hline 180 & Viscosity & 86 & 79 & 68 & 60 & 45 & 16 & 11 & 30 & $\begin{array}{l}94.45 / \\
57.47\end{array}$ \\
\hline
\end{tabular}

Table 7: API Rheology tests for class G cement

Table 8 contains the results for the API fluid loss test for class G cement with no additives. The primary result obtained is the measured volume of fluid loss, which was found to be $46 \mathrm{ml}$. The test was performed at $180^{\circ} \mathrm{F}$ and $1000 \mathrm{psi}$ for 0.1 minute with a conditioning time of 30 minutes.

\section{API Fluid Loss Test for Class G Cement with No Additives}

\begin{tabular}{|c|c|c|c|c|c|c|}
\hline \multicolumn{7}{|c|}{ API Fluid Loss } \\
\hline $\begin{array}{l}\text { Test Temp } \\
\left({ }^{\circ} \mathbf{F}\right)\end{array}$ & \begin{tabular}{|l} 
Test \\
Pressure \\
(psi)
\end{tabular} & $\begin{array}{l}\text { Test Time } \\
(\mathrm{min})\end{array}$ & Meas. Vol. & $\begin{array}{l}\text { Calculated } \\
\text { FL }(<30 \\
\text { min }) \\
\end{array}$ & \begin{tabular}{|l|}
$\begin{array}{l}\text { Conditioni } \\
\text { ng time } \\
(\mathrm{min})\end{array}$ \\
\end{tabular} & \begin{tabular}{|l} 
Conditioni \\
ng Temp \\
$\left({ }^{\circ} \mathrm{F}\right)$
\end{tabular} \\
\hline 180 & 1000 & 0.1 & 46 & 1593 & 30 & 180 \\
\hline
\end{tabular}

Table 8: API Fluid loss test for Class G cement 
Table 9 contains the results for the free fluid test of class $G$ cement with no additives. This test showed that the sample contained $.52 \%$ free fluid. The test sample was conditioned at $180^{\circ} \mathrm{F}$ for 30 minutes. Once the test started, the static temperature was $80^{\circ} \mathrm{F}$ for 120 minutes at a 45 degree inclination angle.

\section{Free Fluid Test for Class G Cement with No Additives}

\begin{tabular}{|l|l|r|r|r|r|}
\hline \multicolumn{5}{|c|}{ Free Fluid API 10B-2 / ISO 10426-2 } \\
\hline & & & & & \\
\hline $\begin{array}{l}\text { Con. Temp } \\
\text { (F) }\end{array}$ & $\begin{array}{l}\text { Cond. } \\
\text { Time (min) }\end{array}$ & Static T. (F) & $\begin{array}{l}\text { Static time } \\
(\text { min) }\end{array}$ & Incl. (deg) & \% Fluid \\
\hline 180 & 30 & 80 & 120 & 45 & 0.52 \\
\hline
\end{tabular}

Table 9: Free Fluid test for class $\mathrm{G}$ cement

The unconfined compressive strength for class $\mathrm{G}$ cement with no additives is 2671 psi after 48 hours as shown by Table 10. Furthermore, the sample reached 500 psi after 3 hours and 44 minutes and 100 psi in 2 hours and 38 minutes. The sample was tested at $180^{\circ} \mathrm{F}$ and $3000 \mathrm{psi}$.

\section{Unconfined Compressive Strength for Class G Cement with No Additives}

\begin{tabular}{|c|c|c|c|c|c|c|c|c|c|c|c|}
\hline \multicolumn{12}{|c|}{ UCA Comp. Strength } \\
\hline $\begin{array}{l}\text { End Temp } \\
\left({ }^{\circ} \mathrm{F}\right)\end{array}$ & \begin{tabular}{|l|}
$\begin{array}{l}\text { Pressure } \\
(\mathrm{psi})\end{array}$ \\
\end{tabular} & \begin{tabular}{|l}
$50 \mathrm{psi}$ \\
(hh:mm)
\end{tabular} & \begin{tabular}{|l|}
100 psi \\
(hh:mm)
\end{tabular} & \begin{tabular}{|l|}
500 psi \\
$(\mathrm{hh}: \mathrm{mm})$
\end{tabular} & $\begin{array}{l}8 \mathrm{hr} \mathrm{CS} \\
(\mathrm{psi})\end{array}$ & $\begin{array}{l}12 \mathrm{hr} \text { CS } \\
\text { (psi) }\end{array}$ & $\begin{array}{l}16 \mathrm{hr} \text { CS } \\
\text { (psi) }\end{array}$ & $\begin{array}{l}24 \mathrm{hr} \text { CS } \\
\text { (psi) }\end{array}$ & $\begin{array}{l}48 \mathrm{hr} \text { CS } \\
\text { (psi) }\end{array}$ & \begin{tabular}{|l}
$\begin{array}{l}\text { End CS } \\
(\mathrm{psi})\end{array}$ \\
\end{tabular} & \begin{tabular}{|l|}
$\begin{array}{l}\text { End Time } \\
(\mathrm{hrs})\end{array}$ \\
\end{tabular} \\
\hline 180 & 3000 & $2: 22$ & $2: 38$ & $3: 44$ & 1568 & 1983 & 2177 & 2425 & 2671 & 2662 & 74.75 \\
\hline
\end{tabular}

Table 10: Compressive strength for class G cement 
The compressive strength graph (Figure 15) for class G cement shows a steady, expected increase of compressive strength as shown by the green line. This graph shows that the compressive strength reaches 100 psi after 2 hours and 38 minutes and 500 psi after 3 hours and 44 minutes.

Compressive Strength Graph of Class G Cement with No Additives

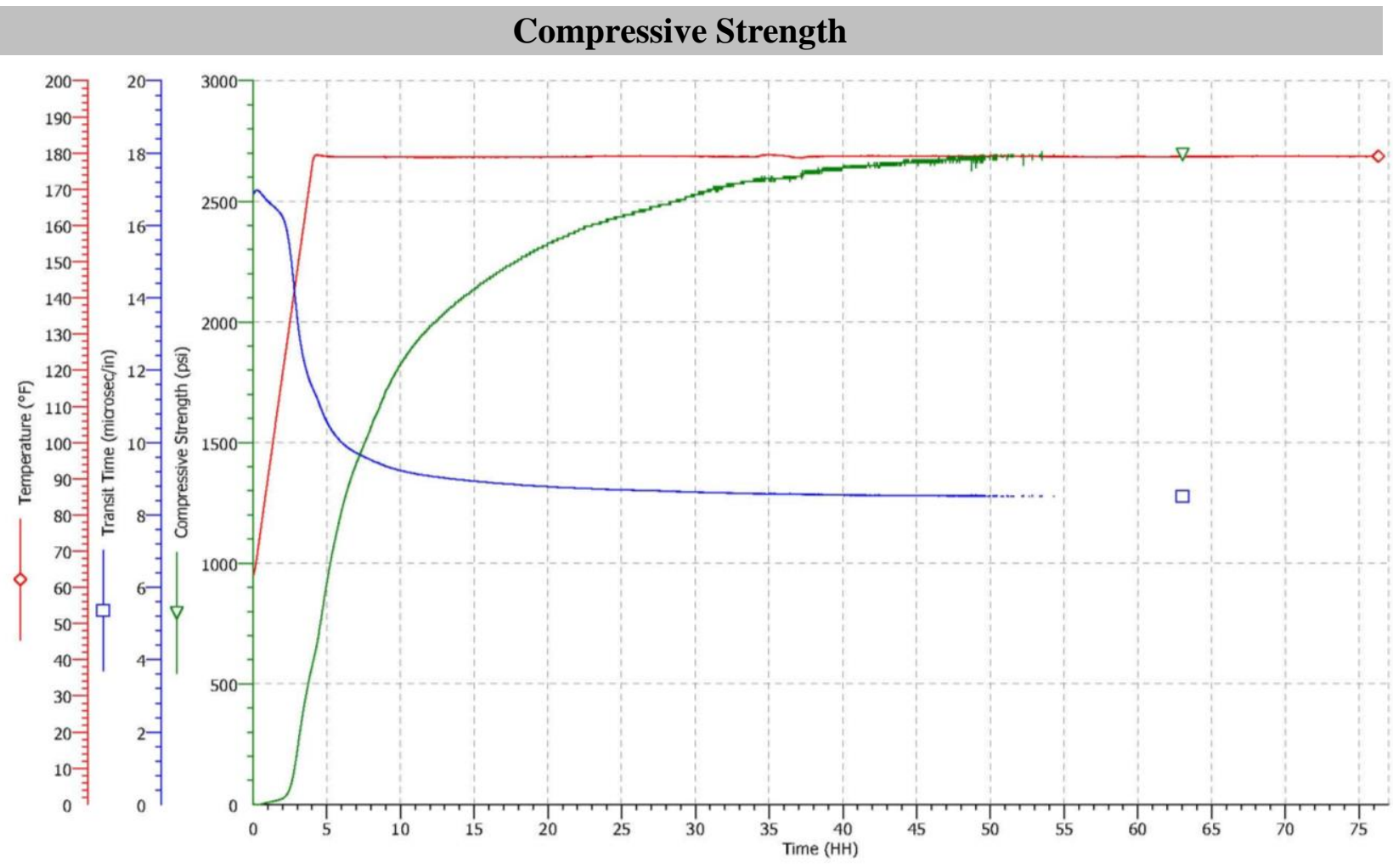

Figure 15: Compressive strength, temperature and transit time measurements of class $\mathrm{G}$ cement 
The time, temperature and transition graph (Figure 16) shows that class $\mathrm{G}$ cement starts to experience an increase in Bc after 1 hour and 30 minutes. The slurry temperature and pressure are also shown by this graph.

\section{Time, Temperature and Transition of Class G Cement with No Additives}

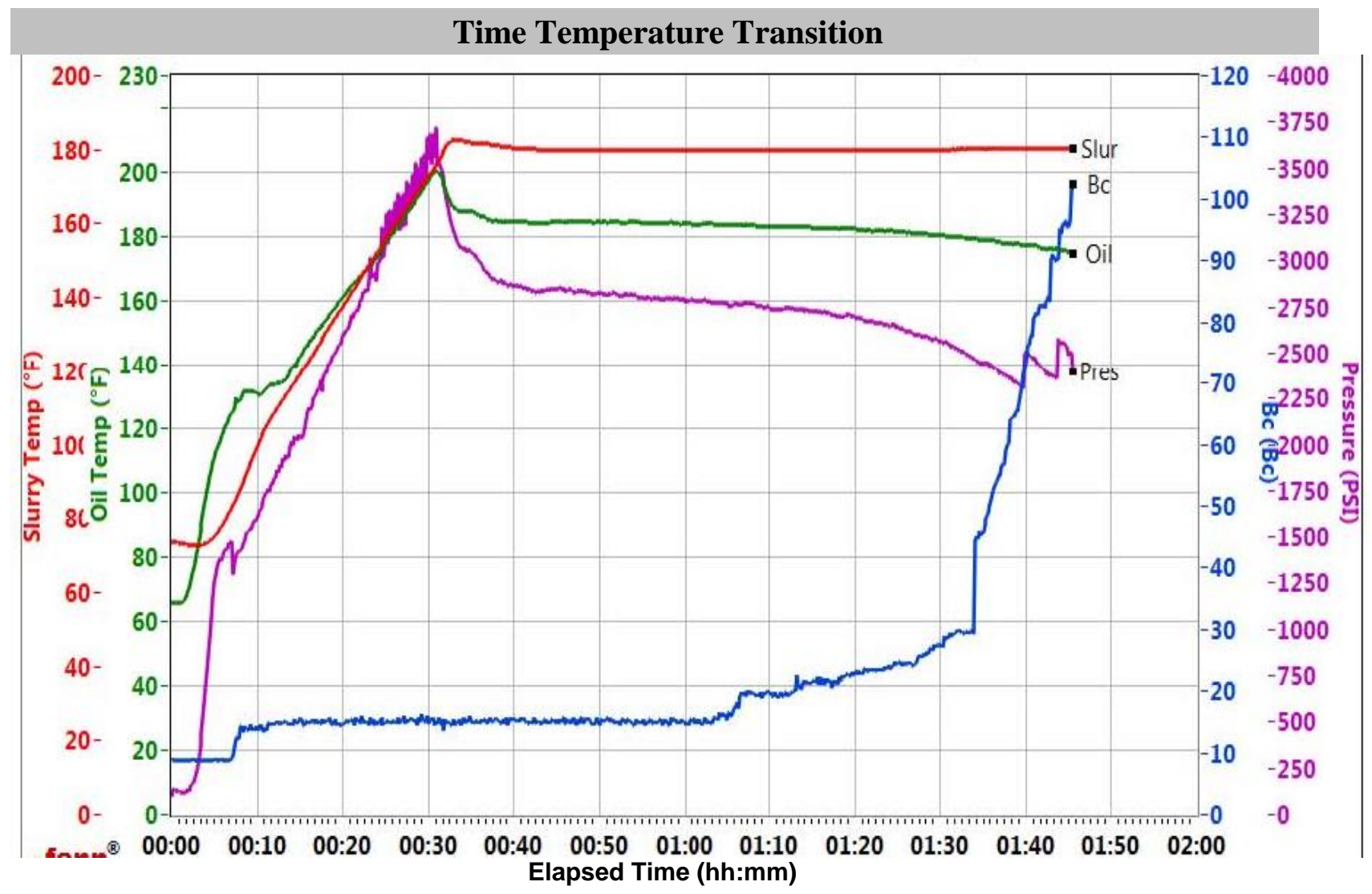

Figure 16: Temperature and Transition of class $\mathrm{G}$ cement versus time 
B.) $1 \%$ BWOC Nano Silica:

In this section, results are presented for experiments conducted with class $\mathrm{G}$ cement containing $1 \%$ nano silica. Table 11 provides the testing conditions that the trial was performed under. The class $\mathrm{G}$ cement trial with $1 \%$ nano silica was tested at 3000 psi and $180^{\circ} \mathrm{F}$.

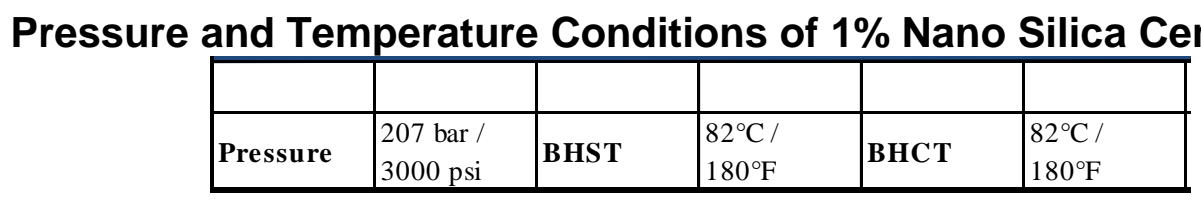

Table 11: Test conditions of $1 \%$ Nano Silica

Table 12 shows that the trial containing class G cement with $1 \%$ nano silica has a slurry density of $15.8 \mathrm{lb} /$ gal. The slurry yield is $1.16 \mathrm{ft}^{3} /$ sack with a water requirement of $5.09 \mathrm{gal} / \mathrm{sack}$. The total fluid for the mix required is $5.1 \mathrm{gal} / \mathrm{sack}$.

\begin{tabular}{|c|c|c|c|c|c|}
\hline & UOM & Cement/Additive & \multicolumn{3}{|c|}{ Cement Properties } \\
\hline 100 & $\%$ BWOC & Evansville Lehigh Premium G & $\begin{array}{l}\text { Slurry } \\
\text { Density }\end{array}$ & 15.8 & $\mathrm{lbm} / \mathrm{gal}$ \\
\hline 5.1 & $\mathrm{gal} / \mathrm{sack}$ & Fresh Water & Slurry Yield & 1.1625 & $\mathrm{ft} 3 / \mathrm{sack}$ \\
\hline \multirow[t]{5}{*}{1} & $\%$ BWOC & zRD Silica Dioxide & $\begin{array}{l}\text { Water } \\
\text { Requirement }\end{array}$ & 5.0977 & gal/sack \\
\hline & & & $\begin{array}{l}\text { Total Mix } \\
\text { Fluid }\end{array}$ & 5.1 & $\mathrm{gal} / \mathrm{sack}$ \\
\hline & & & & & \\
\hline & & & $\begin{array}{l}\text { Water } \\
\text { Source }\end{array}$ & Fresh Water & \\
\hline & & & \begin{tabular}{|l} 
Water \\
Chloride
\end{tabular} & & \\
\hline
\end{tabular}

Table 12: Properties of $1 \%$ nano silica cement used in analysis 
Measurements - 1\% Nano Silica

Table 13 shows that the class $\mathrm{G}$ trial with $1 \%$ nano silica attained a mixability of 4 while being mixed under an average rpm of 12,000 . Furthermore, the blend addition time at 4,000 rpm was 19 seconds. This shows a slight decrease in ability of the slurry to be mixed.

\section{Mixability Test for Class G Cement with $1 \%$ Nano Silica}

\begin{tabular}{|l|l|l|}
\hline \multicolumn{3}{|c|}{ Mixability (0 - 5) - 0 is not mixable } \\
\hline & & \\
\hline $\begin{array}{l}\text { Mixability } \\
\text { rating }(0-5)\end{array}$ & $\begin{array}{l}\text { Avg rpm mixing under } \\
\text { load ( 12,000) }\end{array}$ & $\begin{array}{l}\text { Blend addition time } \\
\text { (sec) @ 4,000 RPM }\end{array}$ \\
\hline & 12000 & \\
\hline
\end{tabular}

Table 13: Mixability test for $1 \%$ nano silica cement

Table 14 shows a thickening time of 1 hour and 16 minutes to $100 \mathrm{Bc} .100 \mathrm{Bc}$ is the primary result for this test. Furthermore, the time required to reach $30 \mathrm{Bc}$ was 25 minutes, $40 \mathrm{Bc}$ was 52 minutes, $50 \mathrm{Bc}$ was 1 hour and 9 minutes and $70 \mathrm{Bc}$ was 1 hour 13 minutes.

Thickening Time Test for Class G Cement with 1\% Nano Silica

\begin{tabular}{|c|c|c|c|c|c|c|c|c|}
\hline \multicolumn{9}{|c|}{ Thickening Time } \\
\hline $\operatorname{Temp}\left({ }^{\circ} \mathbf{F}\right)$ & \begin{tabular}{|l}
$\begin{array}{l}\text { Pressure } \\
(\mathrm{psi})\end{array}$ \\
\end{tabular} & \begin{tabular}{|l|}
$\begin{array}{l}\text { Reached in } \\
(\mathrm{min})\end{array}$ \\
\end{tabular} & Start BC & \begin{tabular}{|l|}
30 Bc \\
$(\mathrm{hh}: \mathrm{mm})$ \\
\end{tabular} & $\begin{array}{l}40 \text { Bc } \\
(\mathrm{hh}: \mathrm{mm})\end{array}$ & \begin{tabular}{|l|l}
50 Bc \\
$(\mathrm{hh}: \mathrm{mm})$
\end{tabular} & \begin{tabular}{|l}
70 Bc \\
$(\mathrm{hh}: \mathrm{mm})$
\end{tabular} & $\begin{array}{l}100 \mathrm{Bc} \\
(\mathrm{hh}: \mathrm{mm})\end{array}$ \\
\hline 180 & 3000 & 30 & 22 & $0: 25$ & $0: 52$ & 1:09 & $1: 13$ & $1: 16$ \\
\hline
\end{tabular}

Table 14: Thickening Time test for $1 \%$ nano silica cement 
Table 15 shows the rheology's tests which provided a PV/YP of 99.38/51.15 at $80^{\circ} \mathrm{F}$ and $144.25 / 61.44$ at $180^{\circ} \mathrm{F}$. This test shows a slightly higher viscosity and shear stress than class $\mathrm{G}$ cement with no additives.

\section{API Rheology under $80^{\circ} \mathrm{F}$ and $180^{\circ} \mathrm{F}$ for Class G Cement with $1 \%$ Nano Silica}

\begin{tabular}{|c|c|c|c|c|c|c|c|c|c|c|}
\hline \multicolumn{11}{|c|}{ API Rheology } \\
\hline $\operatorname{Temp}\left({ }^{\circ} \mathbf{F}\right)$ & RPM & 300 & 200 & 100 & 60 & 30 & 6 & 3 & \begin{tabular}{|l} 
Cond Time \\
$(\mathrm{min})$
\end{tabular} & $\mathbf{P V} / \mathbf{Y P}$ \\
\hline 80 & Viscosity & 134 & 118 & 99 & 90 & 79 & 29 & 22 & $\mathbf{0}$ & $\begin{array}{l}99.38 / \\
51.15\end{array}$ \\
\hline $\operatorname{Temp}\left({ }^{\circ} \mathbf{F}\right)$ & RPM & 300 & 200 & 100 & 60 & 30 & 6 & 3 & $\begin{array}{l}\text { Cond Time } \\
\text { (min) }\end{array}$ & $\mathbf{P V} / \mathbf{Y P}$ \\
\hline 180 & Viscosity & 173 & 164 & 146 & 134 & 88 & 20 & 17 & 30 & $\begin{array}{l}144.24 / \\
61.44\end{array}$ \\
\hline
\end{tabular}

Table 15: API Rheology tests for $1 \%$ nano silica

Table 16 contains the results for the API fluid loss test for class G cement $1 \%$ nano silica. The primary result obtained is the measured volume of fluid loss, which was found to be $39 \mathrm{ml}$. The test was performed at $180^{\circ} \mathrm{F}$ and $1000 \mathrm{psi}$ for .55 minutes with a conditioning time of 30 minutes.

\section{API Fluid Loss Test for Class G Cement with 1\% Nano Silica}

\begin{tabular}{|r|l|l|r|l|l|l|}
\hline \multicolumn{7}{|c|}{ API Fluid LoSS } \\
\hline & & & & & \\
\hline $\begin{array}{l}\text { Test Temp } \\
\left({ }^{\circ} \text { F) }\right.\end{array}$ & $\begin{array}{l}\text { Test } \\
\text { Pressure } \\
(\text { psi })\end{array}$ & $\begin{array}{l}\text { Test Time } \\
(\mathrm{min})\end{array}$ & Meas. Vol. & $\begin{array}{l}\text { Calculated } \\
\text { FL }(<30 \\
\text { min })\end{array}$ & $\begin{array}{l}\text { Conditioni } \\
\text { ng time } \\
(\text { min })\end{array}$ & $\begin{array}{l}\text { Conditioni } \\
\text { ng Temp } \\
\left({ }^{\circ} \text { F }\right)\end{array}$ \\
\hline 180 & 1000 & 0.55 & 39 & 576 & 30 & 180 \\
\hline
\end{tabular}

Table 16: API Fluid loss test for $1 \%$ nano silica cement 
Table 17 contains the results for the free fluid test of class G cement with $1 \%$ nano silica. This test showed that the sample contained $0 \%$ free fluid. The test sample was conditioned at $180^{\circ} \mathrm{F}$ for 30 minutes. Once the test started, the static temperature was $80^{\circ} \mathrm{F}$ for 120 minutes at a 45 degree inclination angle.

\section{Free Fluid Test for Class G Cement with 1\% Nano Silica}

\begin{tabular}{|l|l|r|r|r|r|}
\hline \multicolumn{5}{|c|}{ Free Fluid API 10B-2 / ISO 10426-2 } \\
\hline & & & & & \\
\hline $\begin{array}{l}\text { Con. Temp } \\
\text { (F) }\end{array}$ & $\begin{array}{l}\text { Cond. } \\
\text { Time (min) }\end{array}$ & Static T. (F) & $\begin{array}{l}\text { Static time } \\
(\text { min) }\end{array}$ & Incl. (deg) & \% Fluid \\
\hline 180 & 30 & 80 & 120 & 45 & 0 \\
\hline
\end{tabular}

Table 17: Free Fluid test for $1 \%$ nano silica

The unconfined compressive strength for class $\mathrm{G}$ cement with $1 \%$ nano silica is 2672 psi after 48 hours as shown by Table 18. Furthermore, the sample reached 500 psi after 3 hours and 39 minutes and 100 psi in 2 hours and 31 minutes. The sample was tested at $180^{\circ} \mathrm{F}$ and $3000 \mathrm{psi}$.

\section{Unconfined Compressive Strength for Class G Cement with 1\% Nano Silica}

\begin{tabular}{|c|c|c|c|c|c|c|c|c|c|c|c|}
\hline \multicolumn{12}{|c|}{ UCA Comp. Strength } \\
\hline \begin{tabular}{|l|} 
End Temp \\
$\left({ }^{(} \mathrm{F}\right)$ \\
\end{tabular} & \begin{tabular}{|l} 
Pressure \\
(psi)
\end{tabular} & \begin{tabular}{|l|}
$50 \mathrm{psi}$ \\
$(\mathrm{hh}: \mathrm{mm})$
\end{tabular} & \begin{tabular}{|l|l|}
$100 \mathrm{psi}$ \\
$(\mathrm{hh}: \mathrm{mm})$
\end{tabular} & 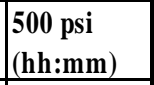 & $\begin{array}{l}8 \mathrm{hr} \mathrm{CS} \\
(\mathrm{psi})\end{array}$ & $\begin{array}{l}12 \mathrm{hr} \mathrm{CS} \\
\text { (psi) }\end{array}$ & \begin{tabular}{|l|}
$16 \mathrm{hr}$ CS \\
(psi)
\end{tabular} & \begin{tabular}{|l|}
$24 \mathrm{hr} \mathrm{CS}$ \\
$(\mathrm{psi})$
\end{tabular} & $\begin{array}{l}48 \mathrm{hr} \mathrm{CS} \\
\text { (psi) }\end{array}$ & $\begin{array}{l}\text { End CS } \\
(\mathrm{psi})\end{array}$ & \begin{tabular}{|l}
$\begin{array}{l}\text { End Time } \\
(\mathrm{hrs})\end{array}$ \\
\end{tabular} \\
\hline 180 & 3000 & $2: 18$ & $2: 31$ & $3: 39$ & 1732 & 2143 & 2347 & 2530 & 2672 & 2696 & 72.27 \\
\hline
\end{tabular}

Table 18: Compressive strength for $1 \%$ nano silica 
The compressive strength graph (Figure 17) for $1 \%$ nano silica shows a higher and earlier increase of compressive strength than that of the baseline case. This graph shows that the compressive strength reaches 100 psi after 2 hours and 31 minutes and 500 psi after 3 hours and 39 minutes.

\section{Compressive Strength Graph of Class G Cement with 1\% Nano Silica}

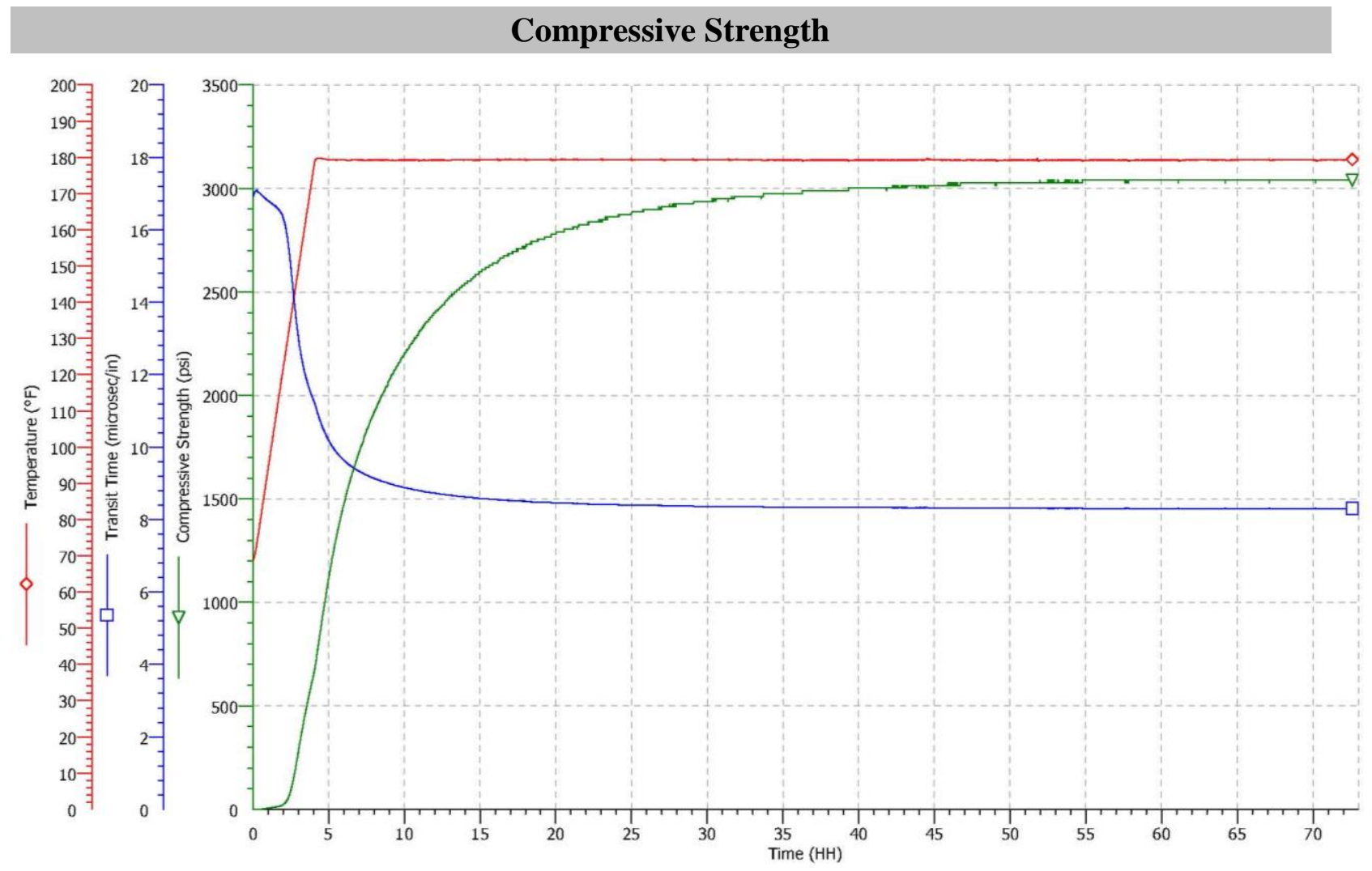

Figure 17: Compressive strength, $1 \%$ Nano Silica 
The time, temperature and transition graph (Figure 18) shows that $1 \%$ nano silica starts to experience an increase in $\mathrm{Bc}$ after 1 hour and 10 minutes.

\section{Time, Temperature and Transition of Class G Cement with 1\% Nano Silica}

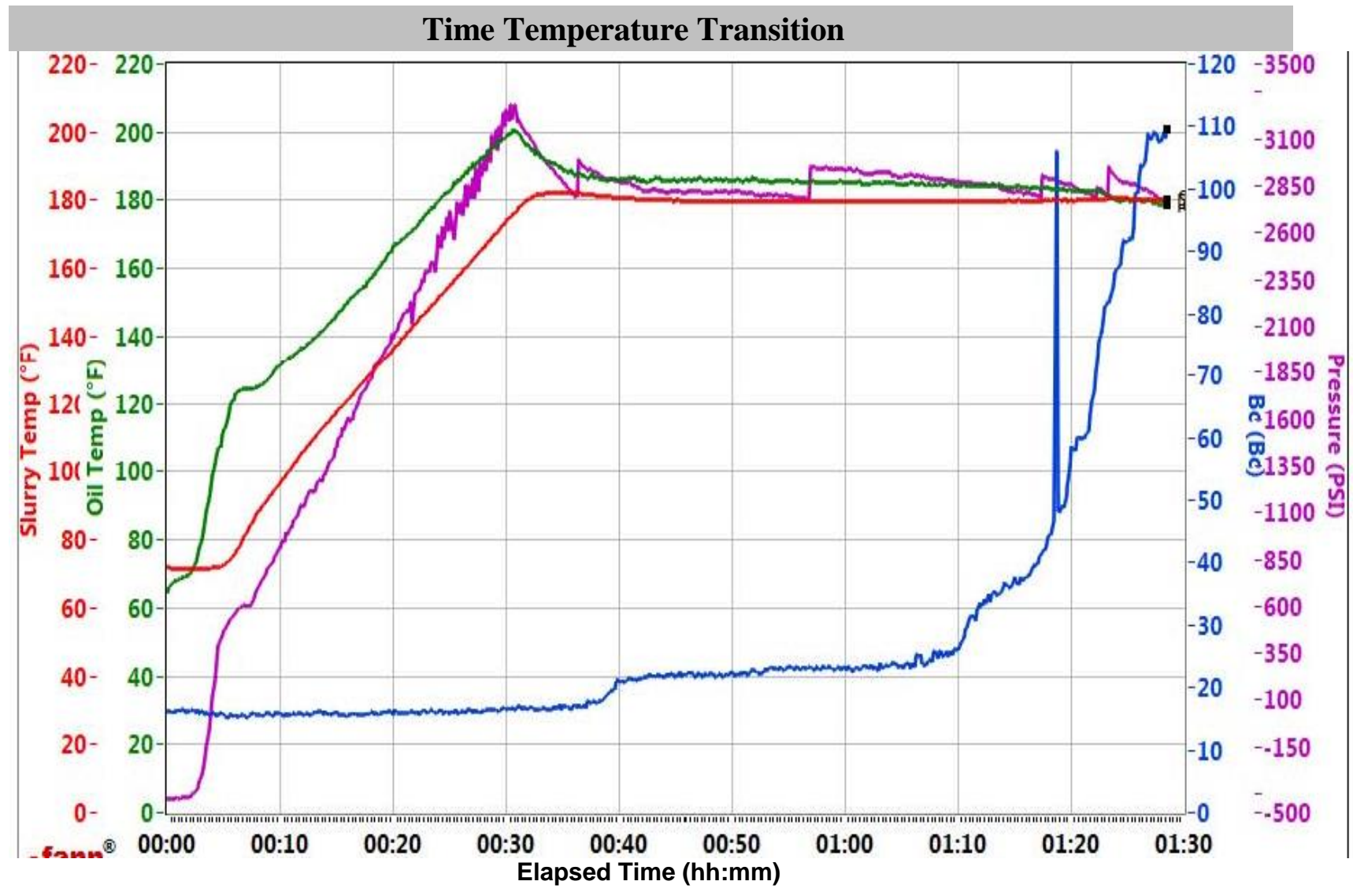

Figure 18: Temperature and Transition of $1 \%$ Nano Silica versus time 
C.) $2 \%$ BWOC Nano Silica:

In this section, results are presented for experiments conducted with class $\mathrm{G}$ cement containing $2 \%$ nano silica. Table 19 provides the testing conditions that the trial was performed under. The class $\mathrm{G}$ cement trial with $2 \%$ nano silica was tested at 3000 psi and $180^{\circ} \mathrm{F}$.

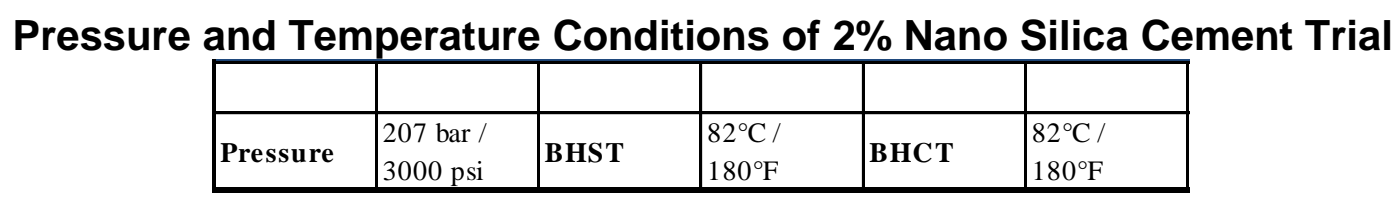

Table 19: Test conditions of $2 \%$ Nano Silica

Table 20 shows that the trial containing class $\mathrm{G}$ cement with $2 \%$ nano silica has a slurry density of $15.8 \mathrm{lb} / \mathrm{gal}$. The slurry yield is $1.17 \mathrm{ft}^{3} / \mathrm{sack}$ with a water requirement of $5.1 \mathrm{gal} / \mathrm{sack}$. The total fluid for the mix required is $5.1 \mathrm{gal} / \mathrm{sack}$.

\section{Composition and Property Analysis of $2 \%$ Nano Silica Cement Trial}

\begin{tabular}{|c|c|c|c|c|c|}
\hline$\underline{\text { Conc }}$ & UOM & $\underline{\text { Cement/Additive }}$ & \multicolumn{3}{|c|}{ Cement Properties } \\
\hline 100 & $\%$ BWOC & Evansville Lehigh Premium G & $\begin{array}{l}\text { Slurry } \\
\text { Density }\end{array}$ & 15.8 & $\mathrm{lbm} / \mathrm{gal}$ \\
\hline 5.1 & $\mathrm{gal} / \mathrm{sack}$ & Fresh Water & Slurry Yield & 1.1709 & $\mathrm{ft} 3 / \mathrm{sack}$ \\
\hline \multirow[t]{2}{*}{2} & $\%$ BWOC & zRD Silica Dioxide & $\begin{array}{l}\text { Water } \\
\text { Requirement }\end{array}$ & 5.1044 & $\mathrm{gal} / \mathrm{sack}$ \\
\hline & & & $\begin{array}{l}\text { Total Mix } \\
\text { Fluid }\end{array}$ & 5.1 & $\mathrm{gal} / \mathrm{sack}$ \\
\hline & & & & & \\
\hline & & & & & \\
\hline & & & $\begin{array}{l}\text { Water } \\
\text { Source }\end{array}$ & Fresh Water & \\
\hline & & & $\begin{array}{l}\text { Water } \\
\text { Chloride }\end{array}$ & & \\
\hline
\end{tabular}

Table 20: Properties of $2 \%$ nano silica cement used in analysis 


\section{Measurements - 2\% Nano Silica}

Table 21 shows that the class $\mathrm{G}$ trial with $2 \%$ nano silica attained a mixability of 5 while being mixed under an average rpm of 12,000. Furthermore, the blend addition time at $4,000 \mathrm{rpm}$ was 15 seconds. This shows that the $2 \%$ nano silica sample can be easily mixed.

\section{Mixability Test for Class G Cement with $2 \%$ Nano Silica}

\begin{tabular}{|l|l|l|}
\hline \multicolumn{3}{|c|}{ Mixability (0 - 5) - 0 is not mixable } \\
\hline & & \\
\hline $\begin{array}{l}\text { Mixability rating } \\
(0-5)\end{array}$ & $\begin{array}{l}\text { Avg rpm mixing under } \\
\text { load }(\approx 12,000)\end{array}$ & $\begin{array}{l}\text { Blend addition time } \\
\text { (sec) @ 4,000 RPM }\end{array}$ \\
\hline 5 & 12000 & 1.5 \\
\hline
\end{tabular}

Table 21: Mixability test for $2 \%$ nano silica cement

Table 22 shows a thickening time of 1 hour and 16 minutes to $100 \mathrm{Bc} .100 \mathrm{Bc}$ is the primary result for this test. Furthermore, the time required to reach $30 \mathrm{Bc}$ was 25 minutes, $40 \mathrm{Bc}$ was 52 minutes, $50 \mathrm{Bc}$ was 1 hour and 9 minutes and $70 \mathrm{Bc}$ was 1 hour 13 minutes.

\section{Thickening Time Test for Class G Cement with 2\% Nano Silica}

\begin{tabular}{|c|c|c|c|c|c|c|c|c|}
\hline \multicolumn{9}{|c|}{ Thickening Time } \\
\hline $\operatorname{Temp}\left({ }^{\circ} \mathbf{F}\right)$ & \begin{tabular}{|l|}
$\begin{array}{l}\text { Pressure } \\
(\mathrm{psi})\end{array}$ \\
\end{tabular} & \begin{tabular}{|l|}
$\begin{array}{l}\text { Reached in } \\
(\mathrm{min})\end{array}$ \\
\end{tabular} & Start BC & \begin{tabular}{|l|}
30 Bc \\
$(\mathrm{hh}: \mathrm{mm})$
\end{tabular} & \begin{tabular}{|l|}
40 Bc \\
$(\mathrm{hh}: \mathrm{mm})$
\end{tabular} & \begin{tabular}{|l|}
50 Bc \\
$(\mathrm{hh}: \mathrm{mm})$
\end{tabular} & \begin{tabular}{|l|}
70 Bc \\
$(\mathrm{hh}: \mathrm{mm})$
\end{tabular} & $\begin{array}{l}100 \mathrm{Bc} \\
(\mathrm{hh}: \mathrm{mm})\end{array}$ \\
\hline 180 & 3000 & 30 & 16 & $1: 11$ & $1: 17$ & 1:19 & $1: 22$ & $1: 26$ \\
\hline
\end{tabular}

Table 22: Thickening Time test for $2 \%$ nano silica cement 
Table 23 shows the rheology's tests which provided a PV/YP of 56.69/37.96 at $80^{\circ} \mathrm{F}$ and $94.45 / 57.47$ at $180^{\circ} \mathrm{F}$. This test shows a slightly higher viscosity and shear stress than class $\mathrm{G}$ cement with no additives.

\section{API Rheology under $80^{\circ} \mathrm{F}$ and $180^{\circ} \mathrm{F}$ for Class G Cement with $2 \%$ Nano Silica}

\begin{tabular}{|c|c|c|c|c|c|c|c|c|c|c|}
\hline \multicolumn{11}{|c|}{ API Rheology } \\
\hline $\operatorname{Temp}\left({ }^{\circ} \mathbf{F}\right)$ & RPM & 300 & 200 & 100 & 60 & 30 & 6 & 3 & \begin{tabular}{|l|} 
Cond Time \\
$(\mathrm{min})$
\end{tabular} & $\mathbf{P V} / \mathbf{Y P}$ \\
\hline 80 & Viscosity & 87 & 76 & 61 & 55 & 49 & 32 & 23 & 0 & \begin{tabular}{|l|}
$56.69 /$ \\
37.96
\end{tabular} \\
\hline $\operatorname{Temp}\left({ }^{\circ} \mathbf{F}\right)$ & RPM & 300 & 200 & 100 & 60 & 30 & 6 & 3 & $\begin{array}{l}\begin{array}{l}\text { Cond Time } \\
(\mathrm{min})\end{array} \\
\end{array}$ & $\mathbf{P V} / \mathbf{Y P}$ \\
\hline 180 & Viscosity & 130 & 124 & 110 & 101 & 77 & 32 & 26 & 30 & $94.45 / 57.47$ \\
\hline
\end{tabular}

Table 23: API Rheology tests for $2 \%$ nano silica

Table 24 contains the results for the API fluid loss test for class G cement $2 \%$ nano silica. The primary result obtained is the measured volume of fluid loss, which was found to be $40 \mathrm{ml}$. The test was performed at $180^{\circ} \mathrm{F}$ and $1000 \mathrm{psi}$ for 0.2 minutes with a conditioning time of 30 minutes.

\section{API Fluid Loss Test for Class G Cement with $2 \%$ Nano Silica}

\begin{tabular}{|c|c|c|c|c|c|c|}
\hline \multicolumn{7}{|c|}{ API Fluid Loss } \\
\hline $\begin{array}{l}\text { Test Temp } \\
\left({ }^{\circ} \mathbf{F}\right)\end{array}$ & \begin{tabular}{|l} 
Test \\
Pressure \\
(psi) \\
\end{tabular} & $\begin{array}{l}\text { Test Time } \\
(\mathrm{min})\end{array}$ & Meas. Vol. & \begin{tabular}{|l|} 
Calculated \\
FL $(<30$ \\
min $)$ \\
\end{tabular} & \begin{tabular}{|l} 
Conditioni \\
ng time \\
$(\mathrm{min})$
\end{tabular} & $\begin{array}{l}\text { Conditioni } \\
\text { ng Temp } \\
\left({ }^{\circ} \mathrm{F}\right)\end{array}$ \\
\hline 180 & 1000 & 0.2 & 40 & 980 & 30 & 180 \\
\hline
\end{tabular}

Table 24: API Fluid loss test for $2 \%$ nano silica cement 
Table 25 contains the results for the free fluid test of class G cement with $2 \%$ nano silica. This test showed that the sample contained $0 \%$ free fluid. The test sample was conditioned at $180^{\circ} \mathrm{F}$ for 30 minutes. Once the test started, the static temperature was $80^{\circ} \mathrm{F}$ for 120 minutes at a 45 degree inclination angle.

\section{Free Fluid Test for Class G Cement with 2\% Nano Silica}

\begin{tabular}{|l|l|r|r|r|r|}
\hline \multicolumn{5}{|c|}{ Free Fluid API 10B-2 / ISO 10426-2 } \\
\hline & & & & & \\
\hline $\begin{array}{l}\text { Con. Temp } \\
\text { (F) }\end{array}$ & $\begin{array}{l}\text { Cond. } \\
\text { Time (min) }\end{array}$ & Static T. (F) & $\begin{array}{l}\text { Static time } \\
\text { (min) }\end{array}$ & Incl. (deg) & \% Fluid \\
\hline 180 & 30 & 80 & 120 & 45 & 0 \\
\hline
\end{tabular}

Table 25: Free Fluid test for $2 \%$ nano silica

The unconfined compressive strength for class $\mathrm{G}$ cement with $2 \%$ nano silica is 3026 psi after 48 hours as shown by Table 26. Furthermore, the sample reached 500 psi after 3 hours and 33 minutes and 100 psi in 2 hours and 31 minutes. The sample was tested at $180^{\circ} \mathrm{F}$ and $3000 \mathrm{psi}$.

\section{Unconfined Compressive Strength for Class G Cement with 2\% Nano Silica}

\begin{tabular}{|c|c|c|c|c|c|c|c|c|c|c|c|}
\hline \multicolumn{12}{|c|}{ UCA Comp. Strength } \\
\hline \begin{tabular}{|l|} 
End Temp \\
$\left({ }^{(} \mathrm{F}\right)$ \\
\end{tabular} & $\begin{array}{l}\begin{array}{l}\text { Pressure } \\
(p s i)\end{array} \\
\end{array}$ & \begin{tabular}{|l}
$50 \mathrm{psi}$ \\
$(\mathrm{hh}: \mathrm{mm})$
\end{tabular} & \begin{tabular}{|l}
$100 \mathrm{psi}$ \\
$(\mathrm{hh}: \mathrm{mm}$ )
\end{tabular} & \begin{tabular}{|l}
$500 \mathrm{psi}$ \\
$(\mathrm{hh}: \mathrm{mm})$
\end{tabular} & $\begin{array}{l}8 \mathrm{hrCS} \\
(\mathrm{psi})\end{array}$ & \begin{tabular}{|l}
12 hr CS \\
(psi)
\end{tabular} & $\begin{array}{l}16 \mathrm{hr} \mathrm{CS} \\
(\mathrm{psi})\end{array}$ & \begin{tabular}{|l}
$24 \mathrm{hr} \mathrm{CS}$ \\
(psi)
\end{tabular} & \begin{tabular}{|l}
48 hr CS \\
(psi)
\end{tabular} & \begin{tabular}{|l|}
$\begin{array}{l}\text { End CS } \\
(\mathrm{psi})\end{array}$ \\
\end{tabular} & \begin{tabular}{|l|}
$\begin{array}{l}\text { End Time } \\
(\mathrm{hrs})\end{array}$ \\
\end{tabular} \\
\hline 180 & 3000 & $2: 18$ & $2: 31$ & $3: 33$ & 1914 & 2396 & 2639 & 2861 & 3026 & 3039 & 72.7 \\
\hline
\end{tabular}

Table 26: Compressive strength for $2 \%$ nano silica 
The compressive strength graph (Figure 19) for $2 \%$ nano silica shows a slightly higher and earlier increase of compressive strength than that of the baseline case and of $1 \%$ nano silica. This graph shows that the compressive strength reaches 100 psi after 2 hours and 31 minutes and 500 psi after 3 hours and 33 minutes.

\section{Compressive Strength Graph of Class G Cement with 2\% Nano Silica}

\section{Compressive Strength}

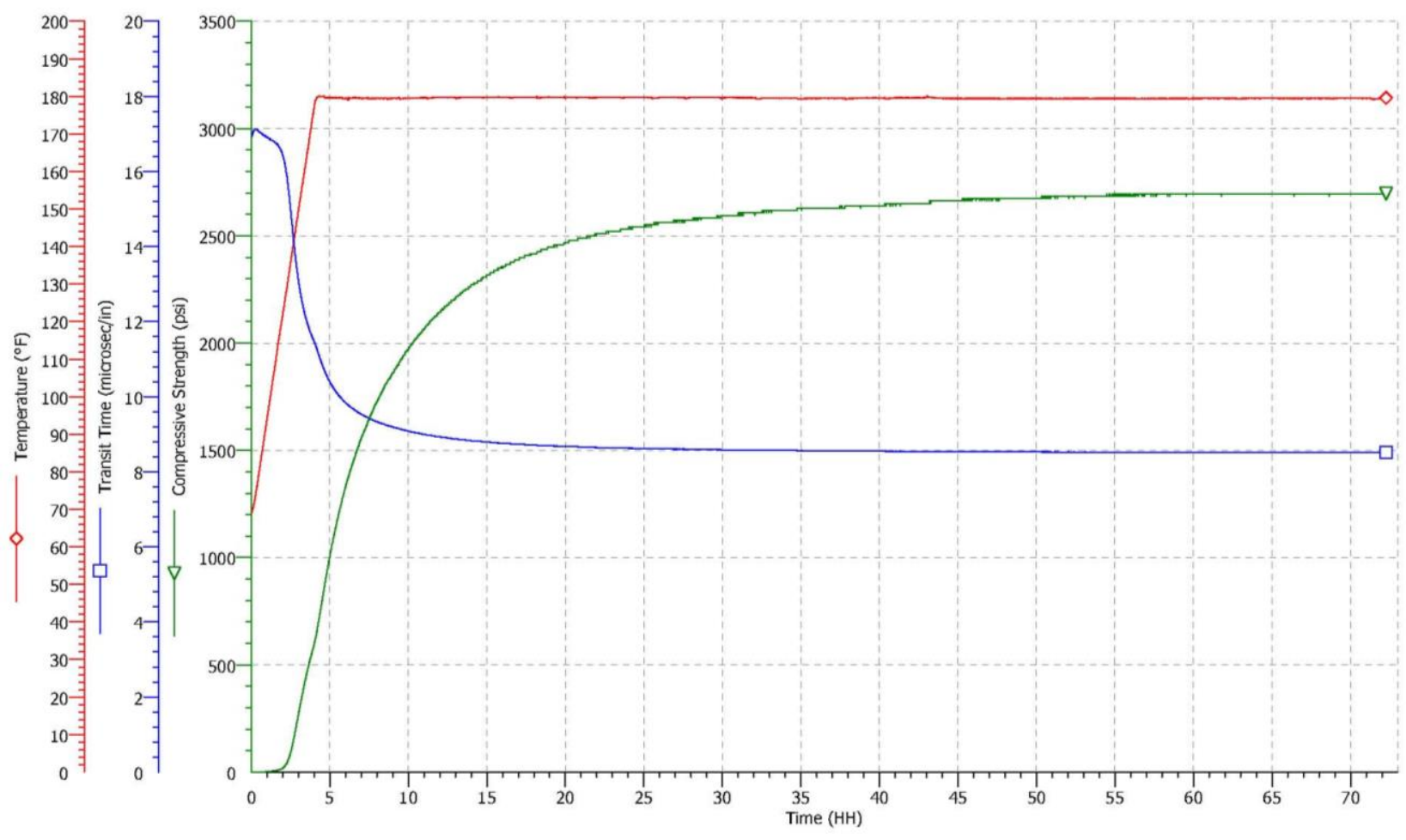

Figure 19: Compressive strength, $2 \%$ Nano Silica 
The time, temperature and transition graph (Figure 20) shows that $2 \%$ nano silica starts to experience an increase in Bc after 1 hour and 7 minutes.

\section{Time, Temperature and Transition of Class G Cement with 2\% Nano Silica}

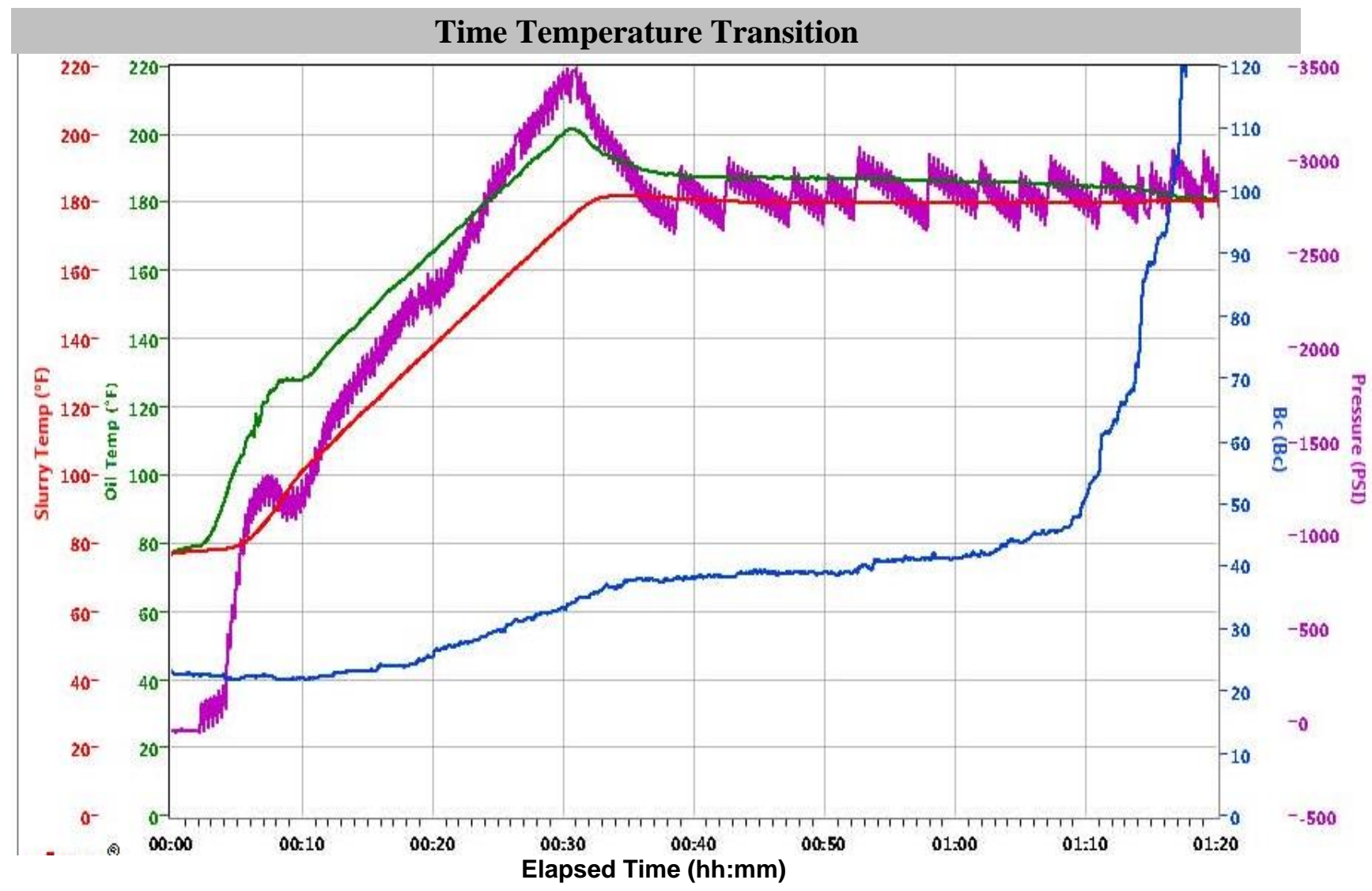

Figure 20: Temperature and Transition of $2 \%$ Nano Silica versus time 
D.) $1 \%$ BWOC Crumb Rubber:

In this section, results are presented for experiments conducted with class $G$ cement containing $1 \%$ crumb rubber. Table 27 provides the testing conditions that the trial was performed under. The class $\mathrm{G}$ cement trial with $1 \%$ crumb rubber was tested at 3000 psi and $180^{\circ} \mathrm{F}$.

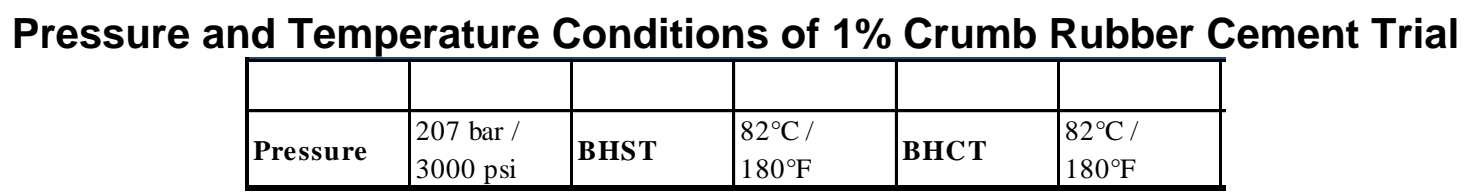

Table 27: Test conditions of $1 \%$ crumb rubber

Table 28 shows that the trial containing class $\mathrm{G}$ cement with $1 \%$ crumb rubber has a slurry density of $15.8 \mathrm{lb} /$ gal. The slurry yield is $1.15 \mathrm{ft}^{3} / \mathrm{sack}$ with a water requirement of $5.0 \mathrm{gal} / \mathrm{sack}$. The total fluid for the mix required is $5.01 \mathrm{gal} / \mathrm{sack}$.

\section{Composition and Property Analysis of $1 \%$ Crumb Rubber Cement Trial}

\begin{tabular}{|c|c|c|c|c|c|}
\hline Conc & UOM & Cement/Additive & \multicolumn{3}{|c|}{ Cement Properties } \\
\hline 100 & $\%$ BWOC & Evansville Lehigh Premium G & $\begin{array}{l}\text { Slurry } \\
\text { Density }\end{array}$ & 15.8 & lbm/gal \\
\hline 5.01 & gal/sack & Fresh Water & Slurry Yield & 1.1563 & $\mathrm{ft} 3 / \mathrm{sack}$ \\
\hline 1 & $\%$ BWOC & zRD Rubber Crumb & $\begin{array}{l}\text { Water } \\
\text { Requirement }\end{array}$ & 5.0097 & gal/sack \\
\hline & & & $\begin{array}{l}\text { Total Mix } \\
\text { Fluid }\end{array}$ & 5.01 & $\mathrm{gal} / \mathrm{sack}$ \\
\hline & & & & & \\
\hline & & & $\begin{array}{l}\text { Water } \\
\text { Source }\end{array}$ & Fresh Water & \\
\hline & & & \begin{tabular}{|l|} 
Water \\
Chloride
\end{tabular} & & \\
\hline
\end{tabular}

Table 28: Properties of $1 \%$ crumb rubber cement used in analysis 
Measurements - 1\% Crumb Rubber

Table 29 shows that the class $\mathrm{G}$ trial with $1 \%$ crumb rubber attained a mixability of 5 while being mixed under an average rpm of 12,000 . Furthermore, the blend addition time at $4,000 \mathrm{rpm}$ was 15 seconds. This shows that the $1 \%$ crumb rubber sample can be easily mixed.

\section{Mixability Test for Class G Cement with $1 \%$ Crumb Rubber}

\begin{tabular}{|c|c|c|}
\hline \multicolumn{3}{|c|}{ Mixability $(0-5)$ - 0 is not mixable } \\
\hline $\begin{array}{l}\text { Mixability } \\
\text { rating }(0-5)\end{array}$ & $\begin{array}{l}\text { Avg rpm mixing under } \\
\text { load }(\sim 12,000)\end{array}$ & $\begin{array}{l}\text { Blend addition time } \\
\text { (sec)@ 4,000 RPM }\end{array}$ \\
\hline 5 & 12000 & 15 \\
\hline
\end{tabular}

Table 29: Mixability test for $1 \%$ crumb rubber cement

Table 30 shows a thickening time of 1 hour and 35 minutes to $100 \mathrm{Bc} .100 \mathrm{Bc}$ is the primary result for this test. Furthermore, the time required to reach $30 \mathrm{Bc}$ was 35 minutes, $40 \mathrm{Bc}$ was 56 minutes, $50 \mathrm{Bc}$ was 1 hour and 26 minutes and $70 \mathrm{Bc}$ was 1 hour 32 minutes.

\section{Thickening Time Test for Class G Cement with 1\% Crumb Rubber}

\begin{tabular}{|c|c|c|c|c|c|c|c|c|}
\hline \multicolumn{9}{|c|}{ Thickening Time } \\
\hline Temp $\left({ }^{(} \mathbf{F}\right)$ & $\begin{array}{l}\text { Pressure } \\
(\mathrm{psi})\end{array}$ & \begin{tabular}{|l|}
$\begin{array}{l}\text { Reached in } \\
(\mathrm{min})\end{array}$ \\
\end{tabular} & Start BC & \begin{tabular}{|l}
$\begin{array}{l}30 \text { Bc } \\
(\mathrm{hh}: \mathrm{mm})\end{array}$ \\
\end{tabular} & \begin{tabular}{|l|l}
40 Bc \\
(hh:mm)
\end{tabular} & \begin{tabular}{|l}
50 Bc \\
(hh:mm)
\end{tabular} & \begin{tabular}{|l}
$\begin{array}{l}70 \text { Bc } \\
(\mathrm{hh}: \mathrm{mm})\end{array}$ \\
\end{tabular} & \begin{tabular}{|l}
100 Bc \\
(hh:mm)
\end{tabular} \\
\hline 180 & 3000 & 30 & 15 & $0: 35$ & $0: 56$ & $1: 26$ & $1: 32$ & $1: 35$ \\
\hline
\end{tabular}

Table 30: Thickening Time test for $1 \%$ crumb rubber cement 
Table 31 shows the rheology's tests which provided a PV/YP of 71.52/30.93 at $80^{\circ} \mathrm{F}$ and $129.55 / 45.67$ at $180^{\circ} \mathrm{F}$. This test shows a slightly higher viscosity and shear stress than class $\mathrm{G}$ cement with no additives.

\section{API Rheology under $80^{\circ} \mathrm{F}$ and $180^{\circ} \mathrm{F}$ for Class $\mathrm{G}$ Cement with $1 \%$ Crumb Rubber}

\begin{tabular}{|c|c|c|c|c|c|c|c|c|c|c|}
\hline \multicolumn{11}{|c|}{ API Rheology } \\
\hline $\operatorname{Temp}\left({ }^{\circ} \mathbf{F}\right)$ & RPM & 300 & 200 & 100 & 60 & 30 & 6 & 3 & $\begin{array}{l}\text { Cond Time } \\
(\min )\end{array}$ & PV/YP \\
\hline 80 & Viscosity & 96 & 79 & 59 & 50 & 42 & 27 & 19 & 0 & \begin{tabular}{|l|}
$71.52 /$ \\
30.93 \\
\end{tabular} \\
\hline $\operatorname{Tem} p\left({ }^{\circ} \mathbf{F}\right)$ & RPM & 300 & 200 & 100 & 60 & 30 & 6 & 3 & $\begin{array}{l}\text { Cond Time } \\
(\min )\end{array}$ & PV/YP \\
\hline 180 & Viscosity & 149 & 140 & 118 & 100 & 65 & 18 & 13 & 30 & \begin{tabular}{|l}
$129.55 /$ \\
45.67
\end{tabular} \\
\hline
\end{tabular}

Table 31: API Rheology tests for $1 \%$ crumb rubber

Table 32 contains the results for the API fluid loss test for class G cement $1 \%$ crumb rubber. The primary result obtained is the measured volume of fluid loss, which was found to be $34 \mathrm{ml}$. The test was performed at $180^{\circ} \mathrm{F}$ and $1000 \mathrm{psi}$ for 0.1 minutes with a conditioning time of 30 minutes.

\section{API Fluid Loss Test for Class G Cement with 1\% Crumb Rubber}

\begin{tabular}{|l|l|l|l|l|l|l|}
\hline \multicolumn{7}{|c|}{ API Fluid LoSS } \\
\hline & & & & & & \\
\hline $\begin{array}{l}\text { Test Temp } \\
\left({ }^{\circ} \text { F) }\right.\end{array}$ & $\begin{array}{l}\text { Test } \\
\text { Pressure } \\
(\text { psi })\end{array}$ & $\begin{array}{l}\text { Test Time } \\
(\text { min) }\end{array}$ & Meas. Vol. & $\begin{array}{l}\text { Calculated } \\
\text { FL }(<30 \\
\text { min })\end{array}$ & $\begin{array}{l}\text { Conditioni } \\
\text { ng time } \\
(\text { min })\end{array}$ & $\begin{array}{l}\text { Conditioni } \\
\text { ng Temp } \\
\left({ }^{\circ} \text { F }\right)\end{array}$ \\
\hline 180 & 1000 & 0.1 & 34 & 1178 & 30 & 180 \\
\hline
\end{tabular}

Table 32: API Fluid loss test for $1 \%$ crumb rubber cement 
Table 33 contains the results for the free fluid test of class $\mathrm{G}$ cement with $1 \%$ crumb rubber. This test showed that the sample contained $0 \%$ free fluid. The test sample was conditioned at $180^{\circ} \mathrm{F}$ for 30 minutes. Once the test started, the static temperature was $80^{\circ} \mathrm{F}$ for 120 minutes at a 45 degree inclination angle.

\section{Free Fluid Test for Class G Cement with 1\% Crumb Rubber}

\begin{tabular}{|l|l|r|r|r|r|}
\hline \multicolumn{5}{|c|}{ Free Fluid API 10B-2 / ISO 10426-2 } \\
\hline & & & & & \\
\hline $\begin{array}{l}\text { Con. Temp } \\
\text { (F) }\end{array}$ & $\begin{array}{l}\text { Cond. } \\
\text { Tim e (m in) }\end{array}$ & Static T. (F) & $\begin{array}{l}\text { Static time e } \\
\text { (min) }\end{array}$ & Incl. (deg) & \% Fu id \\
\hline 180 & 30 & 80 & 120 & 45 & 0 \\
\hline
\end{tabular}

Table 33: Free Fluid test for $1 \%$ crumb rubber

The unconfined compressive strength for class $\mathrm{G}$ cement with $1 \%$ crumb rubber is 2702 psi after 48 hours as shown by Table 34 . Furthermore, the sample reached 500 psi after 3 hours and 39 minutes and 100 psi in 2 hours and 38 minutes. The sample was tested at $180^{\circ} \mathrm{F}$ and $3000 \mathrm{psi}$.

\section{Unconfined Compressive Strength for Class G Cement with 1\% Crumb Rubber}

\begin{tabular}{|c|c|c|c|c|c|c|c|c|c|c|c|}
\hline \multicolumn{12}{|c|}{ UCA Comp. Strength } \\
\hline \begin{tabular}{|l|} 
End Temp \\
$\left({ }^{\circ} \mathrm{F}\right)$
\end{tabular} & \begin{tabular}{|l|}
$\begin{array}{l}\text { Pressure } \\
\text { (psi) }\end{array}$ \\
\end{tabular} & $\begin{array}{l}50 \mathrm{psi} \\
\text { (hh:mm) }\end{array}$ & $\begin{array}{l}100 \mathrm{psi} \\
(\mathrm{hh}: \mathrm{mm})\end{array}$ & $\begin{array}{l}500 \mathrm{psi} \\
\text { (hh:mm) }\end{array}$ & $\begin{array}{l}8 \mathrm{hr} \mathrm{CS} \\
\text { (psi) }\end{array}$ & $\begin{array}{l}12 \mathrm{hrCS} \\
\text { (psi) }\end{array}$ & $\begin{array}{l}16 \mathrm{hr} \text { CS } \\
\text { (psi) }\end{array}$ & $\begin{array}{l}24 \mathrm{hr} \mathrm{CS} \\
(\mathrm{psi})\end{array}$ & $\begin{array}{l}48 \mathrm{hr} \mathrm{CS} \\
(\mathrm{psi})\end{array}$ & $\begin{array}{l}\text { End CS } \\
\text { (psi) }\end{array}$ & $\begin{array}{l}\begin{array}{l}\text { End Time } \\
\text { (hrs) }\end{array} \\
\end{array}$ \\
\hline 180 & 3000 & $2: 24$ & $2: 38$ & $3: 39$ & 1720 & 2174 & 2421 & 2634 & 2702 & 2679 & 72.72 \\
\hline
\end{tabular}

Table 34: Compressive strength for $1 \%$ crumb rubber 
The compressive strength graph (Figure 21) for 1\% crumb rubber shows a lower and later increase of compressive strength than that of the samples with nano silica. However, the $1 \%$ crumb rubber achieved a slightly higher and earlier increase in compressive strength than that of the baseline case. This graph shows that the compressive strength reaches 100 psi after 2 hours and 38 minutes and 500 psi after 3 hours and 39 minutes.

\section{Compressive Strength Graph of Class G Cement with 1\% Crumb Rubber}

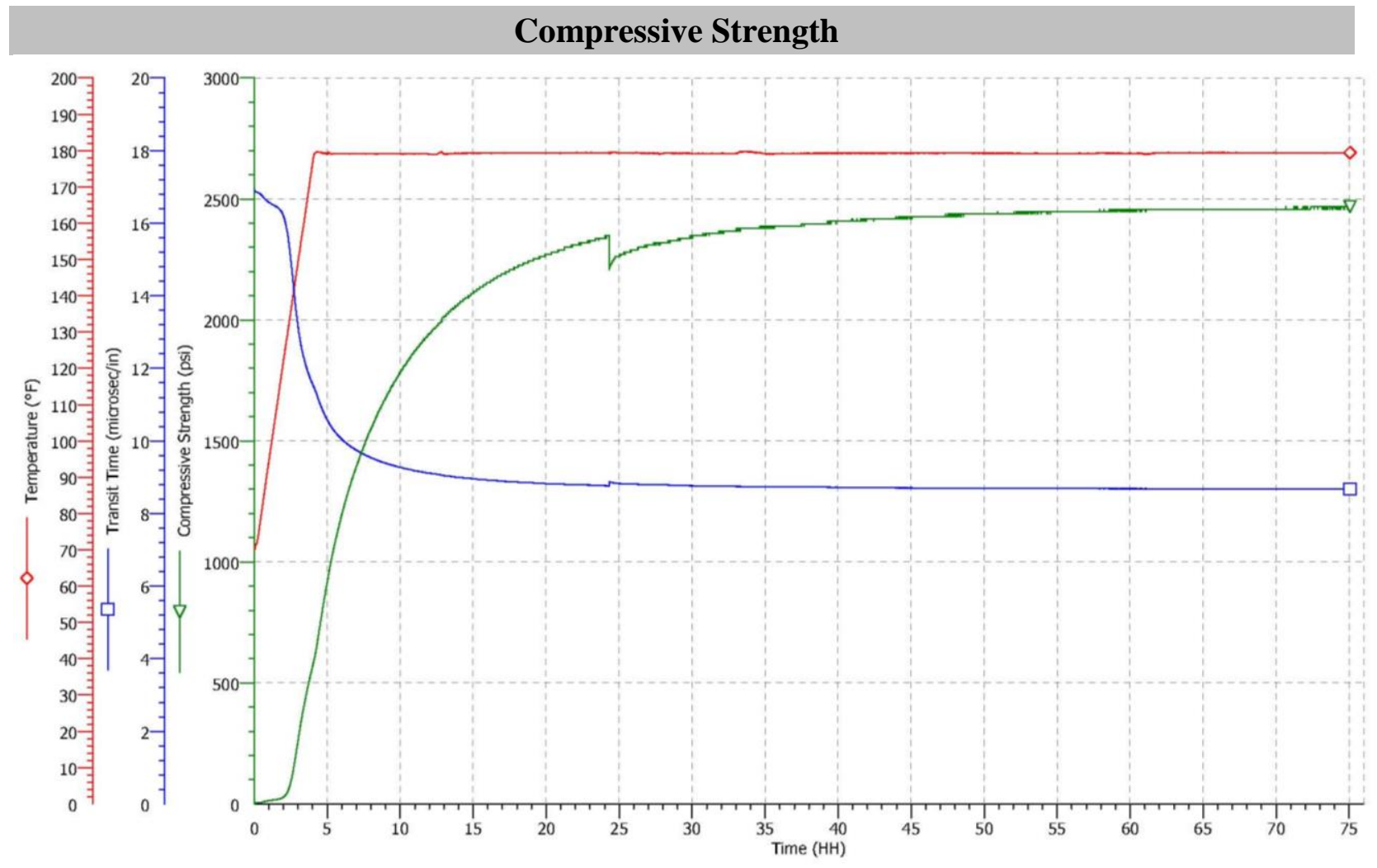

Figure 21: Compressive strength, $1 \%$ Crumb Rubber 
The time, temperature and transition graph (Figure 22) shows that $1 \%$ crumb rubber starts to experience an increase in Bc after 1 hour and 22 minutes.

\section{Time, Temperature and Transition of Class G Cement with 1\% Crumb Rubber}

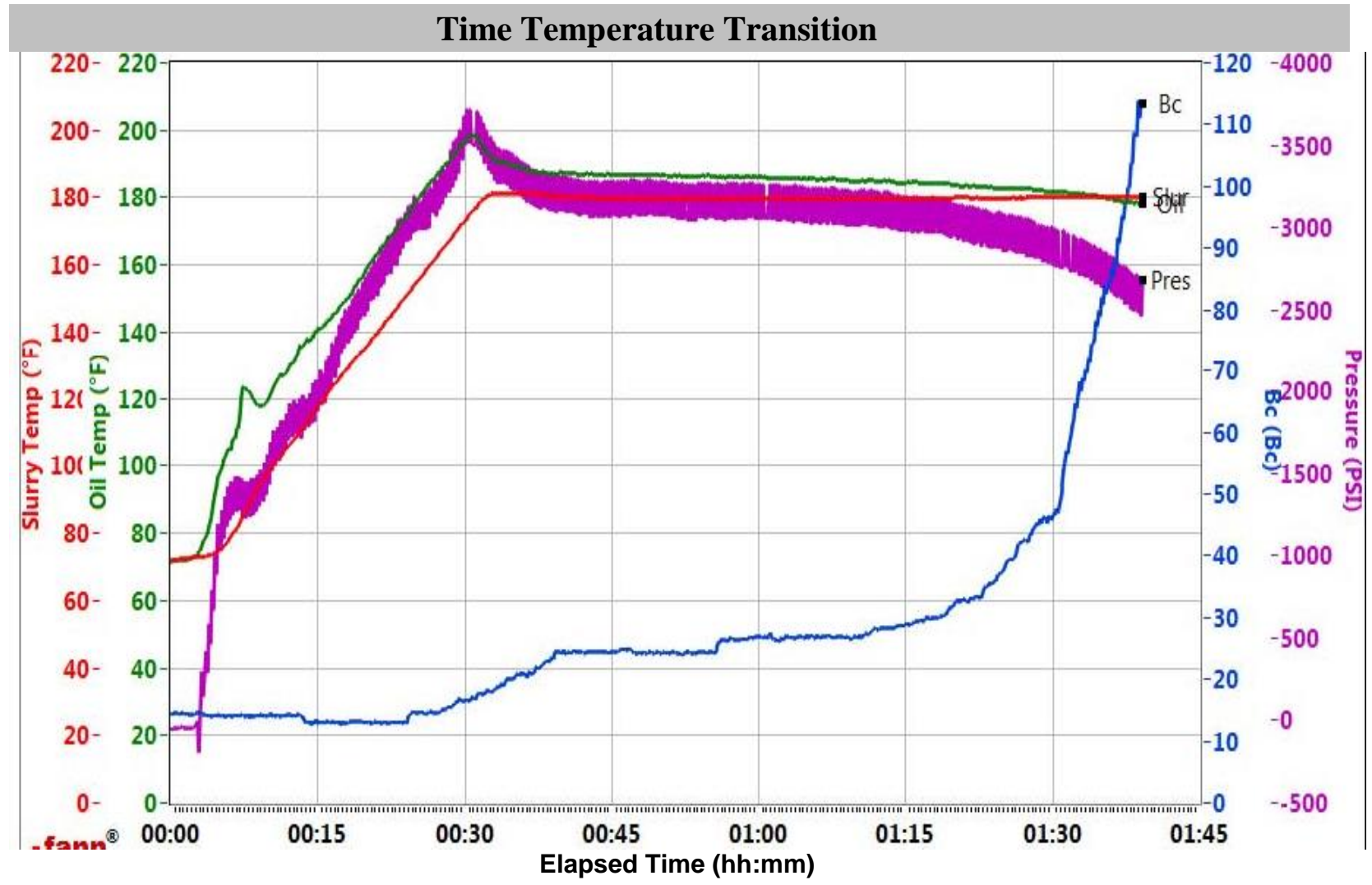

Figure 22: Temperature and Transition of $1 \%$ Crumb Rubber versus time 
E.) $3 \%$ BWOC Crumb Rubber:

In this section, results are presented for experiments conducted with class $\mathrm{G}$ cement containing $3 \%$ crumb rubber. Table 35 provides the testing conditions that the trial was performed under. The class $\mathrm{G}$ cement trial with $3 \%$ crumb rubber was tested at 3000 psi and $180^{\circ} \mathrm{F}$.

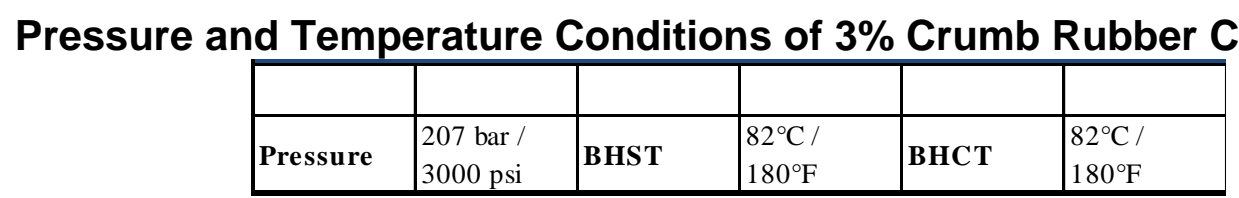

Table 35: Test conditions of $3 \%$ crumb rubber

Table 36 shows that the trial containing class $\mathrm{G}$ cement with $3 \%$ crumb rubber has a slurry density of $15.8 \mathrm{lb} / \mathrm{gal}$. The slurry yield is $1.16 \mathrm{ft}^{3} / \mathrm{sack}$ with a water requirement of $4.8 \mathrm{gal} / \mathrm{sack}$. The total fluid for the mix required is $4.85 \mathrm{gal} / \mathrm{sack}$.

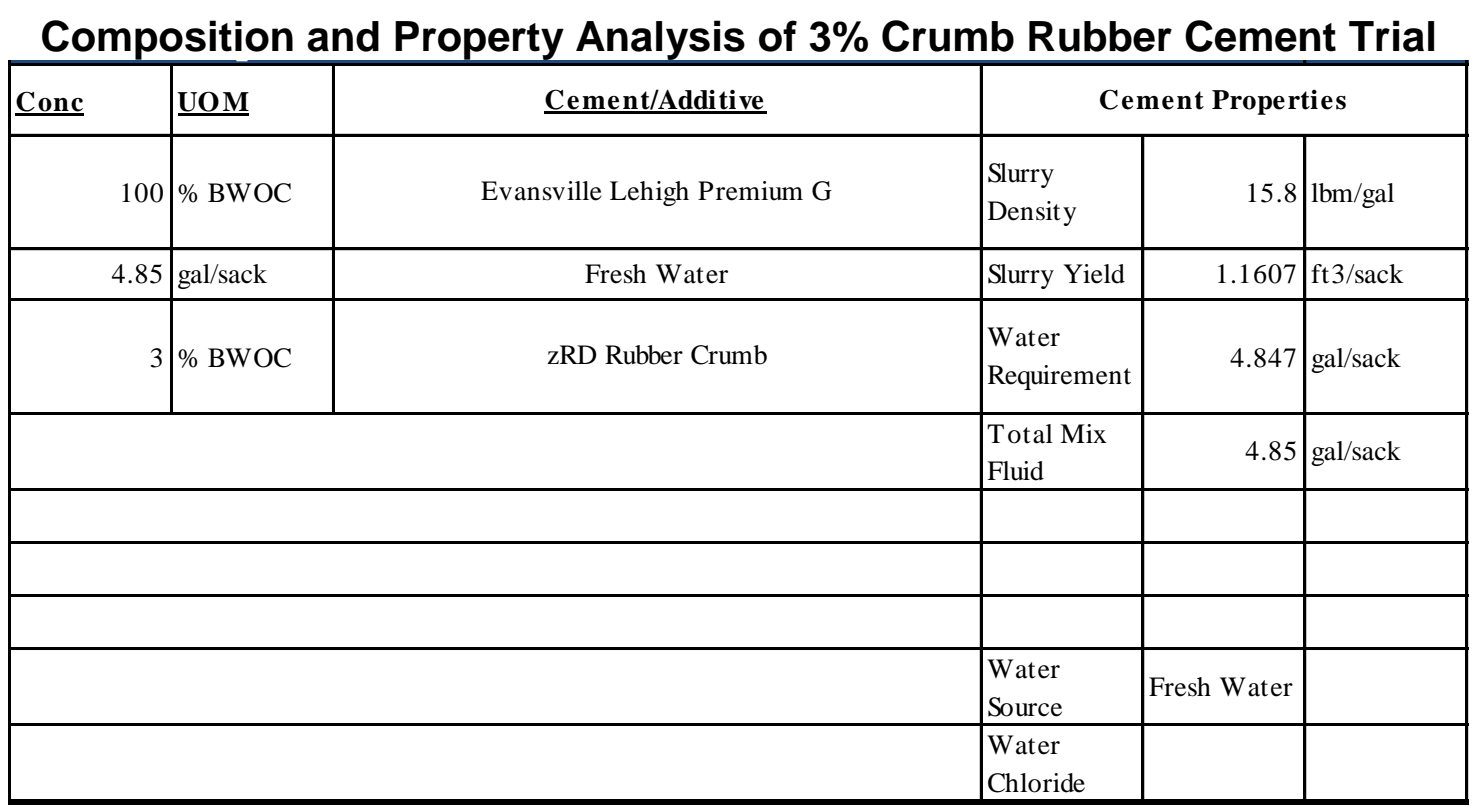

Table 36: Properties of $3 \%$ crumb rubber cement used in analysis 


\section{Measurements - 3\% Crumb Rubber}

Table 37 shows that the class $\mathrm{G}$ trial with $3 \%$ crumb rubber attained a mixability of 5 while being mixed under an average rpm of 12,000 . Furthermore, the blend addition time at 4,000 rpm was 15 seconds. This shows that the $3 \%$ crumb rubber sample can be easily mixed.

\section{Mixability Test for Class G Cement with 3\% Crumb Rubber}

\begin{tabular}{|l|l|l|}
\hline \multicolumn{3}{|c|}{ Mixability (0 - 5) - 0 is not mixable } \\
\hline & \multicolumn{1}{|l|}{$\begin{array}{l}\text { Avg rpm mixing under } \\
\text { Mixability } \\
\text { rating }(0-5)\end{array}$} & $\begin{array}{l}\text { Blend addition time } \\
\text { load }(\sim 12,000)\end{array}$ \\
\hline & 5 (sec00 RPM \\
\hline
\end{tabular}

Table 37: Mixability test for $3 \%$ crumb rubber cement

Table 38 shows a thickening time of 1 hour and 40 minutes to $100 \mathrm{Bc} .100 \mathrm{Bc}$ is the primary result for this test. Furthermore, the time required to reach $30 \mathrm{Bc}$ was 1 hour and 34 minutes, $40 \mathrm{Bc}$ was 1 hour and 37 minutes, $50 \mathrm{Bc}$ was 1 hour and 37 minutes and $70 \mathrm{Bc}$ was 1 hour 38 minutes.

\section{Thickening Time Test for Class G Cement with 3\% Crumb Rubber}

\begin{tabular}{|c|c|c|c|c|c|c|c|c|}
\hline \multicolumn{9}{|c|}{ Thickening Time } \\
\hline $\operatorname{Temp}\left({ }^{(} \mathbf{F}\right)$ & \begin{tabular}{|l} 
Pressure \\
$(\mathrm{psi})$
\end{tabular} & \begin{tabular}{|l} 
Reached in \\
$(\mathrm{min})$
\end{tabular} & Start BC & \begin{tabular}{|l}
30 Bc \\
(hh:mm)
\end{tabular} & $\begin{array}{l}40 \text { Bc } \\
(\mathrm{hh}: \mathrm{mm})\end{array}$ & \begin{tabular}{|l}
50 Bc \\
$(\mathrm{hh}: \mathrm{mm})$
\end{tabular} & \begin{tabular}{|l|}
70 Bc \\
$(\mathrm{hh}: \mathrm{mm})$
\end{tabular} & \begin{tabular}{|l|}
100 Bc \\
$($ hh:mm)
\end{tabular} \\
\hline 180 & 3000 & 30 & 17 & $1: 34$ & $1: 37$ & $1: 37$ & $1: 38$ & $1: 40$ \\
\hline
\end{tabular}

Table 38: Thickening Time test for $3 \%$ crumb rubber cement 
Table 39 shows the rheology's tests which provided a PV/YP of 62.76/26.52 at $80^{\circ} \mathrm{F}$ and $89.57 / 33.56$ at $180^{\circ} \mathrm{F}$. This test shows a similar viscosity and shear stress than class $\mathrm{G}$ cement with no additives.

\section{API Rheology under $80^{\circ} \mathrm{F}$ and $180^{\circ} \mathrm{F}$ for Class $\mathrm{G}$ Cement with $3 \%$ Crumb Rubber}

\begin{tabular}{|c|c|c|c|c|c|c|c|c|c|c|}
\hline \multicolumn{11}{|c|}{ API Rheology } \\
\hline $\operatorname{Temp}\left({ }^{\circ} \mathbf{F}\right)$ & RPM & 300 & 200 & 100 & 60 & 30 & 6 & 3 & $\begin{array}{l}\text { Cond Time } \\
(\min )\end{array}$ & $\mathbf{P V} / \mathbf{Y P}$ \\
\hline 80 & Viscosity & 83 & 69 & 52 & 45 & 37 & 23 & 14 & 0 & $\begin{array}{l}62.76 / \\
26.52\end{array}$ \\
\hline $\operatorname{Temp}\left({ }^{\circ} \mathbf{F}\right)$ & RPM & 300 & 200 & 100 & 60 & 30 & 6 & 3 & $\begin{array}{l}\text { Cond Time } \\
(\min )\end{array}$ & PV/YP \\
\hline 180 & Viscosity & 106 & 96 & 86 & 73 & 44 & 15 & 12 & 30 & \begin{tabular}{|l|}
$89.57 /$ \\
33.56
\end{tabular} \\
\hline
\end{tabular}

Table 39: API Rheology tests for 3\% crumb rubber

Table 40 contains the results for the API fluid loss test for class G cement 3\% crumb rubber. The primary result obtained is the measured volume of fluid loss, which was found to be $34 \mathrm{ml}$. The test was performed at $180^{\circ} \mathrm{F}$ and $1000 \mathrm{psi}$ for 0.08 minutes with a conditioning time of 30 minutes.

\section{API Fluid Loss Test for Class G Cement with 3\% Crumb Rubber}

\begin{tabular}{|c|c|c|c|c|c|c|}
\hline \multicolumn{7}{|c|}{ API Fluid Loss } \\
\hline $\begin{array}{l}\text { Test Temp } \\
\left({ }^{\circ} \mathbf{F}\right)\end{array}$ & $\begin{array}{l}\text { Test } \\
\text { Pressure } \\
\text { (psi) } \\
\end{array}$ & $\begin{array}{l}\text { Test Time } \\
(\mathrm{min})\end{array}$ & Meas. Vol. & $\begin{array}{l}\text { Calculated } \\
\text { FL }(<30 \\
\text { min }) \\
\end{array}$ & $\begin{array}{l}\text { Conditioni } \\
\text { ng time } \\
(\mathrm{min})\end{array}$ & $\begin{array}{l}\text { Conditioni } \\
\text { ng Temp } \\
\left({ }^{\circ} \text { F) }\right. \\
\end{array}$ \\
\hline 180 & 1000 & 0.08 & 34 & 1290 & 30 & 180 \\
\hline
\end{tabular}

Table 40: API Fluid loss test for $3 \%$ crumb rubber cement 
Table 41 contains the results for the free fluid test of class $\mathrm{G}$ cement with $3 \%$ crumb rubber. This test showed that the sample contained $0 \%$ free fluid. The test sample was conditioned at $180^{\circ} \mathrm{F}$ for 30 minutes. Once the test started, the static temperature was $80^{\circ} \mathrm{F}$ for 120 minutes at a 45 degree inclination angle.

\section{Free Fluid Test for Class G Cement with 3\% Crumb Rubber}

\begin{tabular}{|l|l|r|r|r|r|}
\hline \multicolumn{5}{|c|}{ Free Fluid API 10B-2 / ISO 10426-2 } \\
\hline & & & & & \\
\hline $\begin{array}{l}\text { Con. Temp } \\
\text { (F) }\end{array}$ & $\begin{array}{l}\text { Cond. } \\
\text { Time (m in) }\end{array}$ & Static T. (F) & $\begin{array}{l}\text { Static time } \\
\text { (min) }\end{array}$ & Incl. (deg) & \% Fu id \\
\hline 180 & 30 & 80 & 120 & 45 & 0 \\
\hline
\end{tabular}

Table 41: Free Fluid test for $3 \%$ crumb rubber

The unconfined compressive strength for class $\mathrm{G}$ cement with $3 \%$ crumb rubber is 2695 psi after 48 hours as shown by Table 42 . Furthermore, the sample reached 500 psi after 3 hours and 47 minutes and 100 psi in 2 hours and 40 minutes. The sample was tested at $180^{\circ} \mathrm{F}$ and $3000 \mathrm{psi}$.

\section{Unconfined Compressive Strength for Class G Cement with 3\% Crumb Rubber}

\begin{tabular}{|c|c|c|c|c|c|c|c|c|c|c|c|}
\hline \multicolumn{12}{|c|}{ UCA Comp. Strength } \\
\hline \begin{tabular}{|l|} 
End Temp \\
$\left({ }^{\circ} \mathrm{F}\right)$
\end{tabular} & $\begin{array}{l}\text { Pressure } \\
\text { (psi) }\end{array}$ & $\begin{array}{l}50 \mathrm{psi} \\
\text { (hh:mm) }\end{array}$ & $\begin{array}{l}100 \mathrm{psi} \\
(\mathrm{hh}: \mathrm{mm})\end{array}$ & $\begin{array}{l}500 \mathrm{psi} \\
\text { (hh:mm) }\end{array}$ & $\begin{array}{l}8 \mathrm{hr} \mathrm{CS} \\
(\mathrm{psi})\end{array}$ & $\begin{array}{l}12 \mathrm{hr} \mathrm{CS} \\
\text { (psi) }\end{array}$ & $\begin{array}{l}16 \mathrm{hrCS} \\
\text { (psi) }\end{array}$ & $\begin{array}{l}24 \mathrm{hr} C S \\
\text { (psi) }\end{array}$ & $\begin{array}{l}48 \mathrm{hr} C S \\
(\mathrm{psi})\end{array}$ & $\begin{array}{l}\text { End CS } \\
(\mathrm{psi})\end{array}$ & $\begin{array}{l}\text { End Time } \\
\text { (hrs) }\end{array}$ \\
\hline 180 & 3000 & $2: 26$ & $2: 40$ & $3: 47$ & 1632 & 2074 & 2298 & 2529 & 2695 & 2729 & 74.12 \\
\hline
\end{tabular}

Table 42: Compressive strength for $3 \%$ crumb rubber 
The compressive strength graph (Figure 23) for 3\% crumb rubber shows a lower and later increase of compressive strength than that of the samples with nano silica. The $3 \%$ crumb rubber achieved a similar increase in compressive strength to that of the baseline case. This graph shows that the compressive strength reaches 100 psi after 2 hours and 40 minutes and 500 psi after 3 hours and 47 minutes.

\section{Compressive Strength Graph of Class G Cement with 3\% Crumb Rubber}

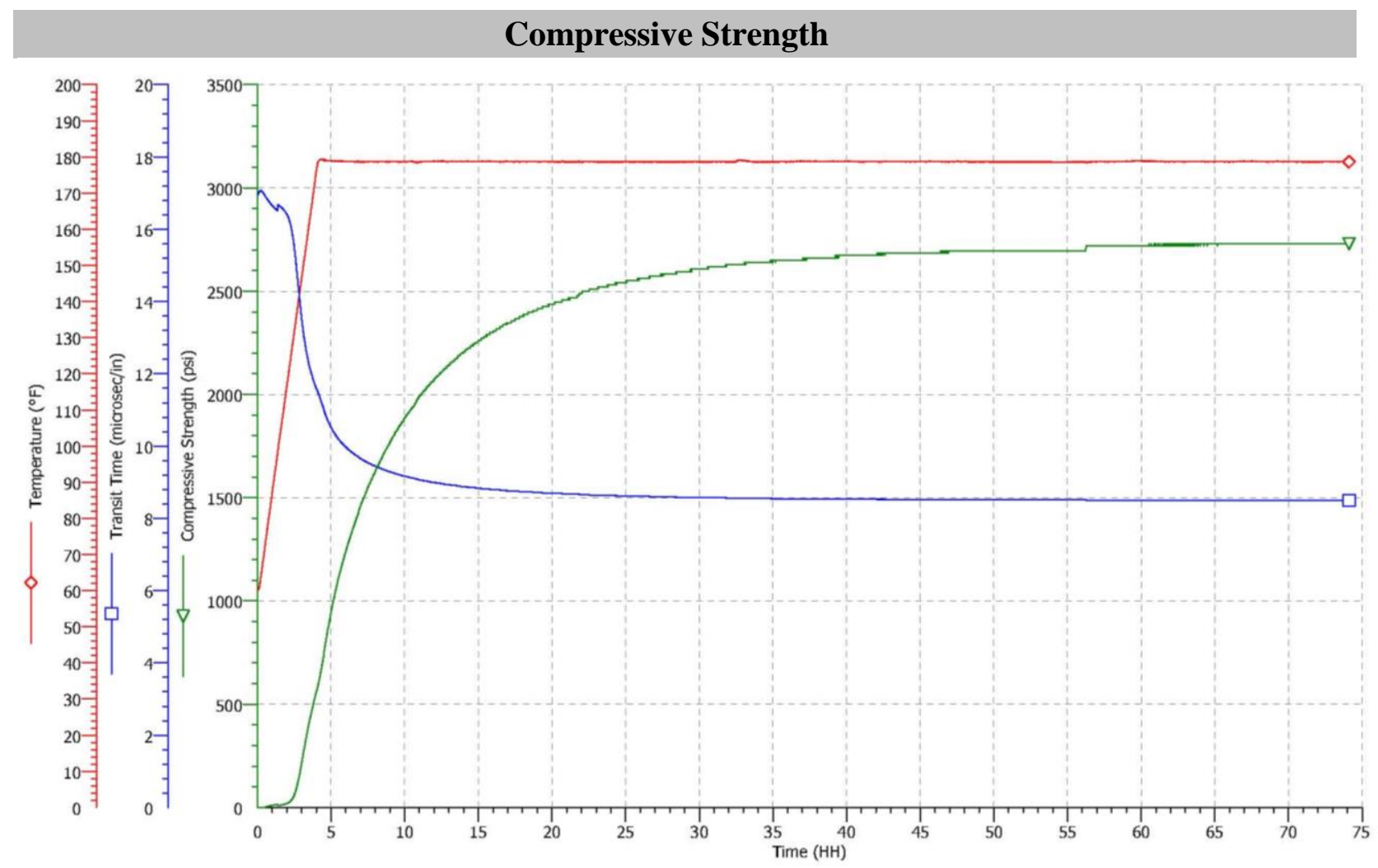

Figure 23: Compressive strength, 3\% Crumb Rubber 
The time, temperature and transition graph (Figure 24) shows that $3 \%$ crumb rubber starts to experience an increase in $\mathrm{Bc}$ after 1 hour and 30 minutes.

\section{Time, Temperature and Transition of Class G Cement with 3\% Crumb Rubber}

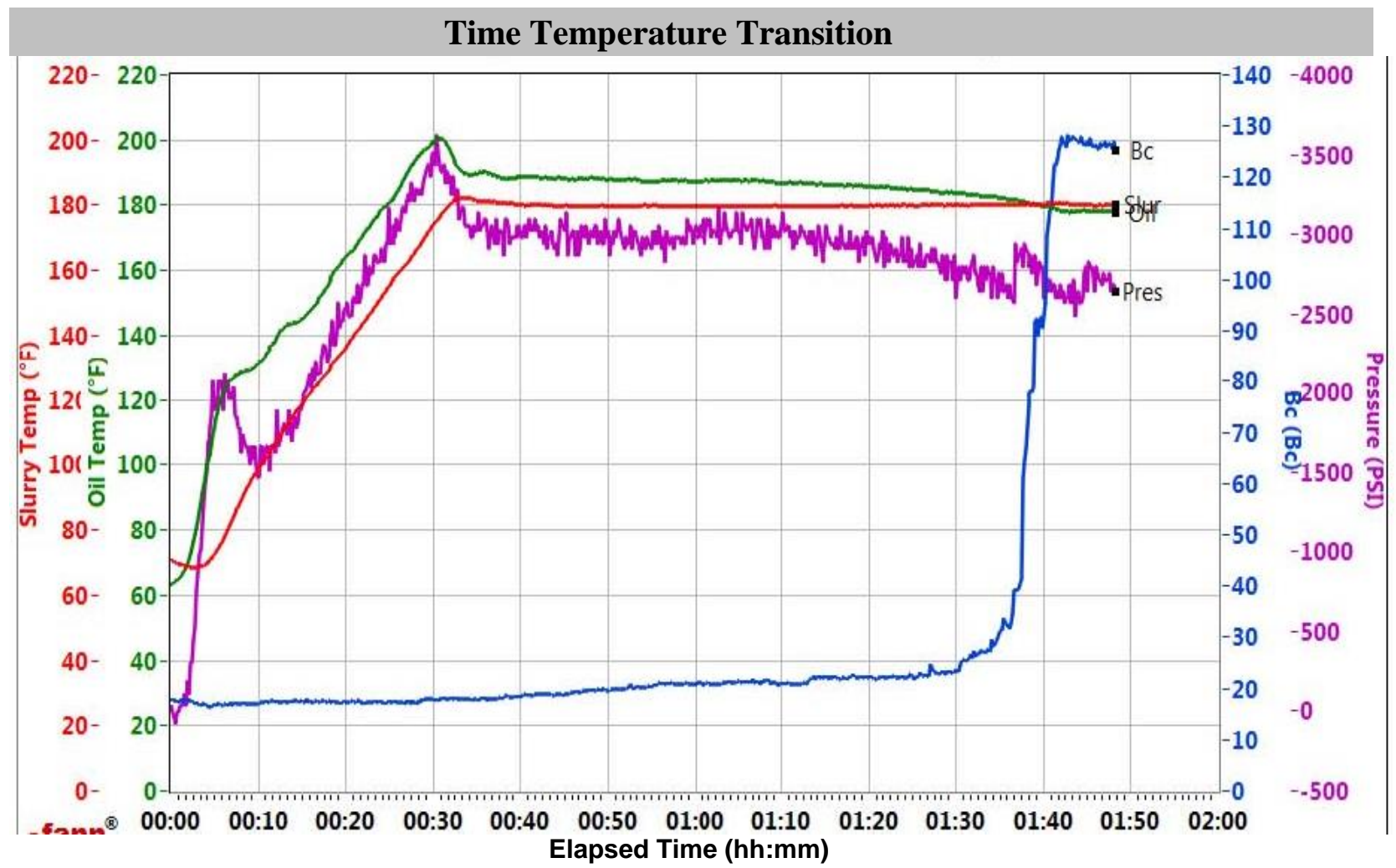

Figure 24: Temperature and Transition of $3 \%$ Crumb Rubber versus time 
F.) 5\% BWOC Crumb Rubber:

In this section, results are presented for experiments conducted with class $G$ cement containing $5 \%$ crumb rubber. Table 43 provides the testing conditions that the trial was performed under. The class $\mathrm{G}$ cement trial with $5 \%$ crumb rubber was tested at 3000 psi and $180^{\circ} \mathrm{F}$.

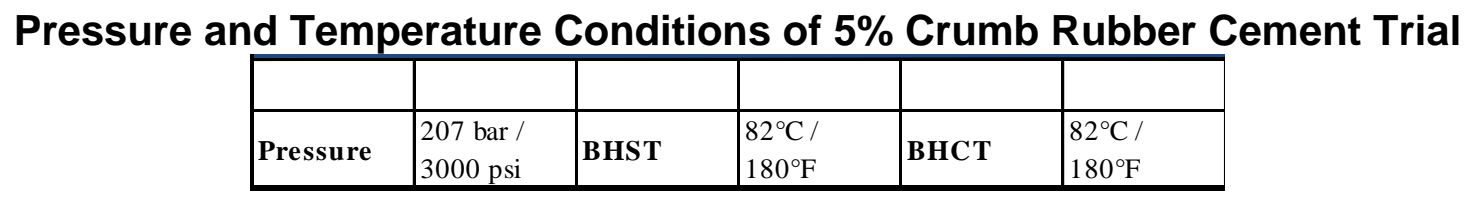

Table 43: Test conditions of $5 \%$ crumb rubber

Table 44 shows that the trial containing class $\mathrm{G}$ cement with $5 \%$ crumb rubber has a slurry density of $15.8 \mathrm{lb} / \mathrm{gal}$. The slurry yield is $1.16 \mathrm{ft}^{3} / \mathrm{sack}$ with a water requirement of $4.68 \mathrm{gal} / \mathrm{sack}$. The total fluid for the mix required is $4.68 \mathrm{gal} / \mathrm{sack}$.

\begin{tabular}{|c|c|c|c|c|c|}
\hline \multirow{2}{*}{$\begin{array}{ll}\text { Conc } & \\
& 100\end{array}$} & \multirow{2}{*}{$\frac{\underline{\text { UOM }}}{\% \text { BWOC }}$} & \multirow{2}{*}{$\frac{\text { Cement/Additive }}{\text { Evansville Lehigh Premium G }}$} & \multicolumn{3}{|c|}{ Cement Properties } \\
\hline & & & $\begin{array}{l}\text { Slurry } \\
\text { Density }\end{array}$ & 15.8 & $\mathrm{lbm} / \mathrm{gal}$ \\
\hline 4.68 & gal/sack & Fresh Water & Slurry Yield & 1.1652 & $\mathrm{ft} 3 / \mathrm{sack}$ \\
\hline \multirow[t]{6}{*}{5} & $\%$ BWOC & zRD Rubber Crumb & $\begin{array}{l}\text { Water } \\
\text { Requirement }\end{array}$ & 4.6844 & $\mathrm{gal} / \mathrm{sack}$ \\
\hline & & & \begin{tabular}{|l|} 
Total Mix \\
Fluid \\
\end{tabular} & 4.68 & $\mathrm{gal} / \mathrm{sack}$ \\
\hline & & & & & \\
\hline & & & & & \\
\hline & & & \begin{tabular}{|l|} 
Water \\
Source
\end{tabular} & Fresh Water & \\
\hline & & & $\begin{array}{l}\text { Water } \\
\text { Chloride }\end{array}$ & & \\
\hline
\end{tabular}

Table 44: Properties of $5 \%$ crumb rubber cement used in analysis 
Measurements - 5\% Crumb Rubber

Table 45 shows that the class $\mathrm{G}$ trial with $5 \%$ crumb rubber attained a mixability of 5 while being mixed under an average rpm of 12,000. Furthermore, the blend addition time at 4,000 rpm was 15 seconds. This shows that the $5 \%$ crumb rubber sample can be easily mixed.

\section{Mixability Test for Class G Cement with 5\% Crumb Rubber}

\begin{tabular}{|l|l|l|}
\hline \multicolumn{3}{|c|}{ Mixability (0 - 5) - 0 is not mixable } \\
\hline & \multicolumn{1}{|l|}{$\begin{array}{l}\text { Avg rpm mixing under } \\
\text { rating }(0-5)\end{array}$} & $\begin{array}{l}\text { Blend addition time } \\
\text { (sec) @ 4,000 RPM }\end{array}$ \\
\hline & load ( 12,000) & \\
\hline
\end{tabular}

Table 45: Mixability test for $5 \%$ crumb rubber cement

Table 46 shows a thickening time of 1 hour and 37 minutes to $100 \mathrm{Bc} .100 \mathrm{Bc}$ is the primary result for this test. Furthermore, the time required to reach $30 \mathrm{Bc}$ was 1 hour and 17 minutes, $40 \mathrm{Bc}$ was 1 hour and 26 minutes, $50 \mathrm{Bc}$ was 1 hour and 30 minutes and $70 \mathrm{Bc}$ was 1 hour 33 minutes.

\section{Thickening Time Test for Class G Cement with 5\% Crumb Rubber}

\begin{tabular}{|c|c|c|c|c|c|c|c|c|}
\hline \multicolumn{9}{|c|}{ Thickening Time } \\
\hline $\operatorname{Temp}\left({ }^{\circ} \mathbf{F}\right)$ & \begin{tabular}{|l} 
Pressure \\
$(\mathrm{psi})$
\end{tabular} & \begin{tabular}{|l|}
$\begin{array}{l}\text { Reached in } \\
(\mathrm{min})\end{array}$ \\
\end{tabular} & Start BC & \begin{tabular}{|l}
$30 \mathrm{Bc}$ \\
(hh:mm)
\end{tabular} & \begin{tabular}{|l}
40 Bc \\
$(\mathrm{hh}: \mathrm{mm})$
\end{tabular} & \begin{tabular}{|l}
50 Bc \\
$($ hh:mm $)$
\end{tabular} & \begin{tabular}{|l|}
70 Bc \\
$(\mathrm{hh}: \mathrm{mm})$
\end{tabular} & $\begin{array}{l}100 \text { Bc } \\
\text { (hh:mm) }\end{array}$ \\
\hline 180 & 3000 & 30 & 14 & 1:17 & $1: 26$ & $1: 30$ & $1: 33$ & $1: 37$ \\
\hline
\end{tabular}

Table 46: Thickening Time test for 5\% crumb rubber cement 
Table 47 shows the rheology's tests which provided a PV/YP of $46.86 / 20.76$ at $80^{\circ} \mathrm{F}$ and $72.78 / 32.54$ at $180^{\circ} \mathrm{F}$. This test shows a similar viscosity and shear stress than class $\mathrm{G}$ cement with no additives.

\section{API Rheology under $80^{\circ} \mathrm{F}$ and $180^{\circ} \mathrm{F}$ for Class $\mathrm{G}$ Cement with $5 \%$ Crumb Rubber}

\begin{tabular}{|c|c|c|c|c|c|c|c|c|c|c|}
\hline \multicolumn{11}{|c|}{ API Rheology } \\
\hline $\operatorname{Temp}\left({ }^{\circ} \mathbf{F}\right)$ & RPM & 300 & 200 & 100 & 60 & 30 & 6 & 3 & $\begin{array}{l}\text { Cond Time } \\
(\min )\end{array}$ & $\mathbf{P V} / \mathbf{Y P}$ \\
\hline 80 & Viscosity & 64 & 52 & 39 & 33 & 28 & 19 & 13 & 0 & $\begin{array}{l}46.86 / \\
20.76\end{array}$ \\
\hline $\operatorname{Temp}\left({ }^{\circ} \mathbf{F}\right)$ & RPM & 300 & 200 & 100 & 60 & 30 & 6 & 3 & \begin{tabular}{|l} 
Cond Time \\
$(\mathrm{min})$
\end{tabular} & PV/YP \\
\hline 180 & Viscosity & 92 & 84 & 70 & 61 & 48 & 17 & 13 & 30 & $\begin{array}{l}72.78 / \\
32.54\end{array}$ \\
\hline
\end{tabular}

Table 47: API Rheology tests for $5 \%$ crumb rubber

Table 48 contains the results for the API fluid loss test for class G cement $5 \%$ crumb rubber. The primary result obtained is the measured volume of fluid loss, which was found to be $47 \mathrm{ml}$. The test was performed at $180^{\circ} \mathrm{F}$ and 1000 psi for 0.1 minutes with a conditioning time of 30 minutes.

\section{API Fluid Loss Test for Class G Cement with 5\% Crumb Rubber}

\begin{tabular}{|c|c|c|c|c|c|c|}
\hline \multicolumn{7}{|c|}{ API Fluid Loss } \\
\hline $\begin{array}{l}\text { Test Temp } \\
\left({ }^{\circ} \mathbf{F}\right)\end{array}$ & $\begin{array}{l}\text { Test } \\
\text { Pressure } \\
\text { (psi) } \\
\end{array}$ & $\begin{array}{l}\text { Test Time } \\
(\text { min })\end{array}$ & Meas. Vol. & $\begin{array}{l}\text { Calculated } \\
\text { FL }(<30 \\
\text { min }) \\
\end{array}$ & \begin{tabular}{|l|} 
Conditioni \\
ng time \\
$(\mathrm{min})$
\end{tabular} & $\begin{array}{l}\text { Conditioni } \\
\text { ng Temp } \\
\left({ }^{\circ} \mathbf{F}\right) \\
\end{array}$ \\
\hline 180 & 1000 & 0.1 & 47 & 1628 & 30 & 180 \\
\hline
\end{tabular}

Table 48: API Fluid loss test for $5 \%$ crumb rubber cement 
Table 49 contains the results for the free fluid test of class $\mathrm{G}$ cement with $5 \%$ crumb rubber. This test showed that the sample contained $0.48 \%$ free fluid. The test sample was conditioned at $180^{\circ} \mathrm{F}$ for 30 minutes. Once the test started, the static temperature was $80^{\circ} \mathrm{F}$ for 120 minutes at a 45 degree inclination angle.

\section{Free Fluid Test for Class G Cement with 5\% Crumb Rubber}

\begin{tabular}{|l|r|r|r|r|r|}
\hline \multicolumn{7}{|c|}{ Free Fluid API 10B-2 / ISO 10426-2 } \\
\hline & & & & & \\
\hline $\begin{array}{l}\text { Con. Temp } \\
\text { (F) }\end{array}$ & $\begin{array}{l}\text { Cond. } \\
\text { Time (m in) }\end{array}$ & Static T. (F) & $\begin{array}{l}\text { Static time e } \\
\text { (min) }\end{array}$ & Incl. (deg) & \% Flu id \\
\hline 180 & 30 & 80 & 120 & 45 & 0.48 \\
\hline
\end{tabular}

Table 49: Free Fluid test for $5 \%$ crumb rubber

The unconfined compressive strength for class $\mathrm{G}$ cement with $5 \%$ crumb rubber is 2437 psi after 48 hours as shown by Table 50. Furthermore, the sample reached 500 psi after 3 hours and 43 minutes and 100 psi in 2 hours and 32 minutes. The sample was tested at $180^{\circ} \mathrm{F}$ and 3000 psi.

\section{Unconfined Compressive Strength for Class G Cement with 5\% Crumb Rubber}

\begin{tabular}{|c|c|c|c|c|c|c|c|c|c|c|c|}
\hline \multicolumn{12}{|c|}{ UCA Comp. Strength } \\
\hline $\begin{array}{l}\text { Fnd Temp } \\
\left({ }^{\circ} \mathrm{F}\right) \\
\end{array}$ & \begin{tabular}{|l}
$\begin{array}{l}\text { Pressure } \\
(\mathrm{psi})\end{array}$ \\
\end{tabular} & \begin{tabular}{|l}
$50 \mathrm{psi}$ \\
(hh:mm)
\end{tabular} & \begin{tabular}{|l}
$100 \mathrm{psi}$ \\
$(\mathrm{hh}: \mathrm{mm})$
\end{tabular} & \begin{tabular}{|l|l}
$500 \mathrm{psi}$ \\
$(\mathrm{hh}: \mathrm{mm})$
\end{tabular} & $\begin{array}{l}8 \mathrm{hr} \mathrm{CS} \\
(\mathrm{psi})\end{array}$ & \begin{tabular}{|l}
$12 \mathrm{hr} \mathrm{CS}$ \\
$(\mathrm{psi})$
\end{tabular} & $\begin{array}{l}16 \mathrm{hr} \mathrm{CS} \\
(\mathrm{psi})\end{array}$ & $\begin{array}{l}24 \mathrm{hr} \mathrm{CS} \\
(\mathrm{psi})\end{array}$ & $\begin{array}{l}48 \mathrm{hr} \mathrm{CS} \\
\text { (psi) }\end{array}$ & $\begin{array}{l}\text { End CS } \\
(\mathrm{psi})\end{array}$ & \begin{tabular}{|l}
$\begin{array}{l}\text { End Time } \\
(\mathrm{hrs})\end{array}$ \\
\end{tabular} \\
\hline 180 & 3000 & $2: 16$ & $2: 32$ & $3: 43$ & 1551 & 1945 & 2153 & 2337 & 2437 & 2467 & 75.07 \\
\hline
\end{tabular}


The compressive strength graph (Figure 25) for 5\% crumb rubber shows a lower and later increase of compressive strength than that of the samples with nano silica and the baseline case. This graph shows that the compressive strength reaches $100 \mathrm{psi}$ after 2 hours and 32 minutes and 500 psi after 3 hours and 43 minutes.

\section{Compressive Strength Graph of Class G Cement with 5\% Crumb Rubber}

\section{Compressive Strength}

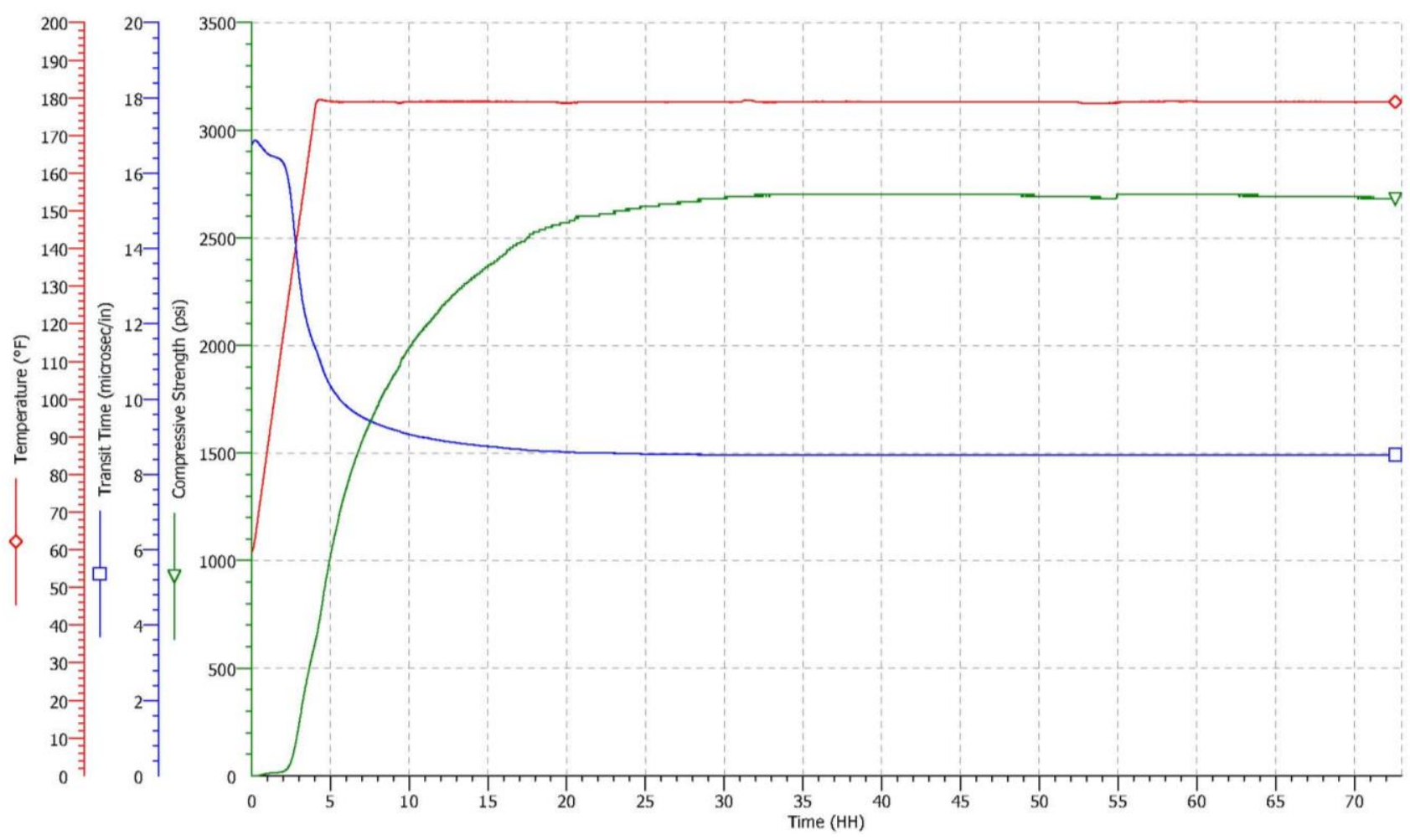

Figure 25: Compressive strength, 5\% Crumb Rubber 
The time, temperature and transition graph (Figure 26) shows that $5 \%$ crumb rubber starts to experience an increase in Bc after 1 hour and 30 minutes. This graph also shows a small increase in Bc after approximately 35 minutes.

\section{Time, Temperature and Transition of Class G Cement with 5\% Crumb Rubber}

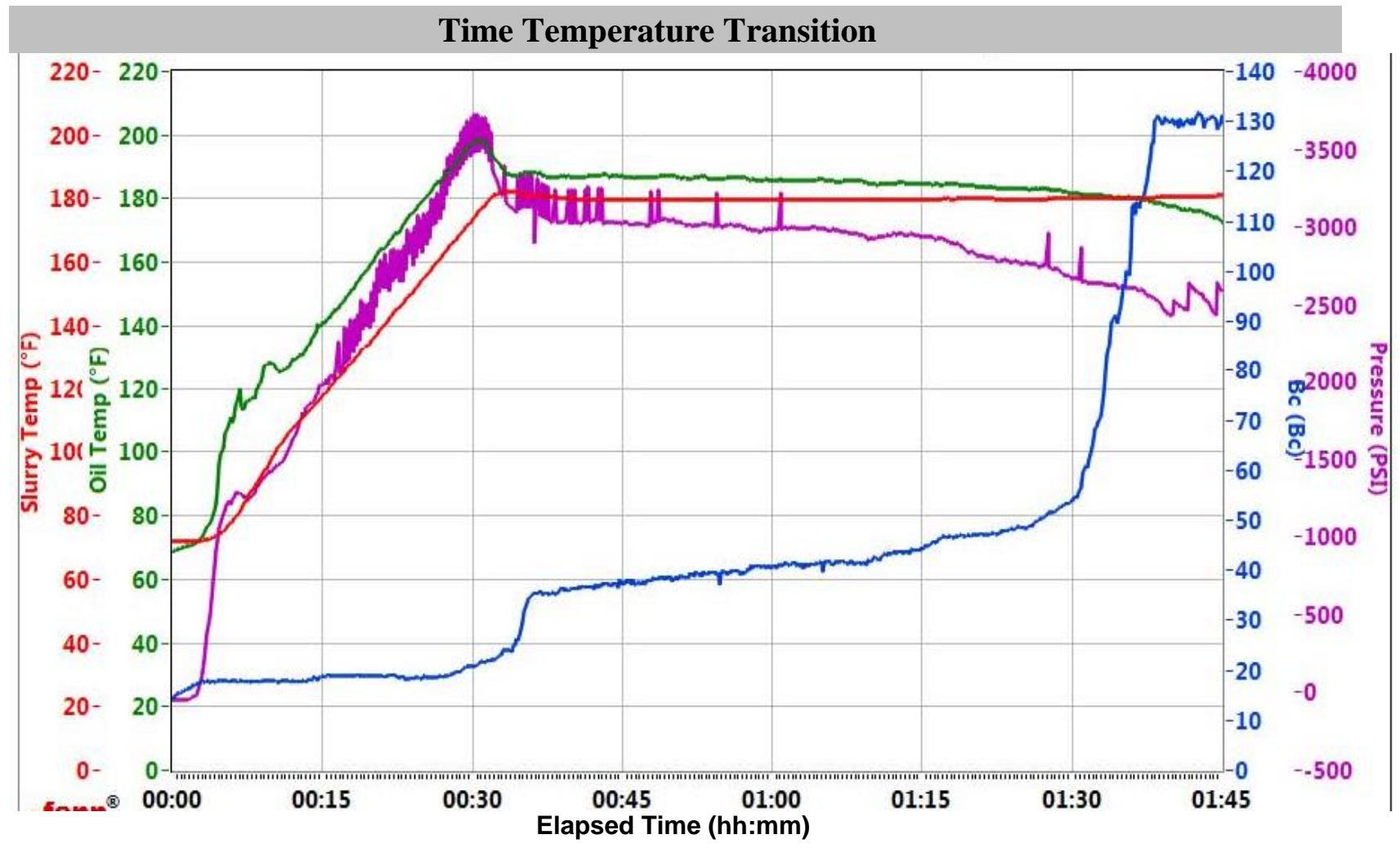

Figure 26: Temperature and Transition of 5\% Crumb Rubber versus time 


\section{DISCUSSION OF INITIAL RESULTS}

The first series of tests are performed with the goal of determining the optimal concentrations of each additive so that they may be combined into one sample and tested. The first series of tests included the base case of class $\mathrm{G}$ cement, one and two percent nano silica, and one, three and five percent crumb rubber samples. The results show that $2 \%$ nano silica and both 1 and $3 \%$ crumb rubber provided the greatest enhancements.

The key requirements to resist gas flow during the setting phase of cement are a measured volume of fluid loss under $50 \mathrm{mls}$ and close to zero free fluid at a 45 degree angle (Dillenbeck, 2010). This 45 degree angle is the standard at which the test is performed so that free fluid may be most accurately measured. This is very important when cementing in zones with a high Flow Potential Factor (FPF) because transmission through the cement during its transition time can be virtually reduced to zero using cement under $50 \mathrm{mls}$ fluid loss. The high FPF means that a zone will have a high risk of forming migration pathways. If the cement does not transition to $500 \mathrm{lbs} . / 100 \mathrm{ft}^{2}$ quick enough, the risk of forming migration pathways may increase. However, if the cement has a fluid loss volume under $50 \mathrm{mls}$, then this risk can be minimized. When two percent nano silica is used with cement, $40 \mathrm{mls}$ fluid loss and zero percent free fluid is measured. Furthermore, the sample with crumb rubber at three percent had a measured volume of $34 \mathrm{mls}$ fluid loss and zero percent free fluid. Whereas the control test with class $\mathrm{G}$ cement had $46 \mathrm{mls}$ fluid loss and $.56 \%$ free fluid. Additionally, the fast 
setting time of the new cement mixture provides a benefit by reducing time for migration pathways have to form.

The sample containing $2 \%$ nano silica shows a high early strength and the highest overall compressive strength out of any sample as shown by Figures 19 and 29 . There was an improvement in all of these parameters compared to the base case. Also, $1 \%$ crumb rubber also provides high early strength and relatively the same end strength as 3\% crumb rubber, which are higher than the class $\mathrm{G}$ cement without additives. When nano silica and crumb rubber were added a decrease in the time to reach 500 psi was observed as shown by the Transition Time graph (Figure 30). This is very beneficial when a cementing job requires less time to complete. Further, quick setting of cement with the addition of these additives prevents the formation of gas migration channels. The other concentrations of nano silica and crumb rubber provided similar benefits but their impact on all parameters was not positive as these concentrations.

The Time Temperature Transition graphs (TTT) show the transformation of the slurry's BC time. More specifically, it shows the kinetics of the isothermal transformation. This is visual representation of the structure in which the slurry reaches different BC times. Since it is not a linear progression, it is important to understand the slurry curing speeds and times. The slope of the line determines this property and can help with the preparation of cement jobs. This method holds true for UCA compression strength graphs as well.

The rheological models created based upon the PV vs. YP provide us with important graphs in determining the manner in which the cement slurry behaves. Each 
samples' rheological model (Figures 31, 32 and 33) can be compared with the rheological models diagram (Figure 27) to determine if it follows the Newtonian model, Bingham Plastic, Power Law, or Herschel-Bulkley model. Each sample tested follows the Bingham Plastic model, which can be expected of a cement slurry.

\section{Rheological Models}
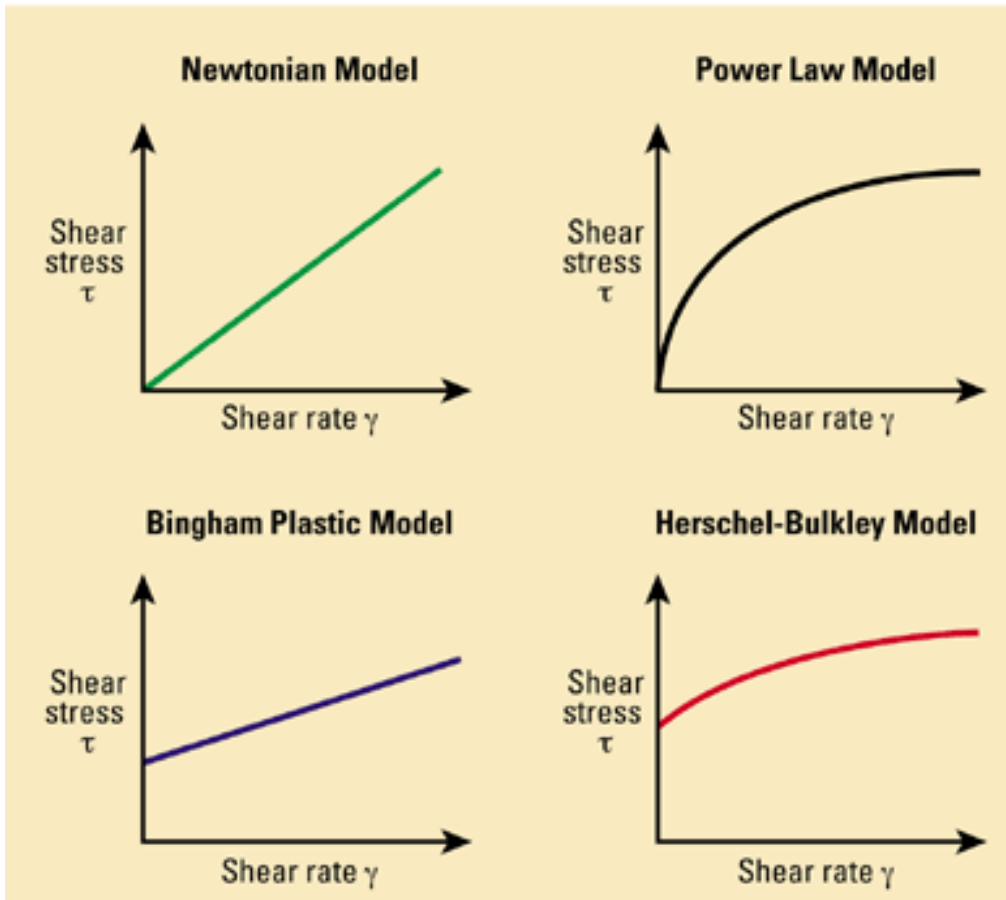

Figure 27: Rheological models diagram (drillingformulas.com, 2010)

Based on the test results, the optimal concentrations of $2 \%$ nano silica and both 1 and $3 \%$ rubber crumb achieved the goal of increasing compressive strength while fully integrating the crumb rubber. The $2 \%$ nano silica test provided an increase in compressive strength by $15 \%$ after 48 hours and $0 \%$ free fluid compared to the base case with $0.52 \%$ and $18 \%$ decrease in thickening time (to $100 \mathrm{BC}$ ). The $2 \%$ nano silica and the $3 \%$ crumb rubber samples retained a mixability factor of 5 , and a decrease in fluid loss by $38.5 \%$. All of these factors are improvements upon the base case. The 
crumb rubber at $3 \%$ provided an increase of compressive strength by $2.5 \%$ after 48 hours, $0 \%$ free fluid compared to the base case with $0.52 \%$ free fluid, decrease in thickening time by $3.5 \%$ (to $100 \mathrm{BC}$ ), a decrease in fluid loss by $19 \%$ and retained a mixability factor of 5 .

This initial analysis compares the baseline case of class $\mathrm{G}$ cement with no additives to that of the various nano silica trials and crumb rubber trials. Figure 28 shows that the base case and $3 \%$ crumb rubber thickening time in $\mathrm{Bc}$ are at the slowest rate while $1 \%$ nano silica reaches thickening time the fastest. Figure 29 shows that $1 \%$ and $3 \%$ crumb rubber have the lowest fluid loss with $1 \%$ and $2 \%$ nano silica being lower than the base case or $5 \%$ crumb rubber sample. Figure 30 shows $2 \%$ nano silica with a significant increase in compressive strength over that of any other sample at any given time. Figure 31 shows that $2 \%$ nano silica transitions faster and earlier than that of any other samples tested. Figures 32, 33 and 34 compare the rheological models for the baseline trial to that of $2 \%$ nano silica and $3 \%$ crumb rubber. The baseline is compared to these two trials because $2 \%$ nano silica and approximately $3 \%$ crumb rubber show the best results. Figure 35 shows a comparison of each rheological model in which $2 \%$ nano silica has the highest shear stress and shear rate. 


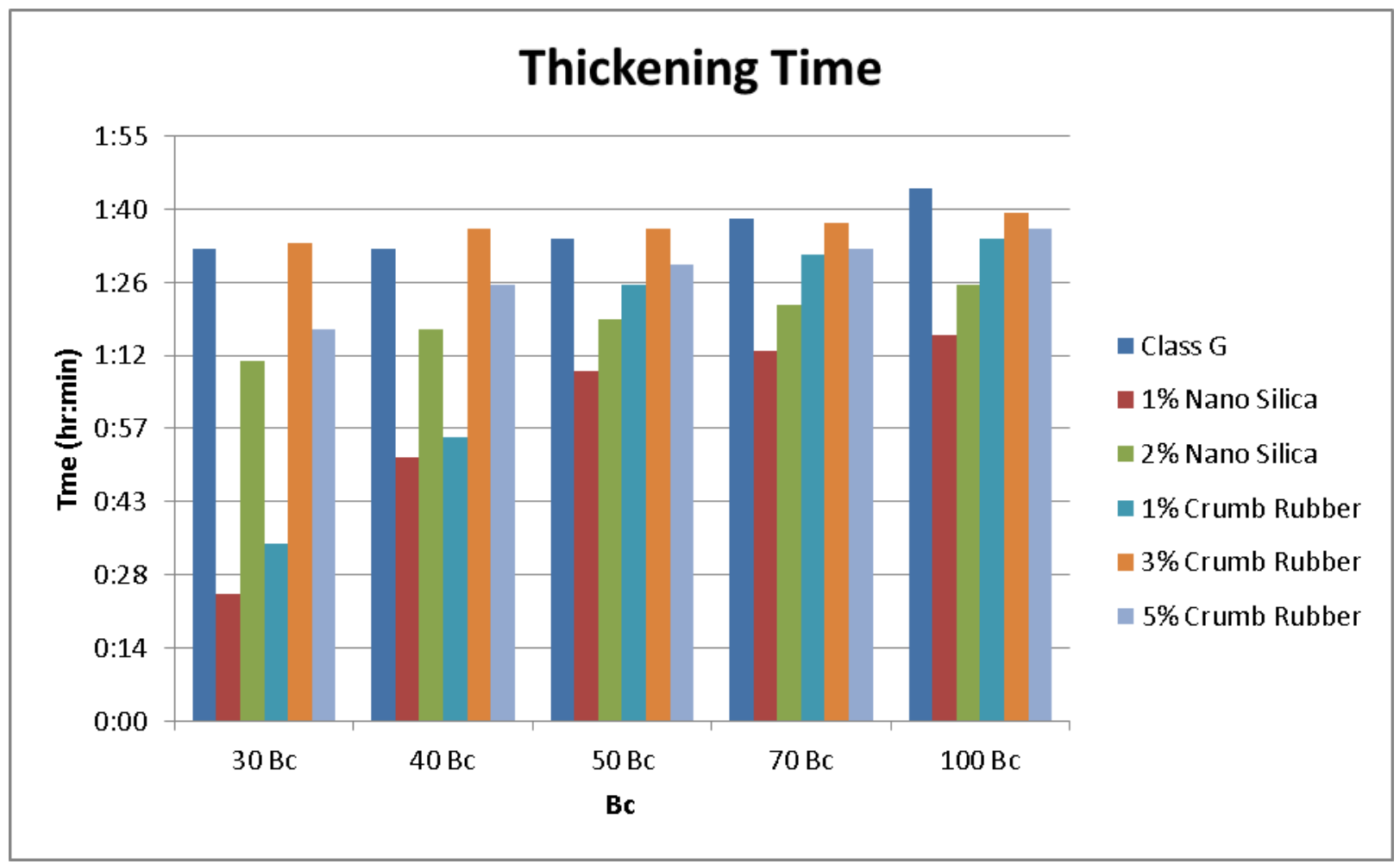

Figure 28: Comparison of thickening time for all initial test samples.

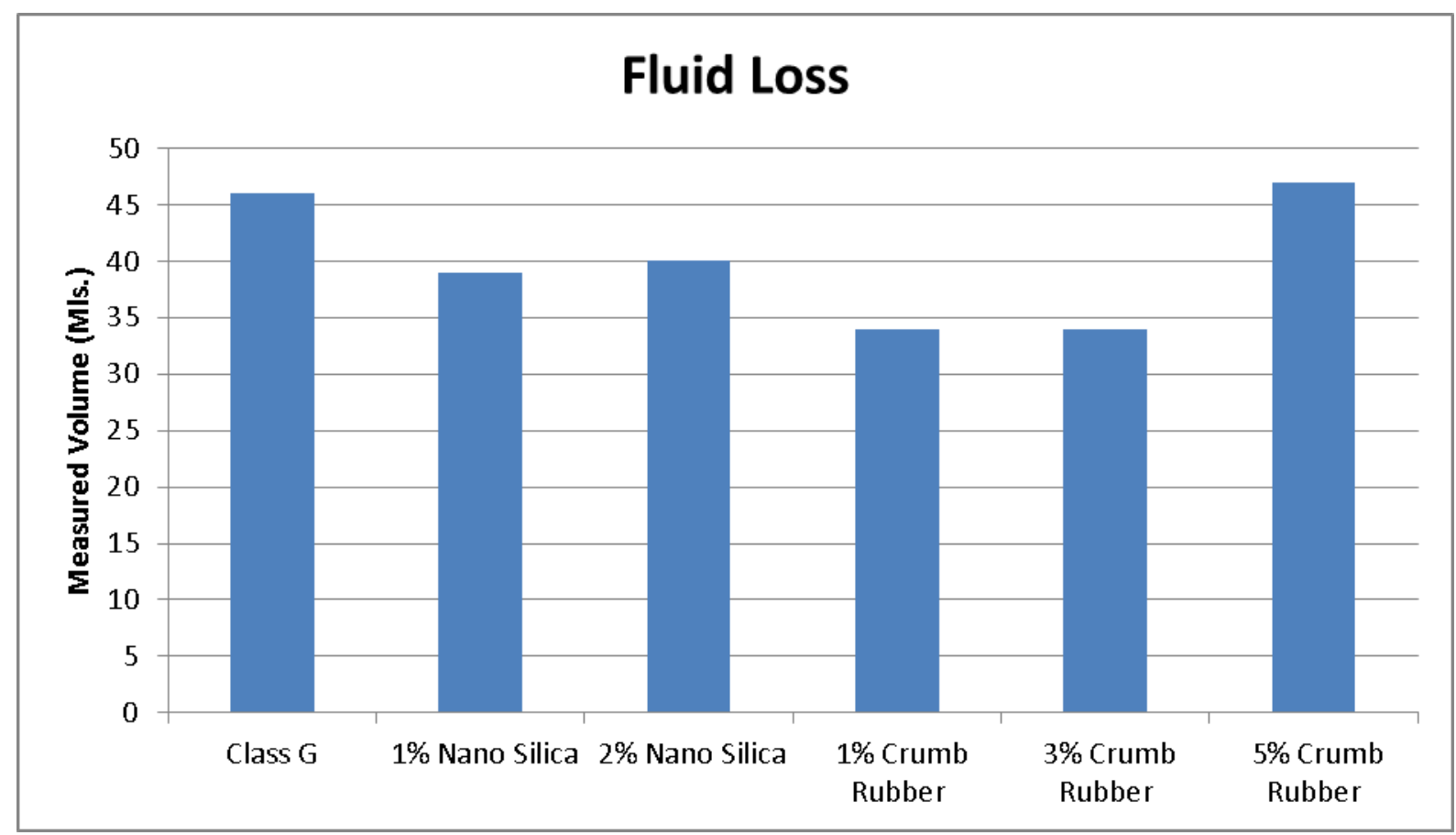

Figure 29: Comparison of measured volume of fluid loss in milliliters for all initial test samples. 


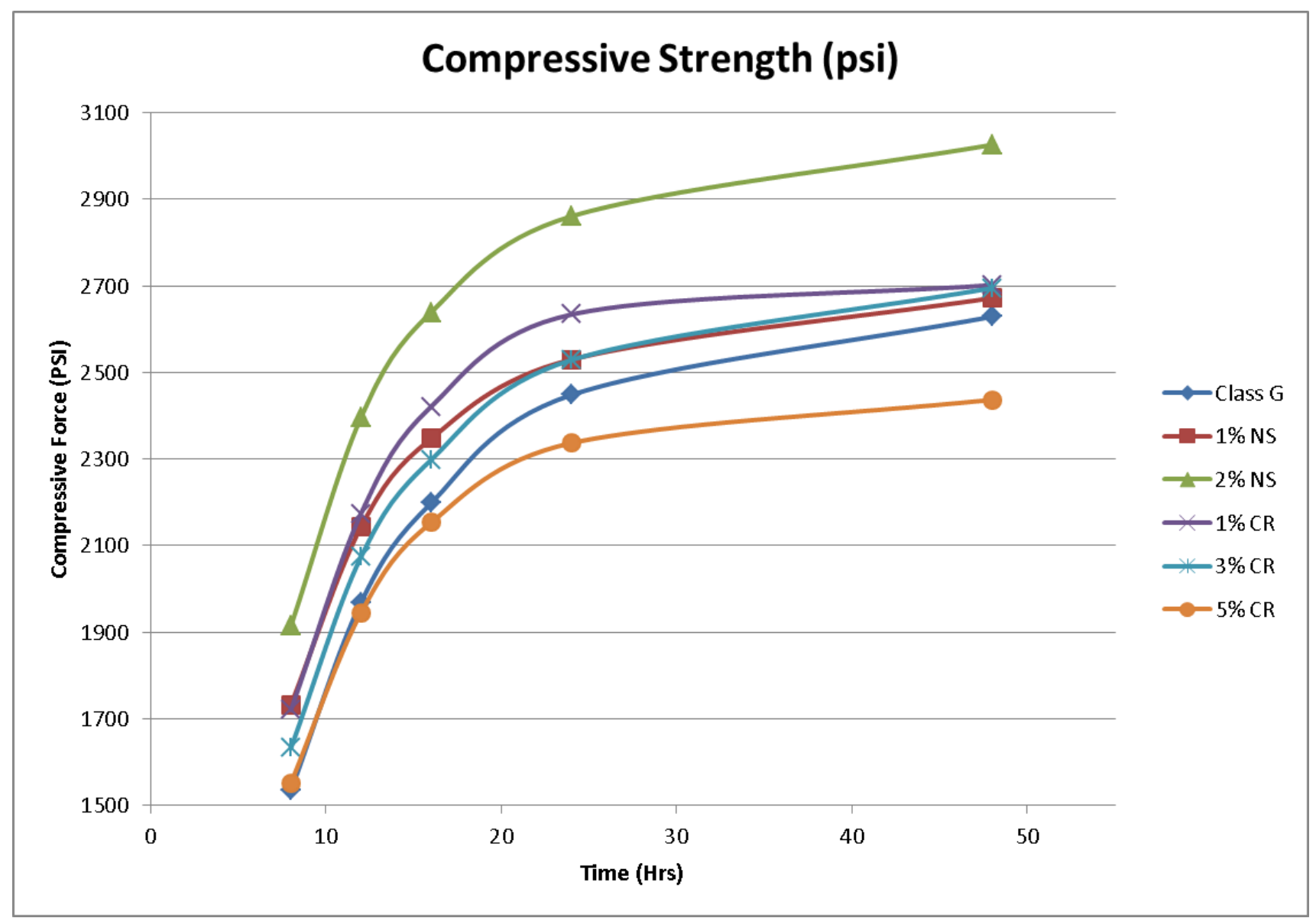

Figure 30: Comparison of compressive strength for all initial test samples. 


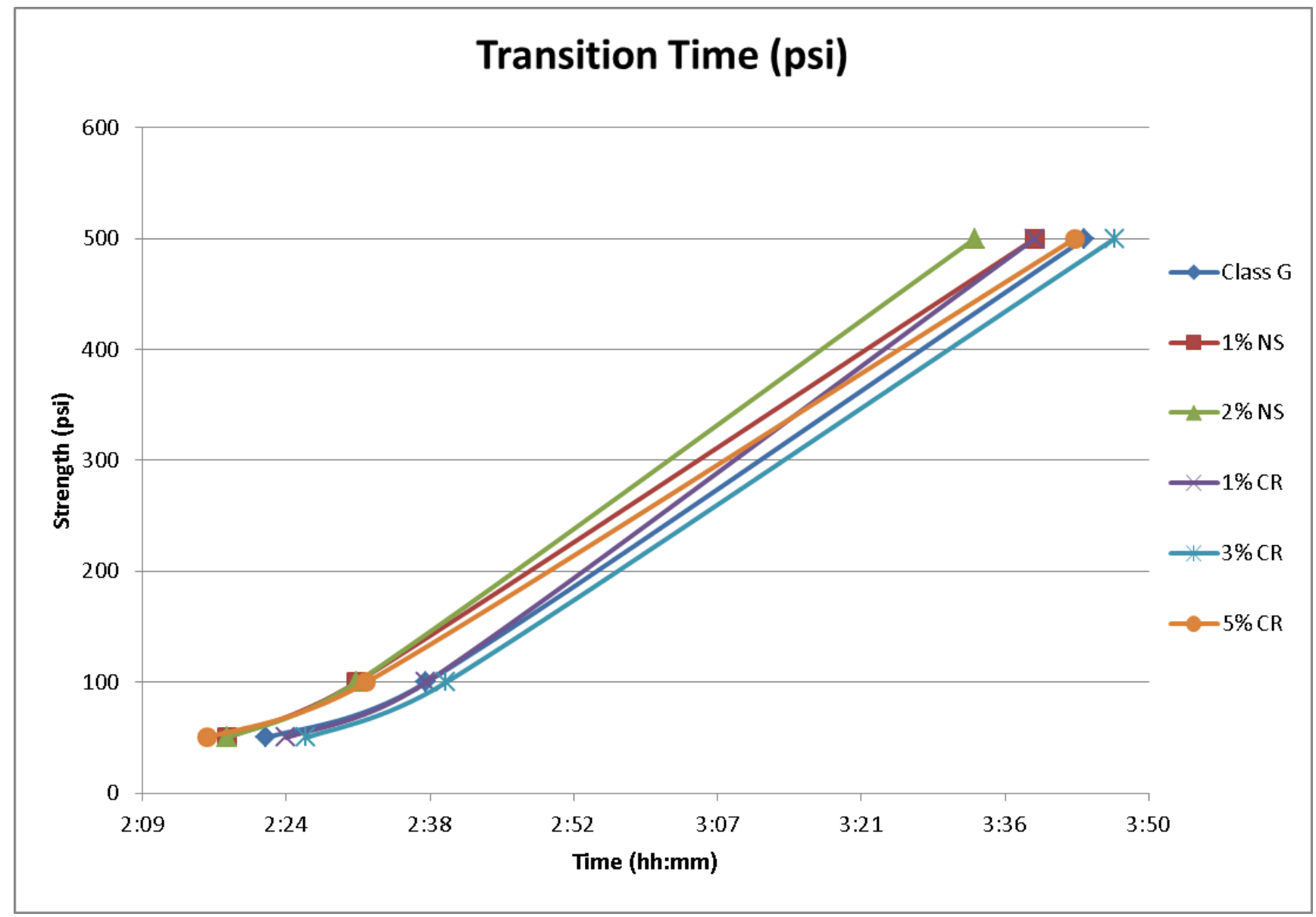

Figure 31: Comparison of transition time for all initial test samples. 


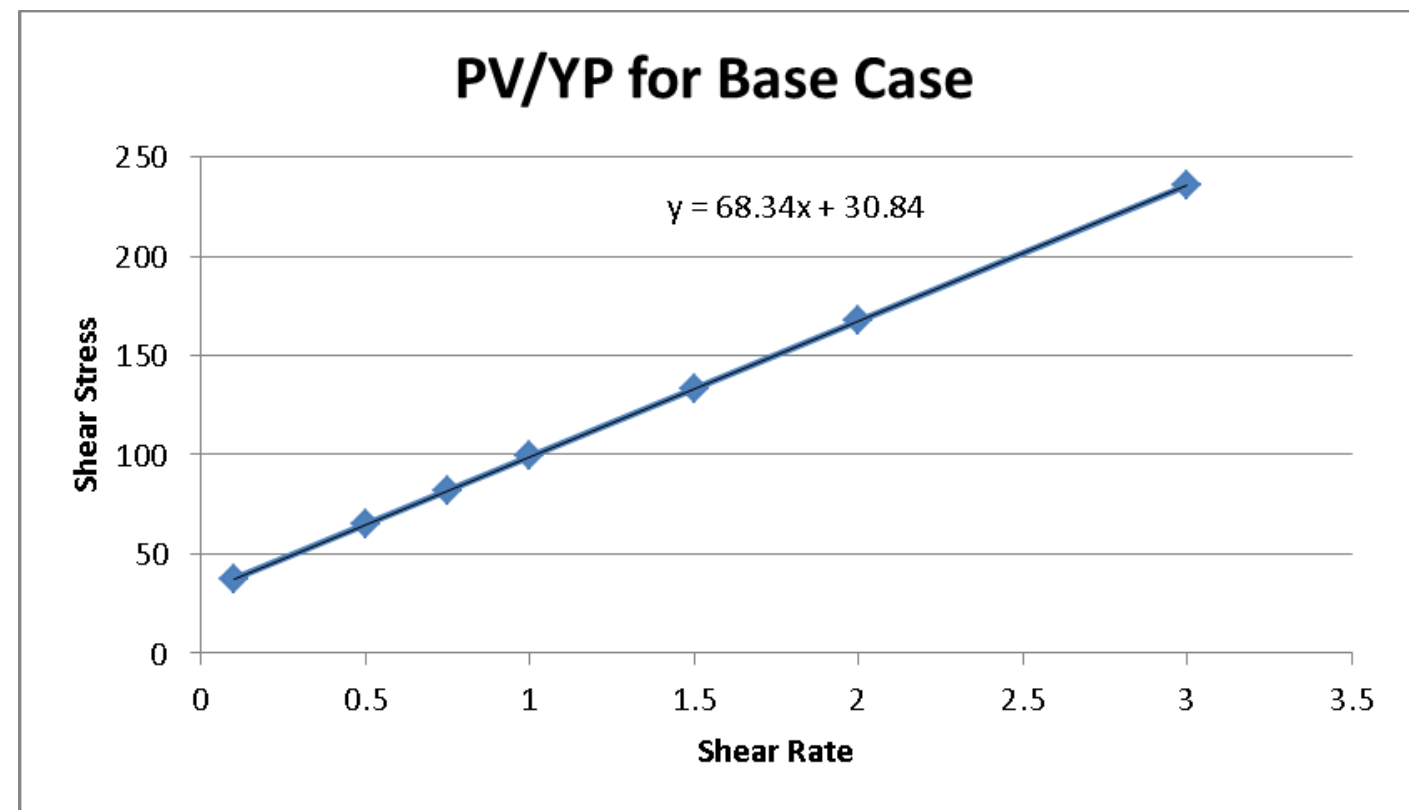

Figure 32: PV vs. YP for the base case of class G cement sample.

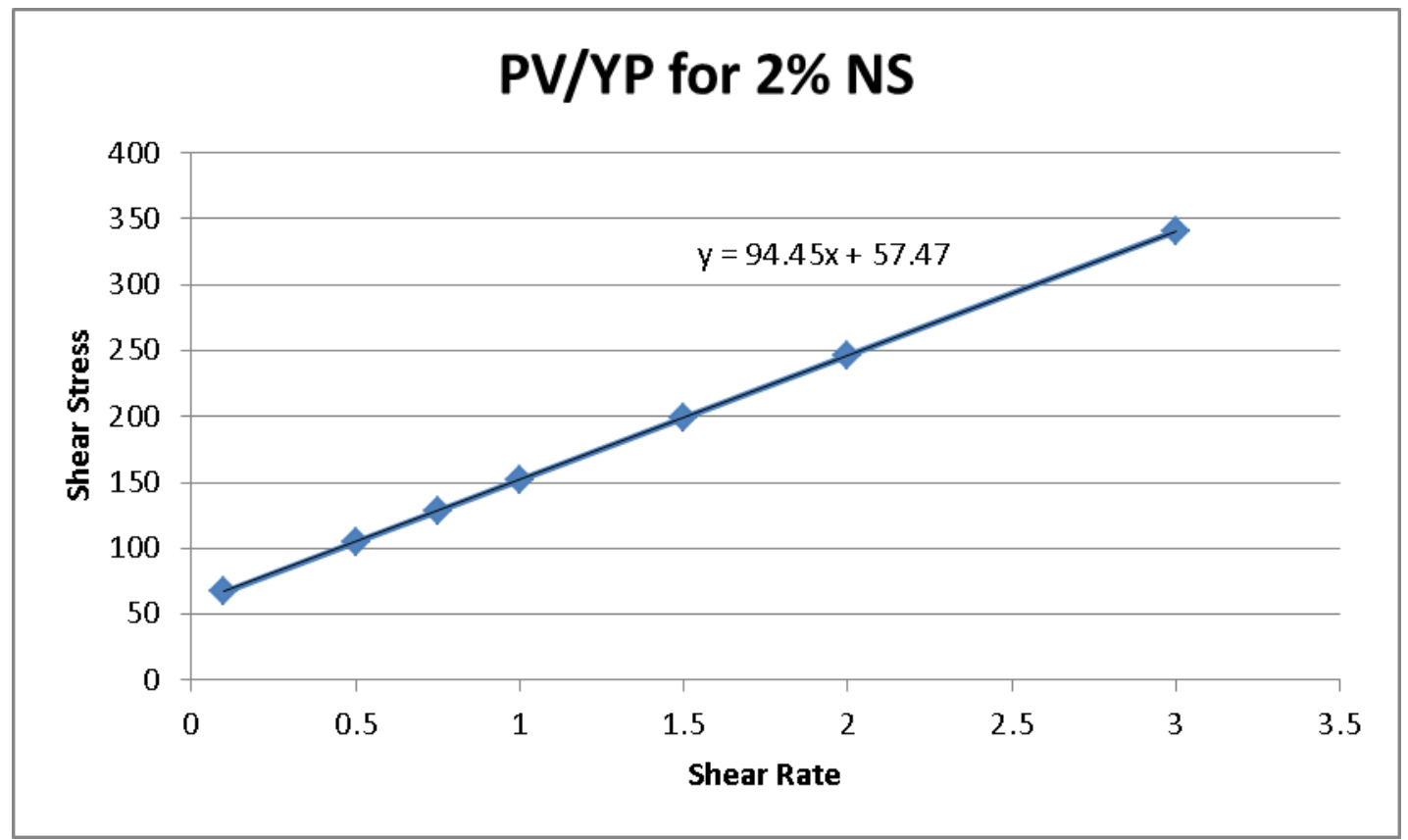

Figure 33: PV vs. YP for the $2 \%$ nano silica BWOC sample. 


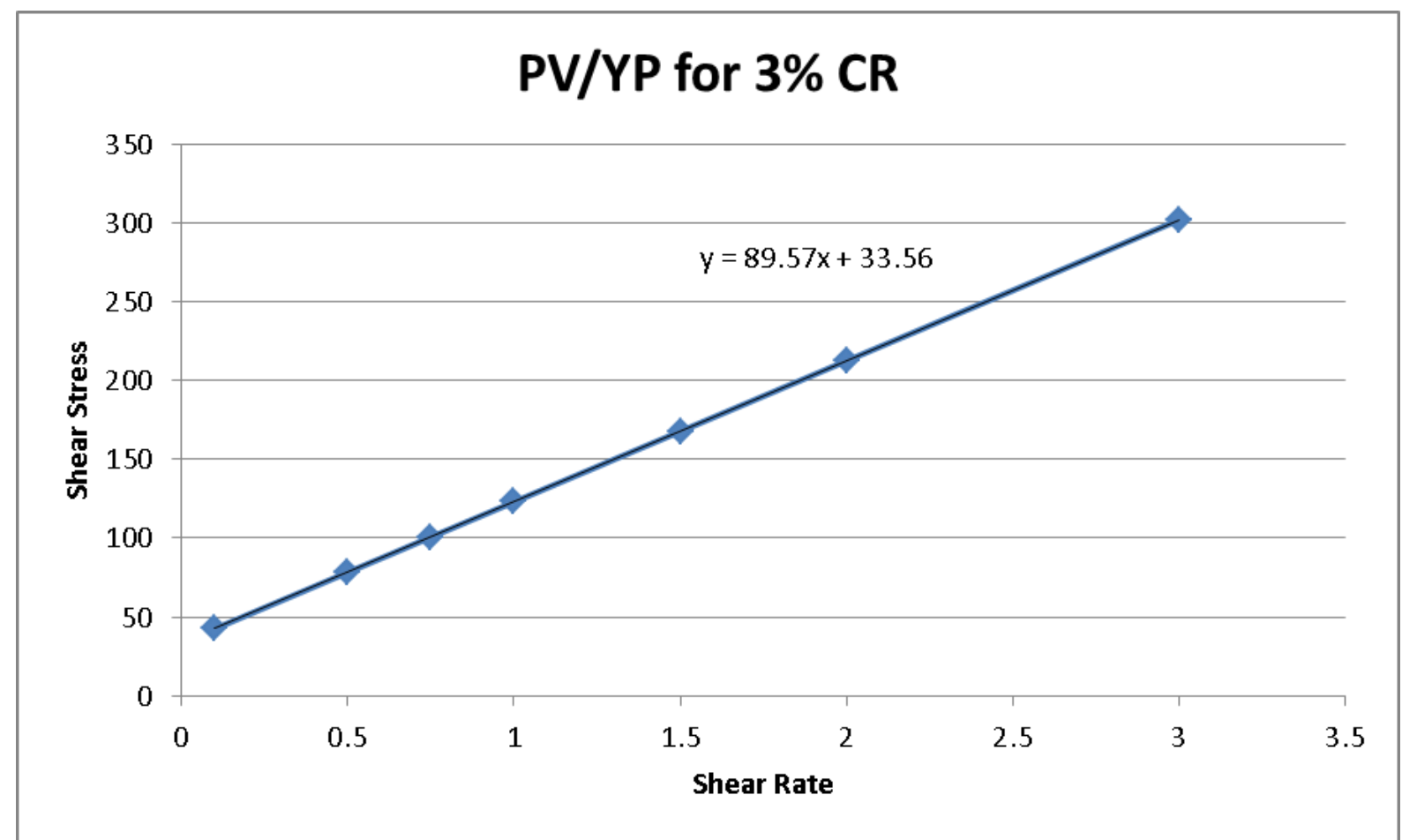

Figure 34: PV vs. YP for the 3\% rubber crumb BWOC sample.

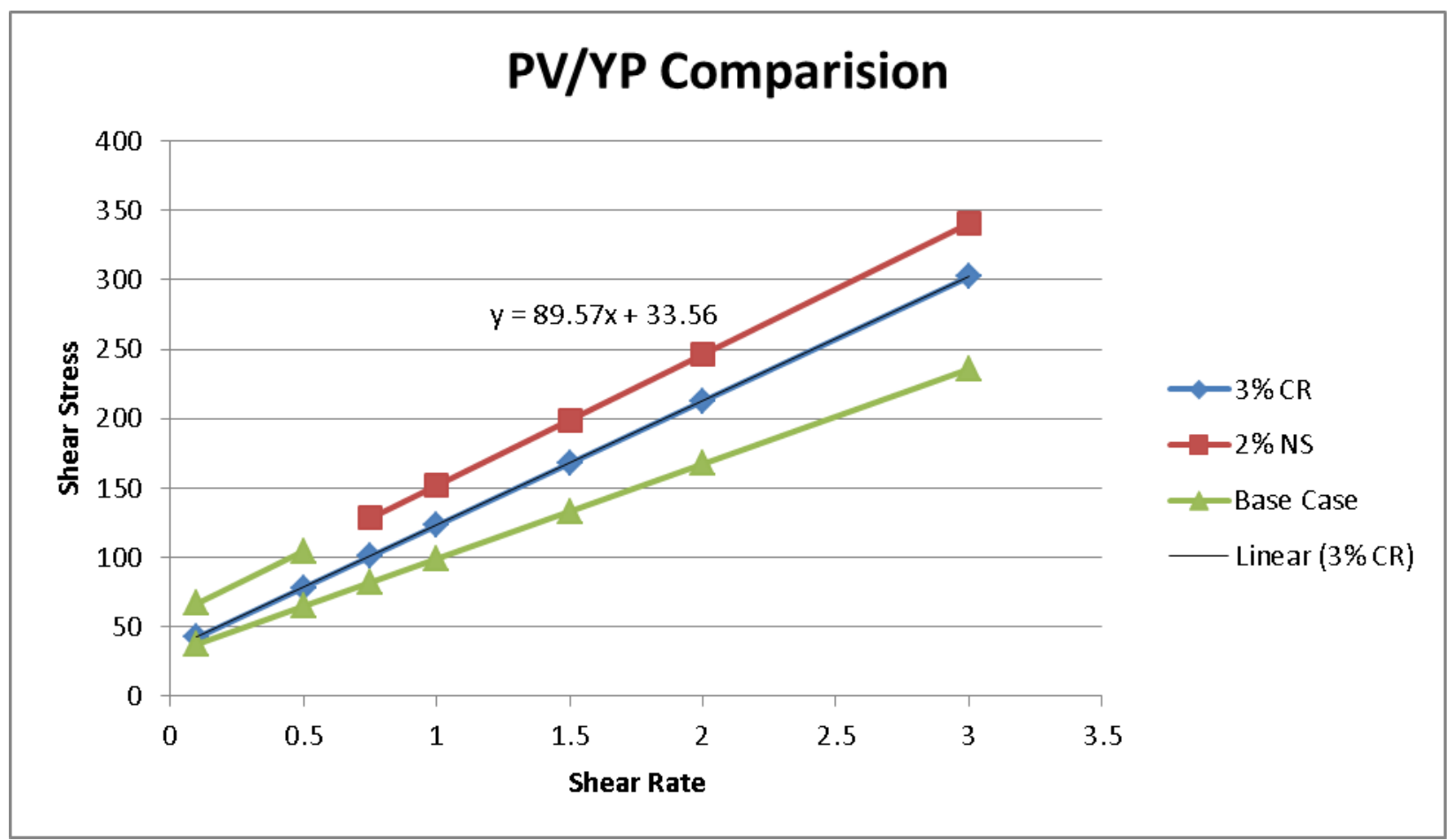

Figure 35: PV vs. YP comparison of samples 
G.) 2\% BWOC Nano Silica and 2\% BWOC Crumb Rubber Results

In this section, results are presented for experiments conducted with $2 \%$ nano silica and $2 \%$ crumb rubber. Table 51 provides the testing conditions that the trial was performed under. The class $\mathrm{G}$ cement trial with $2 \%$ nano silica and $2 \%$ crumb rubber was tested at $3000 \mathrm{psi}$ and $180^{\circ} \mathrm{F}$.

Pressure and Temperature Conditions of 2\% Nano Silica and 2\% Crumb Rubber Cement Trial

\begin{tabular}{|l|l|l|l|l|l|}
\hline & & & & & \\
\hline \multirow{2}{*}{ Pressure } & $207 \mathrm{bar} /$ & \multirow{2}{*}{ BHST } & $82^{\circ} \mathrm{C} /$ & \multirow{2}{*}{ BHCT } & $82^{\circ} \mathrm{C} /$ \\
& $3000 \mathrm{psi}$ & $180^{\circ} \mathrm{F}$ & & \\
\hline
\end{tabular}

Table 51: Test conditions of $2 \%$ nano silica and $2 \%$ crumb rubber

Table 52 shows that the trial containing class G cement with $2 \%$ nano silica and $2 \%$ crumb rubber has a slurry density of $15.8 \mathrm{lb} /$ gal. The slurry yield is $1.17 \mathrm{ft}^{3} /$ sack with a water requirement of $4.9 \mathrm{gal} / \mathrm{sack}$. The total fluid for the mix required is $4.9 \mathrm{gal} / \mathrm{sack}$. 


\section{Composition and Property Analysis of $2 \%$ Nano Silica and 2\% Crumb Rubber}

Cement Trial

\begin{tabular}{|c|c|c|c|c|c|}
\hline \multirow{2}{*}{$\begin{array}{l}\text { Conc } \\
100\end{array}$} & \multirow{2}{*}{$\frac{\text { UOM }}{\% \text { BWOC }}$} & \multirow{2}{*}{$\frac{\text { Cement/Additive }}{\text { Evansville Lehigh Premium G }}$} & \multicolumn{3}{|c|}{ Cement Properties } \\
\hline & & & $\begin{array}{l}\text { Slurry } \\
\text { Density }\end{array}$ & 15.8 & lbm/gal \\
\hline 4.94 & $\mathrm{gal} / \mathrm{sack}$ & Fresh Water & Slurry Yield & 1.1754 & $\mathrm{ft} 3 / \mathrm{sack}$ \\
\hline 2 & $\%$ BWOC & zRD Rubber Crumb & $\begin{array}{l}\text { Water } \\
\text { Requirement }\end{array}$ & 4.9418 & $\mathrm{gal} / \mathrm{sack}$ \\
\hline 2 & $\% \mathrm{BWOC}$ & zRD Silica Dioxide & $\begin{array}{l}\text { Total Mix } \\
\text { Fluid }\end{array}$ & 4.94 & gal/sack \\
\hline & & & & & \\
\hline & & & & & \\
\hline & & & $\begin{array}{l}\text { Water } \\
\text { Source }\end{array}$ & Fresh Water & \\
\hline & & & $\begin{array}{l}\text { Water } \\
\text { Chloride }\end{array}$ & & \\
\hline
\end{tabular}

Table 52: Properties of $2 \%$ nano silica and $2 \%$ crumb rubber cement used in analysis 
Table 53 shows that the class $\mathrm{G}$ trial with $2 \%$ nano silica and $2 \%$ crumb rubber attained a mixability of 3.5 while being mixed under an average rpm of 12,000.

Furthermore, the blend addition time at 4,000 rpm was 28 seconds. This shows that the slurry has an average mixability and any lower concentration would start to become undesirable.

\section{Mixability Test for Class G Cement with 2\% Nano Silica and 2\% Crumb Rubber}

\begin{tabular}{|c|c|c|}
\hline \multicolumn{3}{|c|}{ Mixability (0 - 5) - 0 is not mixable } \\
\hline $\begin{array}{l}\text { Mixability } \\
\text { rating }(0-5)\end{array}$ & $\begin{array}{l}\text { Avg rpm mixing under } \\
\text { load }(\sim 12,000)\end{array}$ & $\begin{array}{l}\text { Blend addition time } \\
\text { (sec)@ 4,000 RPM }\end{array}$ \\
\hline 3.5 & 12000 & 2 \\
\hline
\end{tabular}

Table 53: Mixability test for $2 \%$ nano silica and $2 \%$ crumb rubber cement

Table 54 shows a thickening time of 1 hour and 8 minutes to $100 \mathrm{Bc} .100 \mathrm{Bc}$ is the primary result for this test. Furthermore, the time required to reach $30 \mathrm{Bc}$ was 41 minutes, $40 \mathrm{Bc}$ was 49 minutes, $50 \mathrm{Bc}$ was 1 hour and 4 minutes and $70 \mathrm{Bc}$ was 1 hour 8 minutes.

\section{Thickening Time Test for Class G Cement with 2\% Nano Silica and 2\% Crumb Rubber}

\begin{tabular}{|c|c|c|c|c|c|c|c|c|}
\hline \multicolumn{9}{|c|}{ Thickening Time } \\
\hline Temp $\left({ }^{\circ} \mathbf{F}\right)$ & \begin{tabular}{|l}
$\begin{array}{l}\text { Pressure } \\
(\mathrm{psi})\end{array}$ \\
\end{tabular} & \begin{tabular}{|l|}
$\begin{array}{l}\text { Reached in } \\
\text { (min) }\end{array}$ \\
\end{tabular} & Start BC & \begin{tabular}{|l}
30 Bc \\
(hh:mm)
\end{tabular} & \begin{tabular}{|l}
$40 \mathrm{Bc}$ \\
$(\mathrm{hh}: \mathrm{mm})$
\end{tabular} & \begin{tabular}{|l}
50 Bc \\
hh:mm)
\end{tabular} & \begin{tabular}{|l}
70 Bc \\
$(\mathrm{hh}: \mathrm{mm})$
\end{tabular} & $\begin{array}{l}100 \text { Bc } \\
\text { (hh:mm) }\end{array}$ \\
\hline 180 & 3000 & 30 & 10 & $0: 41$ & $0: 49$ & $1: 04$ & $1: 08$ & $1: 08$ \\
\hline
\end{tabular}

Table 54: Thickening Time test for $2 \%$ nano silica and $2 \%$ crumb rubber cement 
Table 55 shows the rheology's tests which provided a PV/YP of 109.89/75.02 at $80^{\circ} \mathrm{F}$ and $233.89 / 101.97$ at $180^{\circ} \mathrm{F}$. This test shows a higher viscosity and shear stress than class $\mathrm{G}$ cement with no additives.

\section{API Rheology under $80^{\circ} \mathrm{F}$ and $180^{\circ} \mathrm{F}$ for Class G Cement with $2 \%$ Nano Silica and $2 \%$ Crumb Rubber}

\begin{tabular}{|c|c|c|c|c|c|c|c|c|c|c|}
\hline \multicolumn{11}{|c|}{ API Rheology } \\
\hline $\operatorname{Temp}\left({ }^{\circ} \mathbf{F}\right)$ & RPM & 300 & 200 & 100 & 60 & 30 & 6 & 3 & $\begin{array}{l}\text { Cond Time } \\
(\min )\end{array}$ & $\mathbf{P V} / \mathbf{Y P}$ \\
\hline 80 & Viscosity & 167 & 148 & 125 & 114 & 102 & 52 & 44 & $\mathbf{0}$ & $\begin{array}{l}109.89 / \\
75.02\end{array}$ \\
\hline $\operatorname{Temp}\left({ }^{\circ} \mathrm{F}\right)$ & RPM & 300 & 200 & 100 & 60 & 30 & 6 & 3 & \begin{tabular}{|l}
$\begin{array}{l}\text { Cond Time } \\
(\mathrm{min})\end{array}$ \\
\end{tabular} & PV/YP \\
\hline 180 & Viscosity & 292 & 272 & 225 & 188 & 126 & 61 & 55 & 30 & \begin{tabular}{|l|}
$233.89 /$ \\
101.97
\end{tabular} \\
\hline
\end{tabular}

Table 55: API Rheology tests for $2 \%$ nano silica and $2 \%$ crumb rubber

Table 56 contains the results for the API fluid loss test for class G cement $2 \%$ nano silica and $2 \%$ crumb rubber. The primary result obtained is the measured volume of fluid loss, which was found to be $21 \mathrm{ml}$. The test was performed at $180^{\circ} \mathrm{F}$ and 1000 psi for 0.08 minutes with a conditioning time of 30 minutes.

\section{API Fluid Loss Test for Class G Cement with 2\% Nano Silica and 2\% Crumb Rubber}

\begin{tabular}{|c|c|c|c|c|c|c|}
\hline \multicolumn{7}{|c|}{ API Fluid Loss } \\
\hline $\begin{array}{l}\text { Test Temp } \\
\left({ }^{\circ} \mathbf{F}\right)\end{array}$ & \begin{tabular}{|l} 
Test \\
Pressure \\
(psi) \\
\end{tabular} & $\begin{array}{l}\text { Test Time } \\
(\mathrm{min})\end{array}$ & Meas. Vol. & $\begin{array}{l}\text { Calculated } \\
\text { FL }(<30 \\
\text { min })\end{array}$ & \begin{tabular}{|l} 
Conditioni \\
ng time \\
$(\mathrm{min})$
\end{tabular} & \begin{tabular}{|l} 
Conditioni \\
ng Temp \\
$\left({ }^{\circ} \mathrm{F}\right)$
\end{tabular} \\
\hline 180 & 1000 & 0.08 & 21 & 797 & 30 & 180 \\
\hline
\end{tabular}

Table 56: API Fluid loss test for $2 \%$ nano silica cement and $2 \%$ crumb rubber 
Table 57 contains the results for the free fluid test of class $\mathrm{G}$ cement with $2 \%$ nano silica and $2 \%$ crumb rubber. This test showed that the sample contained $0 \%$ free fluid. The test sample was conditioned at $180^{\circ} \mathrm{F}$ for 30 minutes. Once the test started, the static temperature was $80^{\circ} \mathrm{F}$ for 120 minutes at a 45 degree inclination angle.

\section{Free Fluid Test for Class G Cement with 2\% Nano Silica and 2\% Crumb Rubber}

\begin{tabular}{|r|l|r|r|r|r|}
\hline \multicolumn{5}{|c|}{ Free Fluid API 10B-2 / ISO 10426-2 } \\
\hline & & & & & \\
\hline $\begin{array}{l}\text { Con. Temp } \\
\text { (F) }\end{array}$ & $\begin{array}{l}\text { Cond. } \\
\text { Time (m in) }\end{array}$ & Static T. (F) & $\begin{array}{l}\text { Static time } \\
\text { (min) }\end{array}$ & Incl. (deg) & \% Flu id \\
\hline 180 & 30 & 80 & 120 & 45 & 0 \\
\hline
\end{tabular}

Table 57: Free Fluid test for $2 \%$ nano silica and $2 \%$ crumb rubber

The unconfined compressive strength for class $\mathrm{G}$ cement with $2 \%$ nano silica and $2 \%$ crumb rubber is 2720 psi after 48 hours as shown by Table 58 . Furthermore, the sample reached 500 psi after 3 hours and 23 minutes and 100 psi in 2 hours and 23 minutes. The sample was tested at $180^{\circ} \mathrm{F}$ and 3000 psi.

\section{Unconfined Compressive Strength for Class G Cement with $2 \%$ Nano Silica and $2 \%$ Crumb Rubber}

\begin{tabular}{|c|c|c|c|c|c|c|c|c|c|c|c|}
\hline \multicolumn{12}{|c|}{ UCA Comp. Strength } \\
\hline \begin{tabular}{|l|} 
End Temp \\
$\left({ }^{\circ} \mathrm{F}\right)$ \\
\end{tabular} & $\begin{array}{l}\text { Pressure } \\
\text { (psi) }\end{array}$ & \begin{tabular}{|l}
$50 \mathrm{psi}$ \\
$(\mathrm{hh}: \mathrm{mm})$
\end{tabular} & \begin{tabular}{|l}
100 psi \\
$(\mathrm{hh}: \mathrm{mm})$
\end{tabular} & \begin{tabular}{|l}
$500 \mathrm{psi}$ \\
$(\mathrm{hh}: \mathrm{mm})$
\end{tabular} & $\begin{array}{l}8 \mathrm{hr} \mathrm{CS} \\
(\mathrm{psi})\end{array}$ & $\begin{array}{l}2 \mathrm{hr} \mathrm{CS} \\
\text { (psi) }\end{array}$ & $\begin{array}{l}16 \mathrm{hr} \text { CS } \\
\text { (psi) }\end{array}$ & $\begin{array}{l}24 \mathrm{hr} \mathrm{CS} \\
\text { (psi) }\end{array}$ & $\begin{array}{l}48 \mathrm{hr} \text { CS } \\
(\mathrm{psi})\end{array}$ & $\begin{array}{l}\text { End CS } \\
(\mathrm{psi})\end{array}$ & \begin{tabular}{|l}
$\begin{array}{l}\text { End Time } \\
\text { (hrs) }\end{array}$ \\
\end{tabular} \\
\hline 180 & 3000 & $2: 10$ & $2: 23$ & $3: 23$ & 1782 & 2199 & 2398 & 2585 & 2720 & 2731 & 72.2 \\
\hline
\end{tabular}

Table 58: Compressive strength for $2 \%$ nano silica and $2 \%$ crumb rubber 
The compressive strength graph (Figure 36 ) for $2 \%$ nano silica and $2 \%$ crumb rubber shows a higher and earlier increase compressive strength than that of the initial nano silica trials, the initial crumb rubber trials and the baseline case. This graph shows that the compressive strength reaches 100 psi after 2 hours and 23 minutes and 500 psi after 3 hours and 23 minutes.

\section{Compressive Strength Graph of Class G Cement with 2\% Nano Silica and 2\% Crumb Rubber}

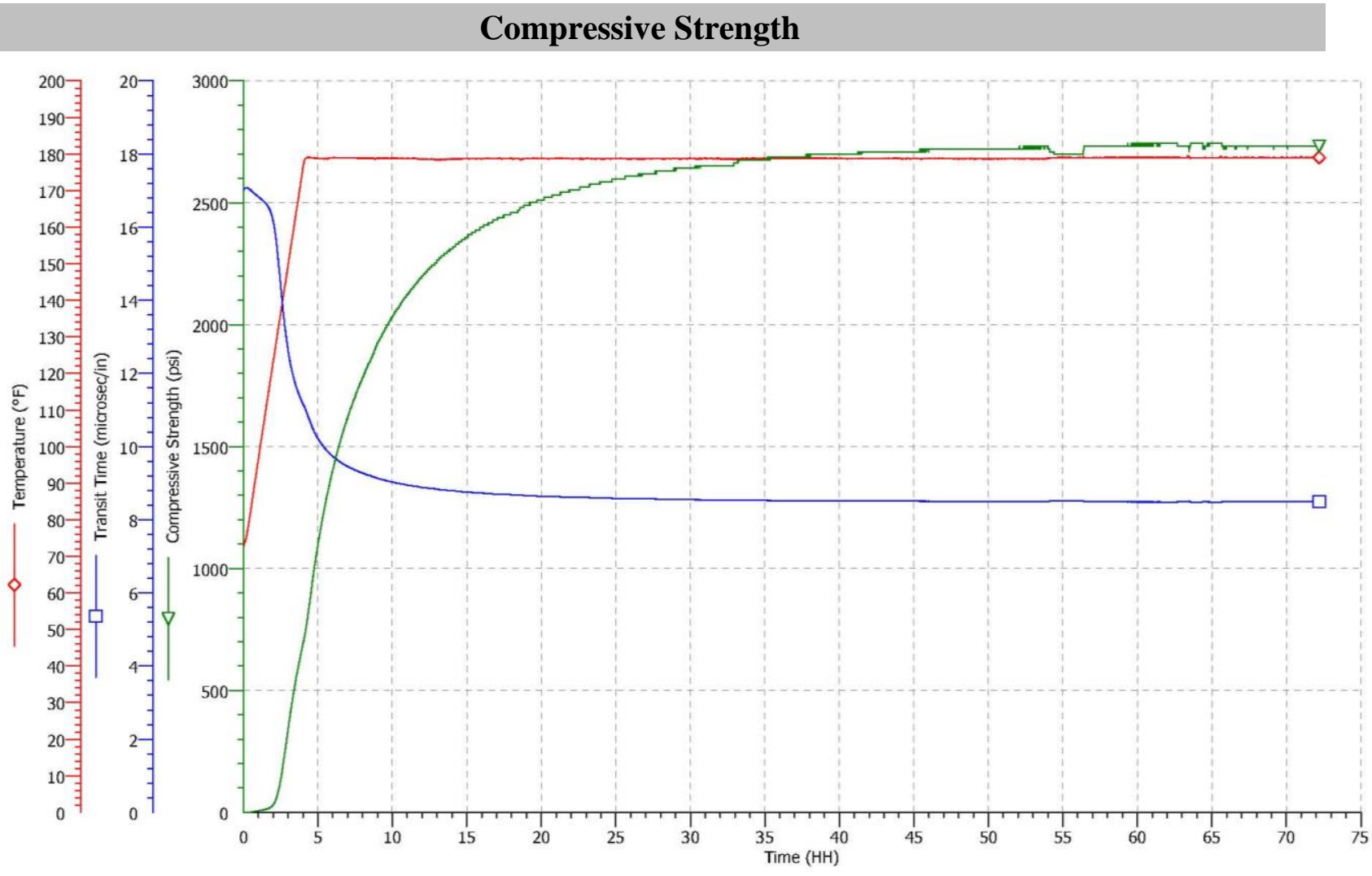

Figure 36: Compressive strength for 2\% Nano Silica and 2\% Crumb Rubber 
The time, temperature and transition graph (Figure 37 ) shows that $2 \%$ nano silica and $2 \%$ crumb rubber starts to see a small increase in $\mathrm{Bc}$ after 22 minutes, another small increase after 40 minutes and the major increase after 1 hour and 10 minutes.

\section{Time, Temperature and Transition of Class G Cement with $2 \%$ Nano Silica and $2 \%$ Crumb Rubber}

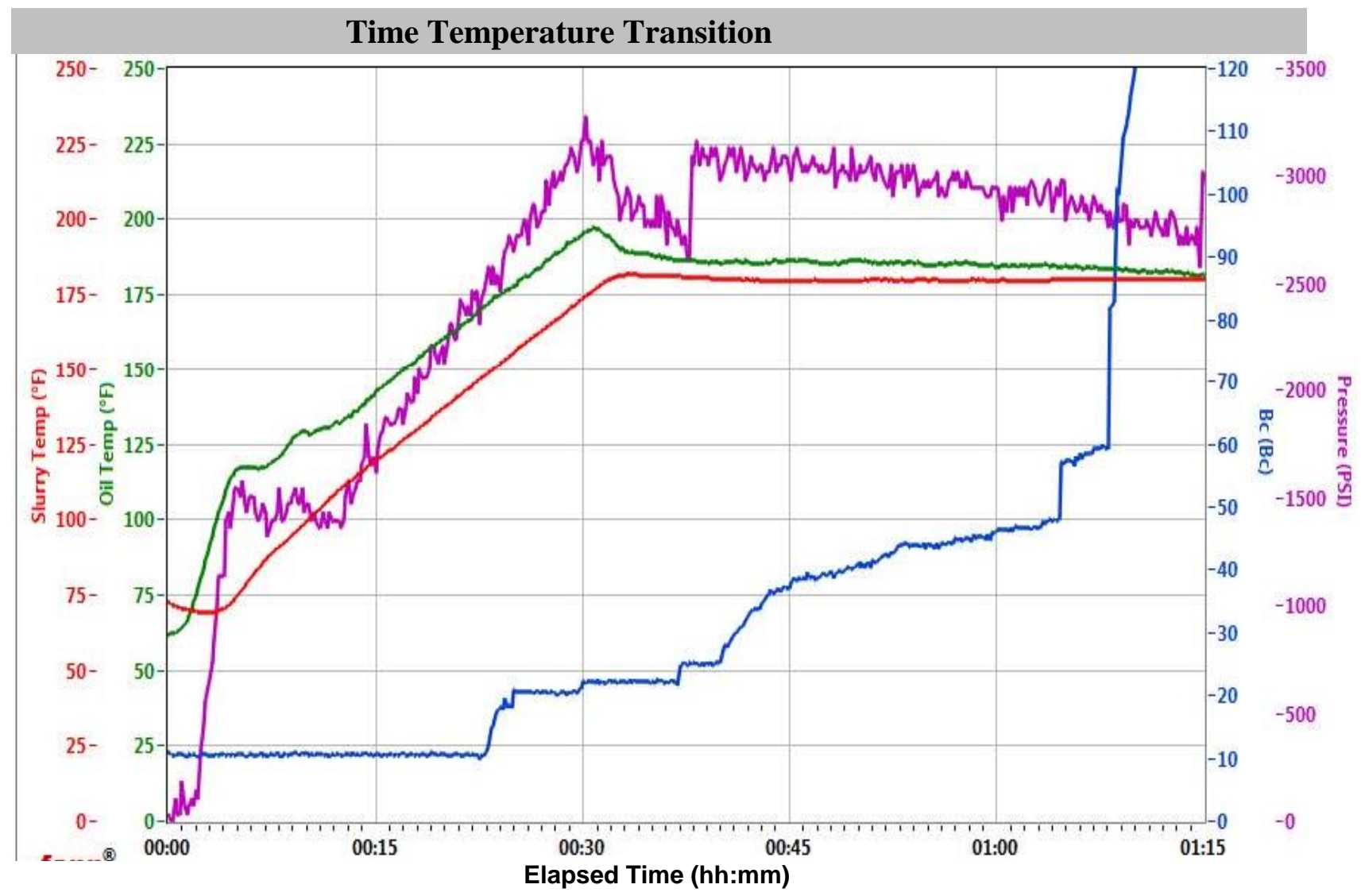

Figure 37: Temperature and Transition for 2\% Nano Silica and 2\% Crumb Rubber versus time 


\section{DISCUSSION OF RESULTS WITH FINAL ADDITIVE CONCENTRATIONS}

Based on results, the desired concentrations were determined for the cement mixture as $2 \%$ nano silica and $2 \%$ crumb rubber. These results for this cement samples with $2 \%$ nano silica and $2 \%$ crumb rubber showed an increase of $3.5 \%$ in compressive strength after 48 hours (Table 58), a decrease to $0 \%$ free fluid, a decrease of approximately $35 \%$ in thickening time (to $100 \mathrm{BC}$ ) (Figure 38), a decrease of more than $50 \%$ fluid loss (Figure 39) and a decrease of $15 \%$ in transition time to 500 psi (Figure 40) when compared to the base case. The compressive strength values (Figures 41) show the significant enhancement that the combination of the two additives have provided. This is important because compressive strength is the defining parameter for this study. Although a slight decrease in the mixability factor was observed for this test, it is not problematic or detrimental in any way to the ability or mechanical properties of the cement. This is attributed to the high total concentration of additives in the slurry. Furthermore, the nano silica sample becomes unmixable above $2 \%$ BWOC. A possible treatment for this would be the addition of superplasticizers to help maintain the slurry mixability at high concentrations. 


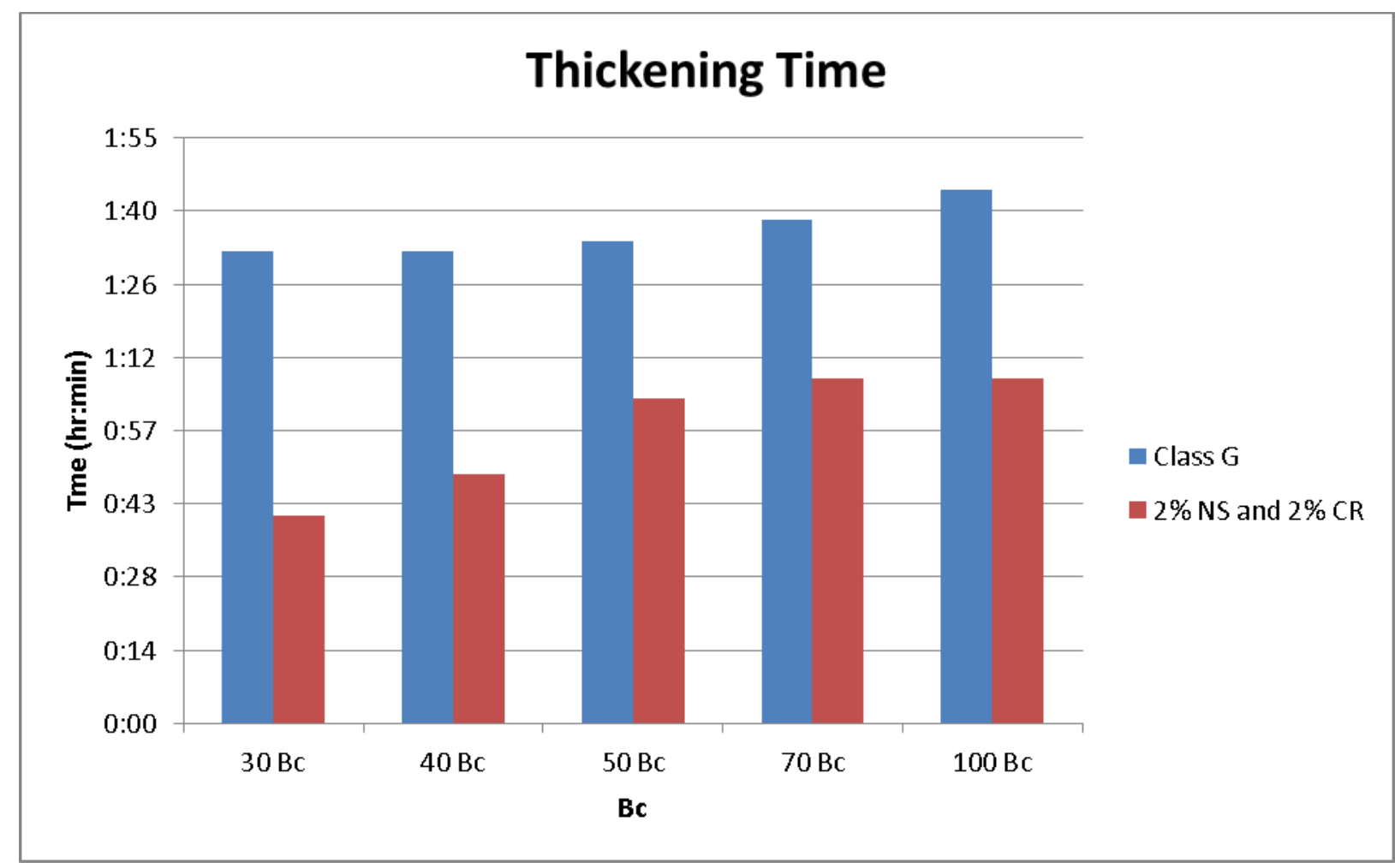

Figure 38: Thickening Time for class G cement vs. 2\% nano silica and 2\% crumb rubber.

A compressive strength increase was seen with the incorporation of approximately $2 \%$ crumb rubber indicating it's fully integrated to the cement matrix. When the crumb rubber is not adequately coated and integrated, the compressive strength will decrease relative to a sample without crumb rubber. This behavior was observed for the $5 \%$ crumb rubber sample. Based on the integration of the crumb rubber with cement resulting in an increase in compressive strength, one can conclude that all the properties of crumb rubber are integrated as well, including the elastic and resilience properties. This was achieved using concentrations of each additive that was slightly less than previous research (Mahajan lqba, 2012). This is attributed to the fact that the two additives were used in combination with one another. Five percent crumb rubber, as was the optimal percent for the concrete in the construction industry 
research, prevents full coating and lack of integration thus decreasing compressive strength and elastic resistance. Furthermore, any concentration higher than two percent nano silica becomes unmixable, and cannot be tested further.

Figure 40 shows the thickening time relative to the base case. It demonstrates the accelerated thickening time provided by the combination of the two additives. Figure 40 shows the transition time of the $2 \%$ nano silica and $2 \%$ crumb rubber sample reaches 500 psi about $15 \%$ faster than that of the base case. These parameters help decrease the risk of migration pathway formation and the time to complete a cement job. From the TTT graph (Figure 37) we can see the highest overall and highest average $\mathrm{BC}$ time throughout the duration of the test.

This demonstrates that the goal of reaching a 1-5\% increase in compressive strength was achieved. Furthermore, with the reduction in fluid loss, thickening time and transition time, the goal of reducing transmissibility in regards to migration pathway formation potential has been achieved as well. This is a key goal because with the incorporation of nano silica comes the ability to reduce permeability. However, if the transition time is too high, the reduced permeability from nano silica may come after a point in time when gas migration channels have already formed. The combination of $2 \%$ nano silica and $2 \%$ crumb rubber has thus been confirmed to provide beneficial qualities to class $G$ cement when high demand for wellbore integrity is a necessity.

This final analysis compares the baseline case of class $\mathrm{G}$ cement with no additives to that of $2 \%$ nano silica and $2 \%$ crumb rubber. Figure 42 shows the rheological model of $2 \%$ nano silica and $2 \%$ crumb rubber to follow the Bingham Plastic model. 


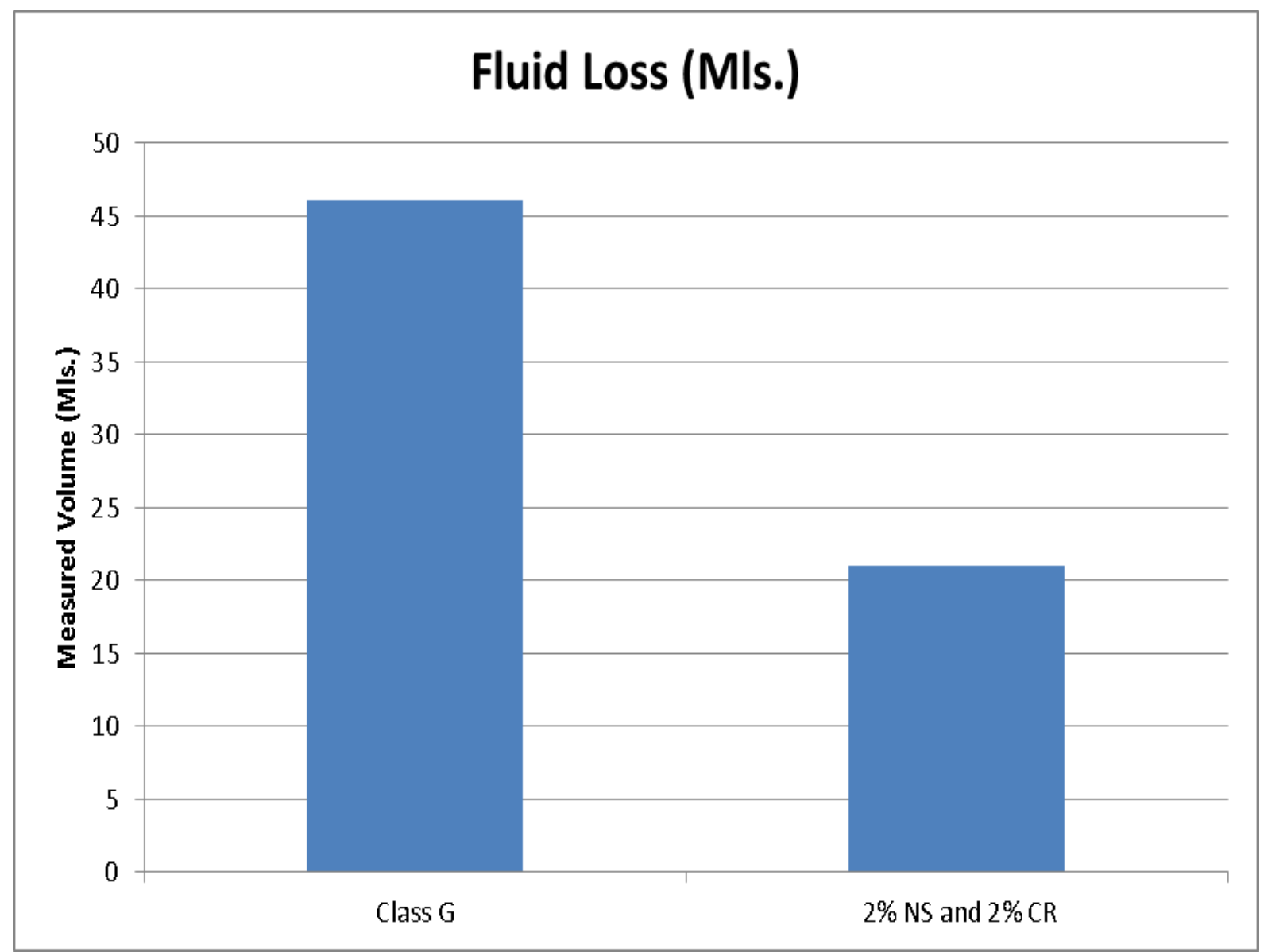

Figure 39: Fluid loss for class G cement vs. $2 \%$ nano silica and $2 \%$ crumb rubber. 


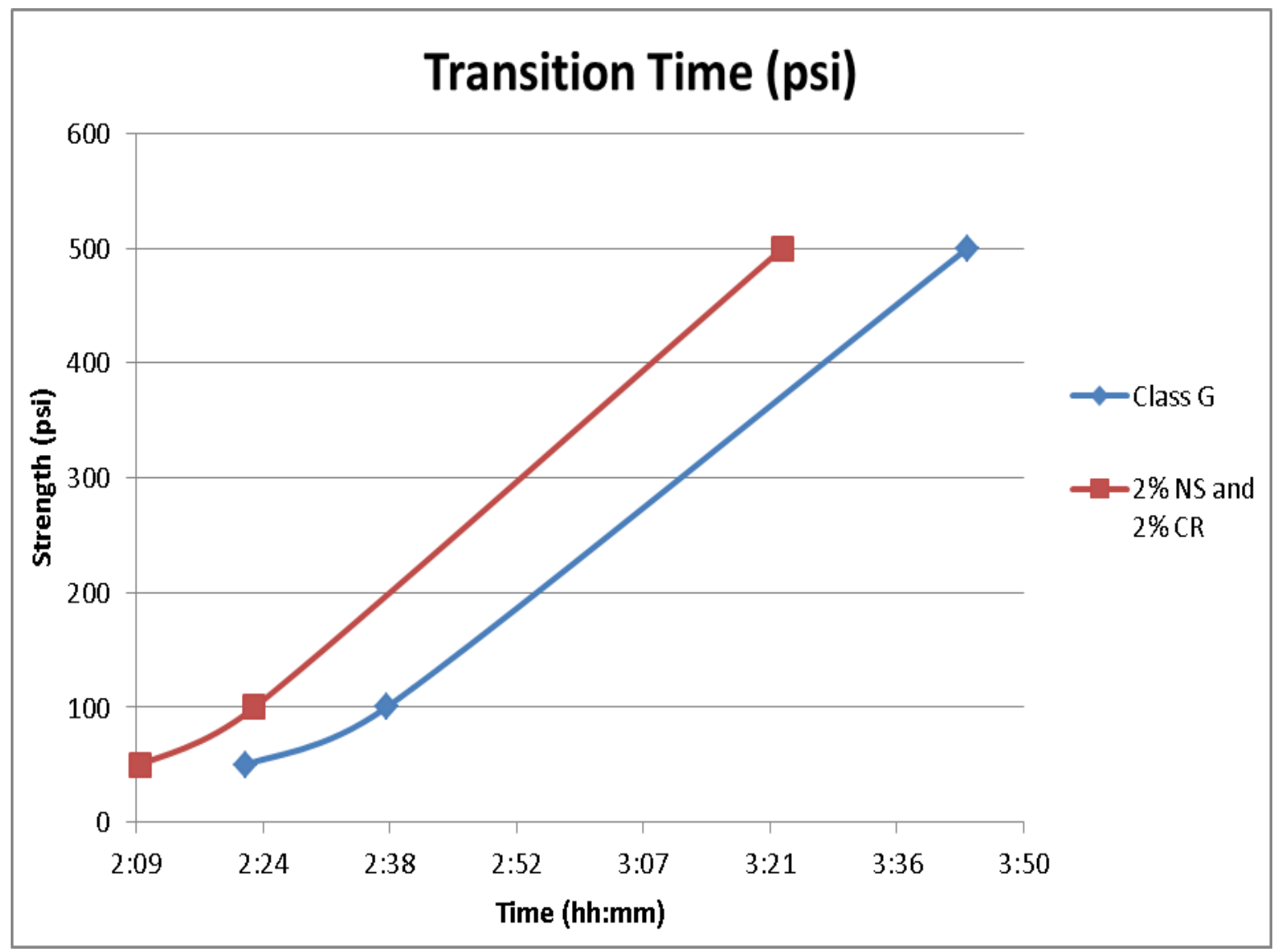

Figure 40: Transition time of class $\mathrm{G}$ cement vs. $2 \%$ nano silica and $2 \%$ crumb rubber. 


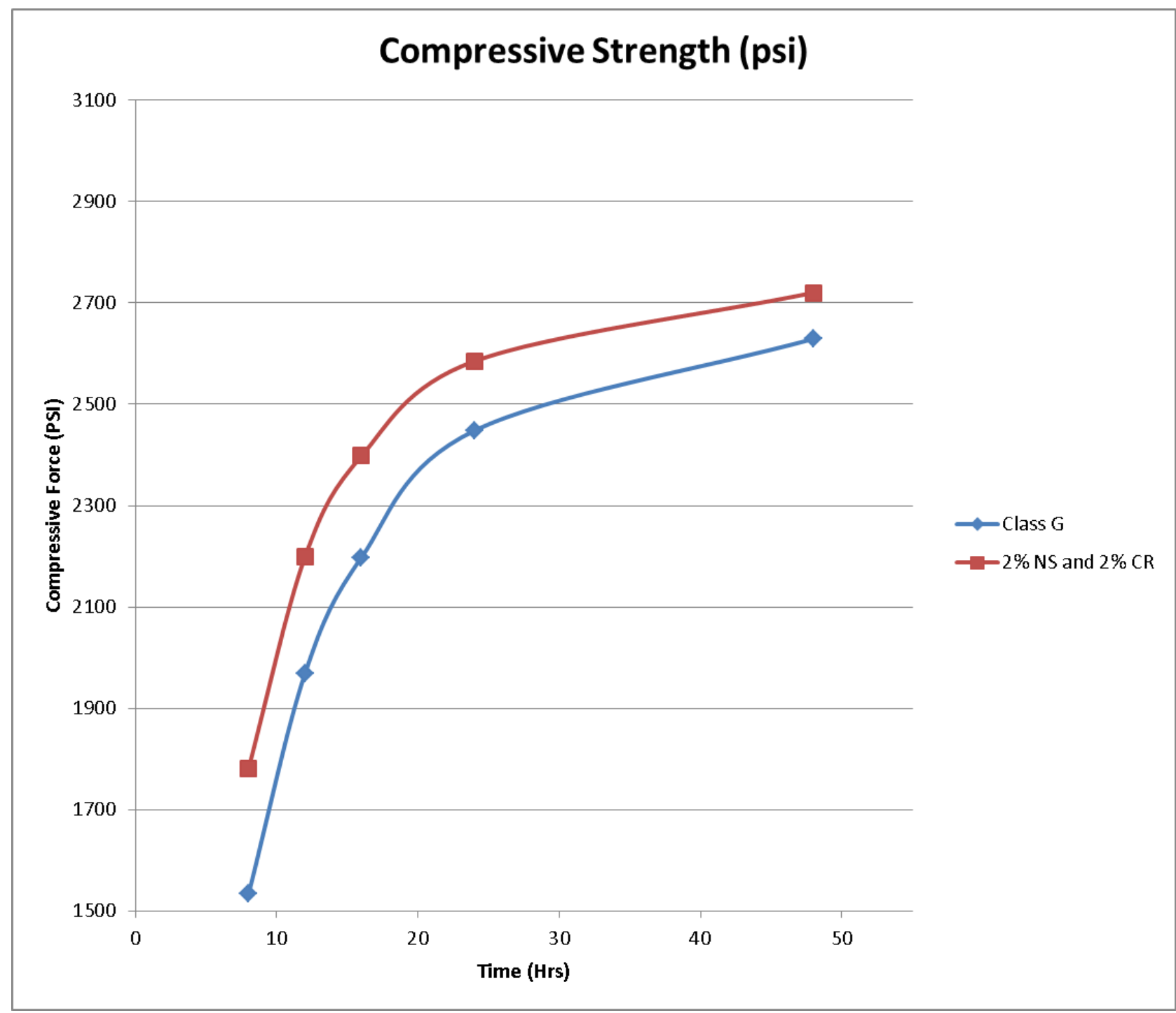

Figure 41: Compressive strength for class G cement vs. $2 \%$ nano silica and $2 \%$ crumb rubber. 


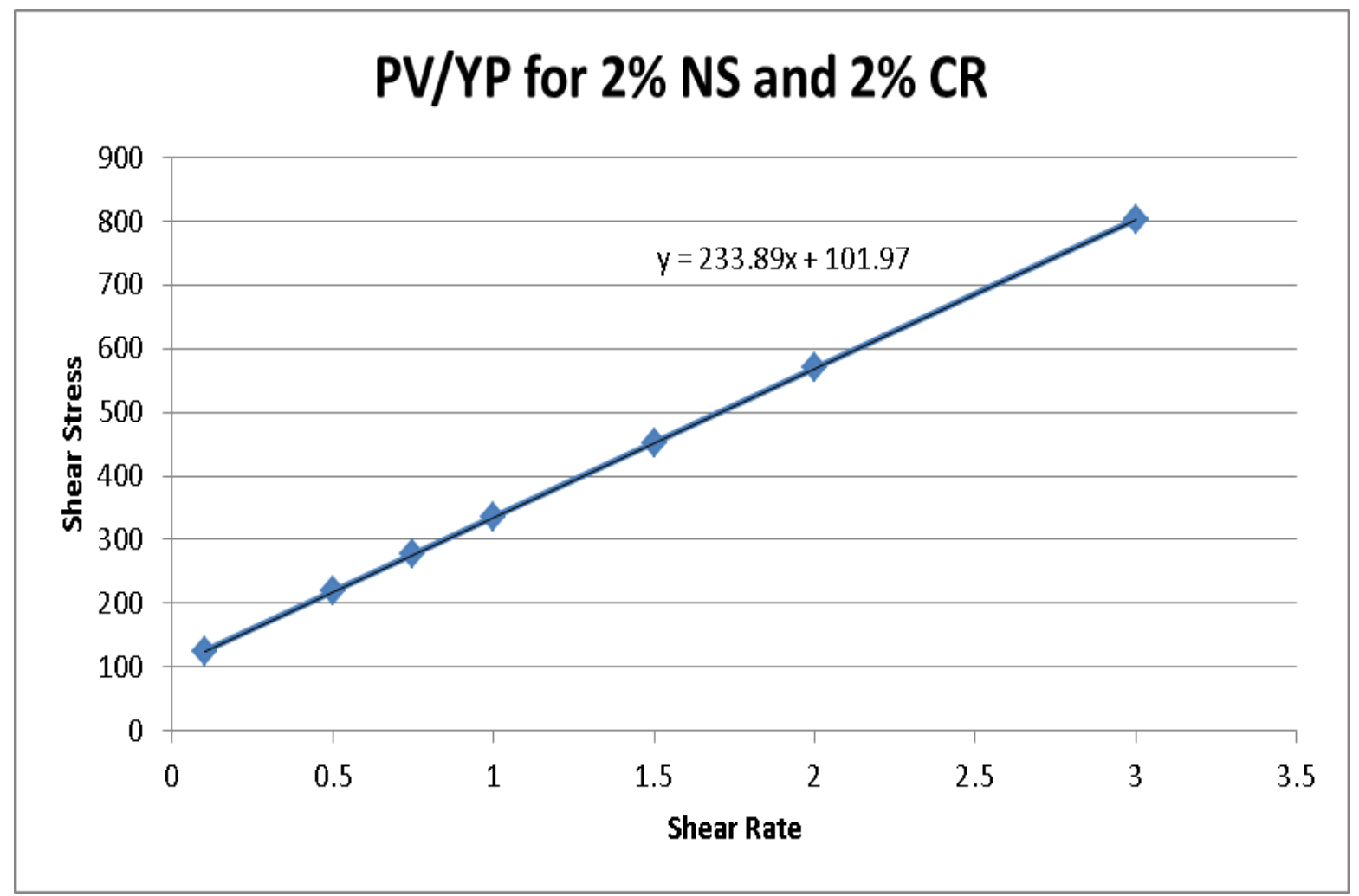

Figure 42: PV vs. YP for $2 \%$ nano silica and $2 \%$ crumb rubber. 


\section{Final Comparison of Results}

The following tables summarize all tests performed with each sample. Table 59 summarizes the mixability test for this study. $2 \%$ nano silica and $2 \%$ crumb rubber together have the lowest mixability rating while every other sample, with the exception of $1 \%$ nano silica, attained a mixability of 5 . Table 60 summarizes the thickening time test for all the samples and shows that $2 \%$ nano silica and $2 \%$ crumb rubber provide the optimal results. The rheology tests are shown by Table 61 and show that $2 \%$ nano silica and $2 \%$ crumb rubber have the highest shear stress and shear rate. Fluid loss and free fluid are summarized in Tables 62 and 63 . These tables again show that $2 \%$ nano silica and $2 \%$ crumb rubber provided improved results. Table 64 summarizes the compressive strength test and again shows that $2 \%$ nano silica and $2 \%$ crumb rubber provided improved results.

\begin{tabular}{|l|r|}
\hline \multicolumn{2}{|c|}{ Mixability test } \\
\hline Class G no additives & 5 \\
\hline $1 \%$ nano silica & 4 \\
\hline $2 \%$ nano silica & 5 \\
\hline $1 \%$ crumb rubber & 5 \\
\hline $3 \%$ crumb rubber & 5 \\
\hline $5 \%$ crumb rubber & 5 \\
\hline $2 \%$ NS and $2 \%$ CR & 3.5 \\
\hline
\end{tabular}

Table 59: Mixability comparison for all samples 


\begin{tabular}{|l|l|l|}
\hline \multicolumn{3}{|c|}{ Thickening Time } \\
\hline & To 100 BC & To 50 BC \\
\hline Class G no additives & 1 hour and 45 minutes & 1 hour and 35 minutes \\
\hline $1 \%$ nano silica & 1 hour and 16 minutes & 1 hour and 9 minutes \\
\hline $2 \%$ nano silica & 1 hour and 16 minutes & 1 hour and 9 minutes \\
\hline $1 \%$ crumb rubber & 1 hour and 35 minutes & 1 hour and 26 minutes \\
\hline $3 \%$ crumb rubber & 1 hour and 40 minutes & 1 hour and 37 minutes \\
\hline $5 \%$ crumb rubber & 1 hour and 37 minutes & 1 hour and 30 minutes \\
\hline $2 \%$ NS and $2 \%$ CR & 1 hour and 8 minutes & 1 hour and 4 minutes \\
\hline
\end{tabular}

Table 60: Thickening time comparison for all samples

\begin{tabular}{|l|l|l|}
\hline \multicolumn{3}{|c|}{ Rheologies } \\
\hline & PV/YP at 80$\%$ F & PV/YP at 180 \% \\
\hline Class G no additives & $41.95 / 18.86$ & $94.45 / 57.47$ \\
\hline $1 \%$ nano silica & $99.38 / 51.15$ & $144.25 / 61.44$ \\
\hline $2 \%$ nano silica & $56.69 / 37.96$ & $94.45 / 57.47$ \\
\hline $1 \%$ crumb rubber & $71.52 / 30.93$ & $129.55 / 45.67$ \\
\hline $3 \%$ crumb rubber & $62.76 / 26.52$ & $89.57 / 33.56$ \\
\hline $5 \%$ crumb rubber & $46.86 / 20.76$ & $72.78 / 32.54$ \\
\hline $2 \%$ NS and $2 \%$ CR & $109.89 / 75.02$ & $233.89 / 101.97$ \\
\hline
\end{tabular}

Table 61: Rheologies comparison for all samples

\begin{tabular}{|l|r|}
\hline \multicolumn{2}{|c|}{ Fluid Loss (MI) } \\
\hline Class G no additives & 46 \\
\hline $1 \%$ nano silica & 39 \\
\hline $2 \%$ nano silica & 40 \\
\hline $1 \%$ crumb rubber & 34 \\
\hline $3 \%$ crumb rubber & 34 \\
\hline $5 \%$ crumb rubber & 47 \\
\hline $2 \%$ NS and $\%$ CR & 21 \\
\hline
\end{tabular}

Table 62: Fluid loss comparison for all samples 


\begin{tabular}{|l|r|}
\hline \multicolumn{2}{|c|}{ Free Fluid } \\
\hline Class G no additives & $0.52 \%$ \\
\hline $1 \%$ nano silica & $0 \%$ \\
\hline $2 \%$ nano silica & $0 \%$ \\
\hline $1 \%$ crumb rubber & $0 \%$ \\
\hline $3 \%$ crumb rubber & $0 \%$ \\
\hline $5 \%$ crumb rubber & $0.48 \%$ \\
\hline $2 \%$ NS and $2 \%$ CR & $0 \%$ \\
\hline
\end{tabular}

Table 63: Free fluid comparison for all samples

\begin{tabular}{|l|r|l|}
\hline \multicolumn{3}{|c|}{ Compressive Strength } \\
\hline & PSI After 48 Hours & Time to Reach 500 PSI \\
\hline Class G no additives & 2671 & 3 hours and 44 minutes \\
\hline $1 \%$ nano silica & 2672 & 3 hours and 39 minutes \\
\hline $2 \%$ nano silica & 3026 & 3 hours and 33 minutes \\
\hline $1 \%$ crumb rubber & 2702 & 3 hours and 39 minutes \\
\hline $3 \%$ crumb rubber & 2695 & 3 hours and 47 minutes \\
\hline $5 \%$ crumb rubber & 2437 & 3 hours and 43 minutes \\
\hline $2 \%$ NS and $\%$ CR & 2720 & 3 hours and 23 minutes \\
\hline
\end{tabular}

Table 64: Compressive strength comparison for all samples 


\section{CHAPTER 6: SUMMARY OF CONCLUSIONS}

When compared to base case of class $\mathrm{G}$ cement with no additives, the following was observed with $2 \%$ nano silica and $2 \%$ crumb rubber in this study.

- Increase of about 3.5\% in compressive strength after 48 hours.

- $0 \%$ free fluid.

- Decrease of approximately $35 \%$ in thickening time (to $100 \mathrm{BC}$ )

- Decrease of greater than $50 \%$ fluid loss.

- Decrease of approximately $15 \%$ in transition time to $500 \mathrm{psi}$.

- Unmixable above $2 \%$ nano silica

- Reaches 100 psi compressive strength after 2 hours and 23 minutes.

- Reaches 500 psi compressive strength after 3 hours 23 minutes.

- Transitions to $100 \mathrm{Bc}$ in 1 hour and 8 minutes.

- Transitions to $30 \mathrm{Bc}$ in 41 minutes.

- High early strength formation (Figures 36 and 37.)

- Decrease in compressive strength above 3\% crumb rubber. 


\section{CHAPTER 7: FEASABILITY ANALYSIS}

One of the main reasons these particular additives were considered for the creation of a new cement design for wellbore integrity was the feasibility of the chosen additives. Both nano silica and crumb rubber are very feasible due to costs, real world applicability, product availability, and ease of creation.

The cost analysis is perhaps the most important factor pertaining to the viability of this research. There are numerous suppliers capable of selling large quantities of nano silica for relatively low prices for wellbore cement additives. Currently, nano silica is available for around $\$ 50$ per kilogram. Based on the optimal percent of nano silica being $2 \%$, it is well within the normal cost of typical additives incorporated into wellbore cement. Furthermore, crumb rubber follows the same pattern in that it too is very economical.

Ease of creation is the final key component of the feasibility of this research. If the proposed blend has a very low mixability factor, or requires diligent and unrealistic preparation procedures, it starts to become unfeasibility for large scale implementation. This is the case for nano silica concentration above two percent. Above this concentration, the slurry becomes unmixable and impractical. The additives must be easily and quickly mixable in a wet phase. It is an objective of this research to make the blend easy, straightforward and trouble free for the industry to use. The proposed blend is effortless to create without additional expenditure to a company performing the cement job. 


\section{CHAPTER 8: RECOMMENDATIONS}

While there are many new directions that wellbore cements are advancing toward, the ultimate goal of maximum wellbore integrity is still paramount.

Advances include quicker setting times, lower weight cements, cheaper additives, better isolation, etc. The prevention of gas migration pathways is a very important factor in wellbore integrity. The formation of migration pathways have been known to occur without the failure of cement. These pathways can form during the hydration process of the setting cement, particularly in foamed cement. These pathways can lead hydrocarbons upwards into adjoining aquifers without any indication of wellbore integrity failure.

An incorporation of this proposed cement design into foamed cement could provide significant enhancements. Foamed cement has a very high porosity when compared to this design. If nano silica could be incorporated into foamed cement, the pore walls of the foamed cement could be strengthened significantly while still maintaining low weight and good workability. Furthermore, with the addition of crumb rubber, alongside nano silica, the pore walls would also become less brittle and therefore significantly prevent and decrease gas migration channels from forming. The prevention of pore wall collapse and pore connection will reduce permeability and prevent permeable channels from forming throughout the life of the well.

Another possibility for future study is the incorporation of nano crumb rubber. Nano crumb rubber is relatively new, slightly more expensive, and more hazardous to work with. However, with proper advances in the field of nano particles, adequate handling and operating procedures could be made to incorporate the particles. These 
particles offer a higher surface area, which allows for an increased effect for the same percent of crumb rubber. However more advances into the understanding and implications of slightly more hazardous nano particles must be established and understood by all individuals that would be handling the mixture.

Self-healing cement is also a new cement with promising potential for the oil industry. It is offered by a few major companies already and has presented promising results thus far. If the blend used in this study was augmented into a self-healing cement, the potential advantages could increase further. The cement would be the most resilient, most durable and most technologically advanced cement available. However, the technology to create self-healing cement still is relatively new, and requires the addition of polymers and catalysts to activate it. The interaction between all these additives in a cement slurry would take significant study.

An important further study that could be performed is the testing for Poisons Ratio and Young's Modulus. These tests can further reveal important mechanical properties of the crumb rubber. The elastic resilience properties could be further demonstrated through the poisons ratio test. However, such a test requires an elastometer which wraps around the sample that can measure horizontal expansion when a vertical force is applied. The full integration of crumb rubber occurs with the increase of compressive strength, but this can be further analyzed by these tests.

The incorporation of the proposed cement blend into other types of cement, such as class $\mathrm{H}$, should also be considered. With the addition of nano silica and crumb rubber at desired concentrations, significant wellbore integrity enhancements can been generated. Therefore, the final recommendation made for the proposed blend for use in 
hydrocarbon wellbore integrity is that it should be incorporated into test wells and studied further with the intention for use in wells everywhere. The proposed cement blend can be further supplemented by any one the aforementioned systems, or any combination thereof. 


\section{REFERENCES}

Allbiz. (2015). Compressive strength testing equipment. Retrieved from allbiz: http://newdelhi.all.biz/compressive-strength-testing-equipment-g21580\#.VZ1TkvlVhBc

ASTM. (2015, June 25). Cement composition and classification. Retrieved from PetroWiki Bonett, Art and Pafitis, Demos. (1996). Getting to the root of gas migration. Oilfield Review, Spring.

ChemTeam. (n.d.). Gay-Lussac's law. Retrieved from http://www.chemteam.info/GasLaw/GasGay-Lussac.html

CRM. (n.d.). Crumb Rubber Manufacturers. Retrieved from http://crmrubber.com/

Davies, R., Almond, S., Ward, R., and Jackson, R. (2015, January). Oil and gas wells and their integrity: implications for shale and unconventional resource exploitation. Marine and Petroleum Geology, 59, 671-673.

DeBruijin, G., Garnier, A., Brignoli, R., Bexte, D. C., and Reinheimer, D. (2009). Flexible cement improves wellbore integrity in SAGD wells. Society of Petroleum Engineers. http://dx.doi.org/10.2118/119960-MS

DeBruijin, G. (n.d.). High-Pressure, High-Temperature Technologies. Oilfield Review.

DELAWARE Riverkeeper. (2011). Natural gas drilling, seismic risk \& aquifer degradation. Retrieved from http://www.delawareriverkeeper.org/resources/Factsheets/Seismic\%20 Hazard\%20Expert\%20Fact\%20Sheet.FINAL.pdf

Dillenbeck, L. (2010). The impact of cementing. Chevron. Retrieved from http://www.iadc.org/wp-content/uploads/The-impact-of-well_-cementing-on-proper-wellcontrol.pdf 
Direct Industry. (2014, May 13). Ultrasonic Cement Analyzer with Static Gel Strength Measurement MODEL RC-5265. Retrieved from http://news.directindustry.com/

Drillingformulas.com. (2010, January 30). Drilling Fluid Properties. Retrieved from http://www.drillingformulas.com/

Elert, G. (2015). The physics hypertextbook. Retrieved from Elasticity: http://physics.info/elasticity/

Engineering Toolbox. (n.d.). Poisson's ratio. Retrieved from http://www.engineeringtoolbox.com/poissons-ratio-d_1224.html

Fann. (2015). Fluid loss test. Retrieved from http://www.fann.com/fann/products/oil-wellcement-testing/fluid-loss-test/owct-fluidloss.page?node-id=hlz0hxpi

Ferraris, C. (1999). Measurement of the rheological properties of cement paste: a new approach. Gaithersburg: National Institute of Standards and Technology.

Hussain, T. and Krishna. (2014). Study of strength properties of concrete by using micro silica and nano silica. Internal Journal of research in engineering and Technology.

Iqba, S. and Mahajan, Y. (2012). Nanotechnology in the cement industry - a patent analysis. Retrieved from Nano Werk: http://www.nanowerk.com/spotlight/spotid=28101.php

Kaloush, K., Way, G. and Zhu, H. (2005). Properties of crumb rubber concrete. Retrieved from https://caplter.asu.edu/docs/smartWebArticles/Kaloush-Way-ZhuTRB2005Nov152004.PDF

Kutchko, B. (2014). Wellbore integrity assurance with NETL's safe cementing research. Retrieved from NETL 
https://www.netl.doe.gov/File\%20Library/Research/onsite\%20research/publications/Well boreIntegrityAssurance_pages-v2-10-14-.pdf

Laval Lab. (2015). Rheometer for cement and concrete. Retrieved from http://lavallab.com/products/cement-research/rheometer-cement-concrete/

Salam, K., Arinkoola, B. and Ajagbe, S. (2013). Evaluation of thickening time of oil field class g cement slurry at high temperature and pressure using experimental design. International Journal of Engineering Sciences, (2)8, 361-367.

Savari, S., and Kumar, A. (2012). Wellbore integrity management: dealing with uncertainties. Society of Petroleum Engineers. http://dx.doi.org/10.2118/153359-MS

Singh, S. K. (2013, October). Beneficial role of nanosilica in cement based materials - A review. Retrieved from ScienceDirect: http://www.sciencedirect.com/science/article/pii/S0950061813004509

Sinosi Group. (2015). Products. Retrieved from http://www.sinosi.com/en/sinosigroup.asp

Society of Petroleum Engineers. (2014, November 19). Cement composition and classification. Retrieved from http://petrowiki.org/Cement_composition_and_classification

Topcu, I. (1995). The properties of rubberized concrete. Retrieved from http://www.researchgate.net/publication/234079706_The_properties_of_rubberized_conc retes

Universal. (2013). Static gel strength measurement device. Retrieved from http://www.universaltechco.com

Wray, B. L. (2009). The application of high-density elastic cements to solve HP/HT challenges in south texas: the success story. Society of Petroleum Engineers. http://dx.doi.org/10.2118/122762-MS 
Zhang, M., Islam, J., and Peethamparan, S. (2012). Use of nano-silica to increase early strength and reduce setting time of concretes with high volumes of slag. Cement and Concrete Composites, 34 (5). 